\title{
Earthquake ground motion estimation using strong-motion records: A review of equations for the estimation of peak ground acceleration and response spectral ordinates
}

\author{
J. Douglas ${ }^{a}, *$ \\ ${ }^{a}$ Department of Civil \& Environmental Engineering; Imperial College of Science, \\ Technology 83 Medicine; London; SW7 2BU; U.K.
}

\begin{abstract}
Engineering seismology is the link between earth sciences and engineering. The main input of engineering seismology in engineering design are loading conditions which must satisfy certain conditions regarding their level and frequency of occurrence during the lifetime of a structure. One method for estimating these loading conditions are through equations based on strong ground motion recorded during previous earthquakes. These equations have a handful of independent parameters, such as magnitude and source-to-site distance, and a dependent parameter, such as peak ground acceleration or spectral acceleration, and the coefficients in the equation are usually found by regression analysis.

This review examines such equations in terms of: data selection, accelerogram processing techniques of the strong-motion records used to construct the equations, the characterisation of earthquake source, travel path and local site used and regression techniques employed to find the final equations.
\end{abstract}


It is found that little agreement has been reached in the past thirty years of ground motion estimation relation studies. Workers have chosen their techniques based on the available data, which varies greatly with geographical region. Also it is noted that there is a need to include more independent parameters into ground motion estimation equations if the large uncertainties associated with such equations are to be significantly reduced. The data required to do this is, unfortunately, scarce.

Key words: seismology, geologic hazards, seismic hazard, engineering seismology, attenuation relations

\section{Introduction}

Engineering seismology is the link between earth sciences and engineering. The main input of engineering seismology in engineering design are loading conditions which must satisfy certain conditions regarding their level and frequency of occurrence during the lifetime of a structure. Loading conditions appropriate for a particular type of structure are expressed in terms of ground motion in the frequency and/or time domains. One method for estimating these loading conditions are through equations based on strong ground motion recorded during previous earthquakes. These equations have a handful of independent parameters, such as magnitude and source-to-site distance, and a dependent parameter, such as peak ground acceleration or spectral acceleration, and the coefficients in the equation are usually found by regression analysis. Although the equations are often referred to as attenuation relationships, attenuation relations or attenuation equations, they predict more than how ground motion

\footnotetext{
* Tel: +44 (0)20 7594 6060, Fax: +44 (0)20 72252716.

Email address: john.douglas@ic.ac.uk (J. Douglas).
} 
varies with distance. The equations are vital to probabilistic seismic hazard analysis, as Cornell (1968) shows, and also to deterministic seismic hazard analysis. Hence over the past thirty years ground motion estimation equations have been much studied and many versions published.

A number of reviews of ground motion estimation studies have been made in the past which provide a good summary of the methods used, the results obtained and the problems associated with such relations. Trifunac and Brady (1975, 1976) provide a brief summary and comparison of published relations. Idriss (1978) presents a comprehensive review of published ground motion estimation relations up until 1978, including a number which are not easily available. Boore and Joyner (1982) provide a review of ground motion estimation studies published in 1981 and comment on empirical prediction of strong ground motion in general. Campbell (1985) contains a full survey of ground motion estimation equations up until 1985. Joyner and Boore (1988) give an excellent analysis of ground motion prediction methodology in general, and ground motion estimation relations in particular; Joyner and Boore (1996) update this by including more recent studies. Ambraseys and Bommer (1995) provide an overview of relations which are used for seismic design in Europe although they do not provide details about methods used. After these studies were completed many more equations were derived. Campbell $(2002 \mathrm{c}, \mathrm{a}, \mathrm{b})$ are three excellent recent reviews of equations for the estimation of strong ground motions and include the coefficents of, and comparisons between, 14 well-used equations.

Douglas (2001a, 2002a) summarises over 120 studies that derived equations for the estimation of peak ground acceleration and over 80 studies that derived equations for the estimation of response spectral ordinates. This article is a 
review of the procedures adopted in the past thirty years to derive equations for the estimation of ground motions using strong-motion records. It seeks to compliment the recent reviews by Campbell by focussing on the methods used to derive the equations. Appendix A summarises the available equations for estimating peak ground acceleration.

The complete procedure that needs to be followed to derive ground motion estimation equations using recorded strong-motion data is outlined below.

(1) Earthquakes are recorded using strong-motion instruments to get a set of records for analysis.

(2) If the earthquakes were recorded on analogue accelerographs, which use paper or film, then the accelerograms are digitised to get the data into a form usable for numerical analysis.

(3) The digitised strong-motion records are processed to remove short- and long-period noise, which is introduced in the recording and digitisation stages. This processing usually consists of fitting a zero baseline to the record and then applying a bandpass filter.

(4) A dependent variable is selected and calculated from the strong-motion records. This dependent variable, such as peak ground acceleration or spectral acceleration, should be useful for seismic design and analysis.

(5) Independent variables, such as magnitude and source-to-site distance, that characterise the strong-motion records in the data set are then collected for all the time-histories used.

(6) Regression analysis is performed to derive equations to estimate the dependent variable (a strong-motion parameter) given the independent variables. At the same time the standard deviation of the equations are calculated. 
(7) The derived equations are used in seismic hazard analysis, either deterministic or probabilistic, to give estimates of the strong ground motion that could be expected at a site during a future earthquake.

\section{Strong ground motion parameters}

Peak ground acceleration (PGA) is still often used as a parameter to describe strong ground motion although it is only useful for analysis of short period $(T \lesssim 0.3 \mathrm{~s})$ structures. PGA is simply the amplitude of the largest peak acceleration recorded on an accelerogram at a site during a particular earthquake. PGA is the most simple strong-motion parameter and hence more than 120 equations (Douglas, 2001a, 2002a) have been derived in the past to predict it. These equations are discussed in this article.

Consider the SDOF system illustrated in Figure 1. This system consists of a mass $m$, moving on a frictionless surface, driven by a horizontal ground motion with acceleration $U_{t t}$, with a spring with stiffness $k$ and a dashpot with a coefficient of viscous damping $c$.

Let $u(t)$ be the horizontal displacement of the mass at time $t$. Then using Newton's second law and resolving forces horizontally gives:

$$
m u_{t t}+c u_{t}+k u+m U_{t t}=0
$$

Dividing by $m$ and letting $\omega_{0}^{2}=k / m$ and $\xi_{0}=c / 2 \omega_{0} m$ yields the equation of motion: 


$$
u_{t t}+2 \xi_{0} \omega_{0} u_{t}+\omega_{0}^{2} u=-U_{t t}
$$

Equation 1 is usually used to model the elastic response of structures to earthquake excitation, see for example Chopra (1995). Under intense ground motion structures often deform beyond their linear elastic range and behave inelastically. A more complex model than that given in Equation 1 is required to model such inelastic behaviour, see for example Chopra (1995, chap. 7). These models are not considered here.

During an earthquake although the response of a structural system changes with time, which may be important for some applications, often only the maximum response which a system undergoes is required for design purposes. Consider the structural model illustrated in Figure 1 and assume the ground acceleration is $U_{t t}(t)$ and the mass, $m$, has displacement $u(t)$, velocity $u_{t}(t)$ and acceleration $u_{t t}(t)$ then the three values of maximum response of interest are:

maximum absolute response acceleration $S_{a}=\max _{t}\left|u_{t t}+U_{t t}\right|$, maximum relative response velocity $S_{v}=\max _{t}\left|u_{t}\right|$, maximum relative response displacement $S_{d}=\max _{t}|u|$.

Two forces act on the mass one is due to the spring and the other due to the equivalent viscous damping. These forces must resist the total inertial forces of the system, $m u_{t t}$ and $m U_{t t}$ hence, $m S_{a}$ gives the maximum force acting which must be resisted by the entire system.

From these quantities two 'pseudo' values can be calculated:

maximum absolute pseudo-acceleration $S_{a}^{\prime}=(2 \pi / T)^{2} S_{d}$, 
maximum relative pseudo-velocity $S_{v}^{\prime}=(2 \pi / T) S_{d}$,

where $T$ is the natural period of the system.

$m S_{a}^{\prime}$ gives the force which must be resisted by the spring (Chopra, 1995) and not the complete system. For small coefficients of critical damping and relatively short periods $S_{a}$ and $S_{a}^{\prime}$ are almost identical (Chopra, 1995).

Maximum relative pseudo-velocity, $S_{v}^{\prime}$, is related to the peak value of strain energy, $E_{S}$, stored in the system during the earthquake by the equation: $E_{S}=$ $m S_{v}^{\prime 2} / 2$ (Chopra, 1995, p. 200).

A plot of the quantities defined above as a function of the natural vibration period, $T$, and damping, $\xi$, of the system is called a response spectrum. It provides a convenient means of summarizing the peak response of all possible linear single-degree-of-freedom (SDOF) systems to a particular component of ground motion (Chopra, 1995).

Over 80 equations (Douglas, 2001a, 2002a) have been derived in the past to predict response spectral ordinates because response spectra have proved to be useful for seismic analysis of structures. These equations are also discussed in this article.

\section{Types of ground motion estimation equations}

Draper and Smith (1981) define three main types of mathematical models used by scientists:

Functional When the true functional relationship between response (the 
value to be predicted) and the predictor variables is known and is used.

Control When the independent effects of each of the control variables (the predictor variables) can be estimated through designed experiments.

Predictive When neither functional or control models can be used and within the data much inter-correlation exists, so called 'problems with messy data'. They do not need to be functional.

Most published ground motion estimation relations have some physical basis, hence some aspects of functional models are present. Since all the physical aspects associated with seismic ground motion are not known in detail and even if they were it would be impossible to express them in the form of one simple equation, ground motion estimation relations are predictive models. Trifunac (1980) notes that ground motion estimation relations should be based on a functional form from the physical nature of phenomena but because of lack of data this cannot be achieved; Caillot and Bard (1993) also state that the form of the equation must have some physical basis. Controlled experiments cannot obviously be performed with ground motion caused by earthquakes because no two earthquakes are the same, nor are the travel paths to station or the local site conditions and hence there is no repeatability ${ }^{1}$. Therefore control models are not possible.

\section{Data selection criteria}

Early ground motion estimation studies (e.g. Milne and Davenport, 1969; Esteva, 1970; Ambraseys, 1975) give little or no information on the data selection

\footnotetext{
$\overline{1}$ Explosions fired at test sites approximate to repeat runs for travel time studies.
} 
criteria adopted, probably because at that time few strong-motion records were available and to ensure that the number of records used was not too small no selection was made. This section concerns what criteria have been applied in the past for the selection of records; in Section 10 selection based on site conditions is discussed.

A major choice made is: data from which country, region or seismotectonic regime will be used. Most often authors only use data from one country (or part of the country), for example western North America (mainly California) (e.g. Milne and Davenport, 1969; Esteva, 1970; Joyner and Boore, 1981; Crouse and McGuire, 1996; Chapman, 1999) or Japan (e.g. Iwasaki et al., 1980; Kawashima et al., 1984; Kamiyama et al., 1992; Molas and Yamazaki, 1995; Kobayashi et al., 2000). For these two regions there are many time-histories from a wide distribution of magnitudes, distances and other seismological parameters such as source mechanism so the coefficients derived through regression are stable and not controlled by a few data points. Trifunac (1976) does not use data from regions, other than western USA, because attenuation varies with geological province and magnitude determination is different in other countries. Even for those authors who use a criteria based on a particular region, differences can still occur, for example Crouse and McGuire (1996) and Sadigh et al. (1997) both develop equations for use in California but Crouse and McGuire (1996) exclude data from the Mammoth Lakes area (which is an active volcanic region) because it is atypical of the rest of California whereas Sadigh et al. (1997) include 65 records from the Mammoth Lakes area.

Others have also limited their data to those recorded within one country, for example Italy (Sabetta and Pugliese, 1987; Mohammadioun, 1991; Tento 
et al., 1992; Caillot and Bard, 1993). Such criteria though is artificial because each country is not a single seismotectonic regime and nor are earthquakes from one country completely different to those in another. To limit the data by such criteria can lead to a small suite of records with a limited spread of independent parameters, for example Sabetta and Pugliese (1987) use 95 records from 17 earthquakes with magnitudes between 4.6 and 6.8. This means the equation may be controlled by a few data points and for independent variables outside this limited range predictions could be incorrect, a problem which Sabetta and Pugliese (1987) themselves note. Some areas, for example Iceland (Sigbjörnsson and Baldvinsson, 1992) and Hawaii (Munson and Thurber, 1997), seem to have much different attenuation properties than nonvolcanic regions which means developing equations based solely on data from these small areas may be justified although again there is a lack of data. Zhao et al. (1997) exclude some New Zealand records which may have been affected by different attenuation properties in volcanic regions.

To overcome the lack of records some authors supplement their data with accelerograms from other regions of the world which are felt to be tectonically similar. For example, Campbell (1981) uses eight records from outside western USA (from shallow tectonic plate boundaries) because they make an important contribution to understanding near-source ground motion and this outweighs differences which may exist due to tectonics and recording practice. Differences in anelastic attenuation between the different areas are minimized by using only near-source records and he uses only data from instruments with similar dynamic characteristics to avoid problems due to recording practice. This increases the distribution of the data space so that the derived equations have a greater applicability. McCann Jr. and Echezwia (1984) also use data from 
outside western N. America, even though tectonics and travel paths may be different, because additional information in the near field is considered more important. Theodulidis and Papazachos (1992) supplement their Greek data with 16 records from other regions (Japan and Alaska) to increase the number of records from large $(7.0 \leq M \leq 7.5)$ shallow earthquakes which can occur in Greece but for which no Greek strong-motion records exist. Fukushima et al. (1988) use 200 records, from distances $0.1-48 \mathrm{~km}$, from western USA to constrain the near-source behaviour of the ground motion estimation equation because Japanese data from this distance range are lacking.

Ground motion estimation relations have been derived for particular tectonic regimes and not simply based on a country's borders. Dahle et al. (1990b) present a study using records from worldwide intraplate areas, defined as tectonically stable and geologically more uniform than plate boundaries, although due to lack of data they choose data from 'reasonably' intraplate areas. Spudich et al. (1996, 1999) find equations for extensional regimes (where lithosphere is expanding 'areally') using worldwide data. Crouse (1991) includes data from any zone with strong seismic coupling, such as younger subduction zones, unless there are compelling reasons to exclude data. This is done because there are not enough data available from Cascadia, which is his area of interest. A number of workers (Abrahamson and Litehiser, 1989; Ambraseys and Bommer, 1991; Ambraseys, 1995; Ambraseys et al., 1996; Sarma and Srbulov, 1996; Campbell, 1997; Bozorgnia et al., 2000) derived equations for shallow crustal earthquakes using data from wide regions, including the whole Earth, because, it is felt, such earthquakes and regions are similar worldwide. Campbell (1997) includes shallow subduction interface earthquakes in his mainly shallow crustal set of records, because previous studies have found 
that their near-source ground motion is similar to that from shallow crustal earthquakes. The distance calibration functions of regional local magnitude scales for different parts of the world are examined by Boore (1989) and it is found that they are similar to distances of about $100 \mathrm{~km}$ but differ beyond that. Boore (1989) thinks that this is because differing anelastic attenuation and wave propagation effects in different crustal structures should not play a large role at close distances. Therefore within the range where ground motions have engineering significance (about $100 \mathrm{~km}$ ) data from different parts of the whole could be combined as far as distance dependence is concerned.

Criteria based on source depth have been used as an earthquake selection criterion, see Table 2.

A minimum magnitude criterion is often applied, see Table 3. A natural constraint on the minimum magnitude which often occurs for spectral ordinates is that records from analogue instruments of small magnitude earthquakes are not always digitised, because digitization is a time-consuming and expensive process. Therefore the digital form of such records, from which response spectra are calculated, are not available and so such records cannot be used for deriving ground motion estimation equations. This constraint does not occur for records from digital accelerographs, which are becoming more common, because they are recorded directly in digital form. Blume (1977) and Ambraseys (1995) study the effect of different minimum magnitude cut-offs; Ambraseys (1995) finds that the cut-off used has little effect on ground motion estimates. Selection based on accuracy of the magnitudes is used by Campbell (1981) and Sabetta and Pugliese (1987), who use only earthquakes with magnitudes accurate to within 0.3 units, and Ambraseys and Bommer (1991), who require the standard deviation of $M_{s}$ to be known. 
Minimum and maximum distance criteria are sometimes applied for a variety of reasons. Blume (1977) investigates the effect of using different distance cut-offs. McGuire (1977) excludes records with epicentral or rupture distance smaller than one-half the estimated length of rupture to exclude those records from the near-source region which are governed by different physical laws than those far from the source. A minimum distance criterion, of $2 \mathrm{~km}$, was applied by Wang et al. (1999) because $2 \mathrm{~km}$ is the minimum error in epicentral locations and hence including records from smaller distances may give errors in the results. Lack of far-field data motivates Molas and Yamazaki (1995) to exclude records from greater than $200 \mathrm{~km}$ and Crouse et al. (1988) to remove data with distances or magnitudes well outside the range of most selected records. Campbell $(1981,1997)$ uses only near-source records to avoid complex propagation effects observed at longer distances. Only records associated with reliable distances are used by Campbell (1981) and Sabetta and Pugliese (1987) by including only earthquakes with locations (epicentres or rupture distance) known to within $5 \mathrm{~km}$ or less. Other studies use previously published ground motion estimation relations to impose magnitude dependent distance limits. Fukushima and Tanaka (1990) remove records with predicted $\mathrm{PGA}<0.1 \mathrm{~ms}^{-2}$ (the assumed trigger level) to avoid biasing the attenuation rate, Fukushima et al. (1995) exclude records with predicted $\mathrm{PGV}<0.1 \mathrm{cms}^{-1}$ so precise attenuation is found and Kobayashi et al. (2000) exclude data from distances with predicted PGA $<0.02 \mathrm{~ms}^{-2}$.

Previous studies have tried to reduce possible bias due to using records from large distances which may not be typical of the attenuation rate, through two alternative procedures. Joyner and Boore (1981) exclude records from distances greater than or equal to shortest distance to an instrument which did 
not trigger. This has been made more strict by Boore et al. (1993) who exclude records from distances greater than the distance to the first record triggered on the $\mathrm{S}$ wave and for spectral ordinates exclude records from distances greater than the distance to the first non-digitised record (which is assumed to be of smaller amplitude than the digitised records). Boore et al. (1994a) conclude that this criterion may be over strict because it is independent of geology and azimuth. Ambraseys and Bommer (1991) and Spudich et al. (1996, 1999) do not use such a criterion because their sets of records are non-homogeneous and from irregularly spaced networks with different and unknown trigger levels, thus making such a criterion difficult or impossible to apply. Crouse (1991) also does not apply this criterion but considers his sample adequate for regression and although it may overestimate smaller distant motion it would properly estimate larger motions which are of greater concern for design. Although this is true the ground motion estimation equation obtained would not predict the median hazard at all distances and therefore the use of it in seismic hazard analysis, for example, which requires the $50 \%$ hazard curve would bias the results. The other method for removing bias due to non-triggered instruments is the regression based method of Campbell and Bozorgnia (1994), Campbell (1997) and Chapman (1999) which uses all the available strong-motion data to derive ground motion estimation relations to predict the non-triggering cut-off distance.

Exclusion of records based on minimum PGA has been proposed as a selection criteria, see Table 4. Blume (1977) studies effect of different PGA cut-offs but Blume (1980) does not employ a PGA cut-off because it is, by itself, a poor index of damage in most cases.

Time-history quality is also a criterion used by some authors. Campbell (1981) 
only includes records which triggered early enough to capture the strong phase of shaking and hence the ground motion is not underestimated. Dahle et al. (1990b) exclude records which are not available unprocessed and without sufficient information on instrument natural frequency and damping. Lee (1995) only uses records with high signal-to-noise ratio. Youngs et al. (1997) remove poor quality time-histories and those which do not contain the main portion of shaking from their set of data. Records of short duration terminating early in the coda are not including in the analysis of Chapman (1999). Sabetta and Pugliese (1987) use only the first shock of a record if it is a well separated multiple shock record and magnitude and focal parameters apply only to first shock. All these criteria are valid and would help to reduce some of the scatter in the ground motion but less subjective methods are required if records are not simply rejected because they do not seem to match the rest of the data. Cousins et al. (1999) retains data from clipped seismograms.

It is common to use only those records which are not significantly affected by soil-structure interaction although many alternative suggestions have been made on how to select such records, see Tables 5 and 6 which give the first time that an author applies a particular criterion.

Ohsaki et al. (1980a), Campbell (1981) and Crouse and McGuire (1996) remove records thought to be affected by high topographical relief.

Criteria are sometimes used to achieve a set of data which will not lead to biased results simply because of its distribution. McGuire (1978) uses no more that seven records from the same earthquake and no more than nine from a single site to minimize underestimation of variance and he retains records to give a large distance and magnitude range. Campbell (1981) and Devillers and 
Mohammadioun (1981) do not use all data from San Fernando to minimize bias due to the large number of records. This problem is also noted by Trifunac (1976) who screens the data to minimize possible bias due to uneven distribution of data amongst different magnitude ranges and soil conditions and from excessive contribution to the database from several abundantly recorded earthquakes. Boore et al. (1993) do not use data from more than one station with the same site condition within a circle of radius $1 \mathrm{~km}$ so that the underestimation of variance is minimized. Niazi and Bozorgnia (1991) select earthquakes to cover broad range of magnitude, distance and azimuth and to ensure thorough coverage of whole SMART-1 array (at least 25 stations recorded each shock). Other criteria for the minimum number of records per earthquake used are 3 or more (Atkinson, 1997) and 2 or more (Abrahamson and Litehiser, 1989), both to improve ability of regression to distinguish between magnitude and distance dependence. Caillot and Bard (1993) selects records so mean and standard deviation of magnitude and hypocentral distance in each site category are equal.

One other selection criterion is that based on the intensity measured at the recording site (Devillers and Mohammadioun, 1981; Mohammadioun, 1991, 1994b). They group their data by single intensities (from V to VIII and higher) and by ranges of intensities and perform the analysis separately on each of these subsets. Therefore even though they do not include site intensity as an independent parameter explicitly, to use their equations still requires a prediction of the intensity which will occur at the site, along with choosing the magnitude and distance. Hence they require the user to make a choice for a parameter, site-intensity, which if known would mean there would be little reason for using a ground motion estimation relation to predict the response 
spectrum at the site. Mohammadioun (1994b) highlights another problem with the technique because the recording site intensities may be average intensities within the area of the site and hence would neglect possible microzoning effects. A more technical problem is mentioned by Mohammadioun (1991), who does not use intensity-based selection for his derivation of spectral equations for Italy because of the risk of creating a data population which is not statistically significant.

\section{Correction techniques}

As with data selection procedures, early ground motion estimation studies do not state how their strong-motion records were corrected (e.g. Milne and Davenport, 1969; Esteva, 1970; Ambraseys, 1975), thus either uncorrected records were used or standard correction procedures were employed. Since the paper of Trifunac (1976) who gives frequencies between which the accelerations used are thought to be accurate, details of correction techniques used for deriving ground motion estimation relations have often been reported, but again, like data selection procedures, there is little agreement about the best method to use. However, because time-histories from different types of accelerographs have been used and because of the wide variety of levels of ground motion that have been used in different studies, there is no general best procedure. Tento et al. (1992) state that correction procedure plays a relevant role in analysis and that it introduces inhomogeneities and errors due to the subjective choice of low frequency filter limits.

Almost all studies, where details are given, have filtered their strong-motion records using a variety of passbands and types of filter. The cut-off frequencies 
used either have been the same for all records or have been chosen for each record individually using a number of different techniques. Table 7 summarises the methods for individually selecting low and high cut-off frequencies and the frequencies chosen.

Some authors have applied standard filter cut-offs to their records apparently irrespective of the quality of time-histories. Gaull (1988) bandpass filters his records to get the PGA associated with periods between 2 and $10 \mathrm{~Hz}$, because high frequency PGA from uncorrected records is not of engineering significance. Although this is true, because the PGA is often used to anchor a response spectrum at zero period, using the PGA not associated with high frequencies to estimate the spectrum is incorrect. Dahle et al. (1990b) use an elliptical filter with passband 0.25 to $25 \mathrm{~Hz}$. Niazi and Bozorgnia (1992) use a trapezoidal filter with corner frequencies $0.07,0.10,25$ and $30.6 \mathrm{~Hz}$. Kamiyama et al. (1992) filter with passband 0.24 and $11 \mathrm{~Hz}$. Molas and Yamazaki (1995) use a low-cut filter with cosine shaped transition from 0.01 to $0.05 \mathrm{~Hz}$. For long records (more than $10 \mathrm{~s}$ duration) and some shorter records (between 5 and $10 \mathrm{~s}$ duration) Ambraseys et al. (1996) use a passband 0.20 to $25 \mathrm{~Hz}$. Sarma and Srbulov (1996) employ a low pass elliptical filter. Caillot and Bard (1993) use cut-offs 0.5 and $30 \mathrm{~Hz}$. The application of the same cut-off frequencies for all accelerograms used is justified for those studies which use a homogeneous set of records recorded on the same type of instrument and digitised in the same way (e.g. Niazi and Bozorgnia, 1992; Molas and Yamazaki, 1995). For those authors who use strong-motion records from a wide variety of sources which have been recorded on different types of instrument and have different digitisation qualities (Dahle et al., 1990b; Ambraseys et al., 1996; Sarma and Srbulov, 1996) using such a general procedure is probably not justified. 
Bommer et al. (1998) show, however, that the choice of the cut-off frequencies does not significantly affect spectral ordinates for periods within the range of main engineering interest (about 0.1 to $2 \mathrm{~s}$ ), therefore a common correction may not affect the results. For special structures, with periods longer than $2 \mathrm{~s}$, the cut-off frequency used could be important.

Since the paper of Trifunac (1976), removal of the transducer response (instrument correction) from the time-history is often performed (e.g. Sabetta and Pugliese, 1987; Spudich et al., 1996; Cousins et al., 1999). The need to correct records from Japanese instruments to yield reliable PGAs, because they substantially suppress high frequencies, is noted by Kawashima et al. (1986). Data from seismographs also needs to be instrument corrected because of their different frequency response compared with accelerographs (Cousins et al., 1999). Instrument correction requires, at least, the natural frequency and damping of the accelerograph, information which is sometimes lacking and hence such corrections cannot be applied (Ambraseys et al., 1996). Chiaruttini and Siro (1981) do not correct their Friuli records for instrument response but find this does not substantially alter PGA and Bommer et al. (1998) do not employ instrument correction because it is not important for displacement spectra.

Whether the corrected or uncorrected PGAs should be included is another topic of debate. Campbell (1981) uses PGA from unprocessed accelerograms because fully processed PGAs are generally smaller due to decimation and filtering of records. Uncorrected PGAs are also used by Munson and Thurber (1997). Other studies, it is supposed, use corrected PGAs. Ambraseys and Bommer (1991) and Ambraseys (1995) use PGAs from accelerograms which have undergone a wide variety of different processing techniques, including no correction, for their studies. They find that most differences (which they 
can check) are small (below 4 or $5 \%$ ) but for some records the differences may be larger (up to 10\%). Munson and Thurber (1997) also find small differences between uncorrected and corrected PGA. Sabetta and Pugliese (1987) find their correction technique provides reliable estimates of PGA and hence uncorrected PGA values do not need to be used. Accelerogram correction procedures are used to find the actual ground motion which occurred at the site therefore uncorrected PGA values are not the real PGAs. There is an inconsistency between using uncorrected estimates of PGA but correcting the records to find spectral ordinates which leads to the PGA ground motion estimation equation not matching the spectral ordinate equations at high frequencies. However, such differences are probably small enough to be neglected when compared with other assumptions made.

A few studies have included other sources of PGA values apart from those given on accelerograms. Chiaruttini and Siro (1981) use some PGA estimates from velocity time-histories. Garcia-Fernandez and Canas (1995) only use PGA values derived from Fourier amplitude spectra at $5 \mathrm{~Hz}$ from short-period analogue time-histories. Cousins et al. (1999) differentiate seismograms to yield PGA estimates. Such techniques to supplement a limited set of records, particularly in the far field where accelerographs may not be triggered, are useful but estimates of PGA from the transformation of measurements from instruments with much different characteristics than accelerographs must be verified to be consistent with those from accelerographs.

The choice of correction method strongly affects the range of periods within which the spectral ordinates calculated can be assumed to be correct and not significantly affected by the correction procedure. This question has started to be discussed recently because seismic design is becoming more interested 
in long-period ground motion which is the range most affected by noise and hence by the correction technique, which seeks to remove this noise but in the process also removes information on the actual ground motion. Mohammadioun (1991) provides no ground motion estimation equations for periods greater than $2 \mathrm{~s}$ because he uses uncorrected time-histories which it is felt contain long-period noise. The $2 \mathrm{~s}$ limit on the acceptability of the derived equations is also noted by Tento et al. (1992), who find that the record dependent correction procedure they adopt significantly affects the results for periods greater than $2 \mathrm{~s}$. Boore et al. (1993) also only provide spectral ordinate equations for periods between 0.1 and $2 \mathrm{~s}$ because of the low sampling rate of older time-histories, low signal-to-noise ratios and filter cut-offs affecting spectral ordinates for periods outside this range. Lee (1995) believes his records are not adequate for response spectrum calculation outside the period range 0.04 to $2 \mathrm{~s}$. An even shorter period range for acceptable spectral ordinates is stated by Theodulidis and Papazachos (1994), who believe that for periods greater than $0.5 \mathrm{~s}$ the different digitisation (manual or automatic) and correction (baseline fitting or filtering) techniques they have used means longer period values are significantly affected. Niazi and Bozorgnia (1992) believe their low frequency cut-off may be too low for records from small earthquakes but choosing a higher frequency for this cut-off would remove information on long-period ground motion. If they adopted a record dependent correction procedure and then in deriving long-periods equations use only those records which did not require a higher frequency cut-off, this problem would be overcome. Such a method has been adopted by a number of recent workers (Spudich et al., 1996, 1999; Abrahamson and Silva, 1997; Bommer et al., 1998). Spudich et al. (1996) use spectral values only from the passband of the filter. Abrahamson and Silva (1997) use spectral values only within frequency 
band $1.25 f_{h}$ to $0.8 f_{l}$ (where $f_{h}$ is the high-pass corner frequency and $f_{l}$ is the low-pass corner frequency). Spudich et al. (1999) uses a similar criteria of only using spectral ordinates within $1.25 f_{h}$ and $0.75 f_{l}$ and for eight records which were processed in a different way the acceptable range was 0.1 to 1 s. Bommer et al. (1998) use each record's spectral ordinates for regression up to $0.1 \mathrm{~s}$ less than the period of the filter cut-off used for that record. These techniques mean that the number of records and distribution of records used for the regression analysis changes with period and hence it must be checked that for each period the number and distribution of data points is adequate to derive reliable coefficients. There may be a problem of consistency between spectral estimates, derived from the ground motion estimation relations, for short periods, for which probably most of the records were used, compared with long periods, for which the stronger ground motions are probably more represented.

\section{Combination of horizontal measurements}

Most accelerograms consist of three mutually orthogonal components: two horizontal and one vertical. Seven different ways of combining the horizontal components have been investigated, these are given below.

(1) Arithmetic mean: $a_{M}=\left[\max \left|a_{1}(t)\right|_{\text {for } t}+\max \left|a_{2}(t)\right|_{\text {for } t}\right] / 2$.

(2) Both: $a_{B, 1}=\max \left|a_{1}(t)\right|_{\text {for } t}$ and $a_{B, 2}=\max \left|a_{2}(t)\right|_{\text {for } t}$.

(3) Geometric mean: $a_{G}=\sqrt{\max \left|a_{1}(t)\right|_{\text {for } t} \max \left|a_{2}(t)\right|_{\text {for } t}}$.

Note that: $\log a_{G}=\left\{\log \left[\max \left|a_{1}(t)\right|_{\text {for } t}\right]+\log \left[\max \left|a_{2}(t)\right|_{\text {for } t}\right]\right\} / 2$.

(4) Largest component: $a_{L}=\max \left[\max \left|a_{1}(t)\right|_{\text {for } t}, \max \left|a_{2}(t)\right|_{\text {for } t}\right]$.

(5) Random: $a_{r}=\max \left|a_{1}(t)\right|_{\text {for } t}$ or $a_{r}=\max \left|a_{2}(t)\right|_{\text {for } t}$, chosen randomly. 
(6) Resultant: $a_{R}=\max \left[\max \left|a_{1}(t) \cos \theta+a_{2}(t) \sin \theta\right|_{\text {for } t}\right]_{\text {for } \theta}$. Correct calculation of this combination requires that the two horizontal components records are perfectly aligned with respect to time and that they are exactly mutually perpendicular. This may not always be true, especially for digitised accelerograms from mechnically triggered analogue instruments.

(7) Vectorial addition: $a_{V}=\sqrt{\max \left|a_{1}(t)\right|_{\text {for } t}^{2}+\max \left|a_{2}(t)\right|_{\text {for } t}^{2}}$. This assumes that the maximum ground amplitudes occur simultaneously on the two horizontal components; this is a conservative assumption.

Using both horizontal components or the geometric mean of the two components leads to exactly the same regression coefficients when logarithms of the ground motion measurements are used. This can be demonstrated by considering the normal equations which are solved to give the least squares estimate of the coefficients (Douglas, 2001b). The standard deviation of the equation derived using both horizontal components will, however, usually be different to the standard deviation of the equation derived using the geometric mean of the two horizontal components.

\section{Separation of ground motion estimation relations into source, path and site dependence}

Traditionally discussion of ground motion from earthquakes has been split into three sections: source, travel path and site, upon which the ground motion at the site depends. This separation is somewhat simplistic, because the boundaries between each part are not clearly defined and because the source affects the path's properties and path properties affect site conditions. This separation though will be followed here because it makes reviewing previous ground 
motion estimation relationships easier but it is complicated by the previously described problems and by the use of non-linear equations in which source, path and site parameters are not separated.

The following discussion is in terms of the untransformed ground motion, $y$, as opposed to $\log y$ on which the regression is almost always performed.

\section{Characterisation of source}

Earthquake magnitude, $M$, has been almost the only parameter used to characterise the earthquake source in ground motion estimation relations, although many different magnitude scales and combinations of scales have been used. Recently parameters associated with the source mechanism have also been included although again there are a number of alternative methods for including this information in the equation.

Early studies (e.g. Esteva, 1970; Donovan, 1973), did not state which magnitude scale they use. Many authors use local magnitude (also called Richter magnitude), $M_{L}$, to derive their ground motion estimation relations (e.g. McGuire, 1977; Campbell, 1989; Tento et al., 1992; Mohammadioun, 1994b). This may be because these are the only magnitude estimates available for the chosen earthquakes. Chiaruttini and Siro (1981) use $M_{L}$ because it is determined at short distances, it is homogeneously determined for small earthquakes up to saturation at about $M_{L}=7.0$ and because it is determined at about $1 \mathrm{~Hz}$ which is close to the accelerometer band. Mohammadioun (1994b) uses $M_{L}$ because it is generally available and is uniformly determined but states that it may not be the best choice. Ambraseys (1995) does not use $M_{L}$ 
because there are no $M_{L}$ estimates for many of the earthquakes in his set and many estimates of $M_{L}$ are unreliable. Boore (1989) states that $M_{L}$ is difficult to predict for design earthquakes because catalogues of historical earthquakes often contain unreliable $M_{L}$ estimates.

Another magnitude scale which is commonly used is surface-wave magnitude, $M_{s}$ (Dahle et al., 1990b; Ambraseys and Bommer, 1991; Ambraseys, 1995; Ambraseys et al., 1996; Crouse and McGuire, 1996; Bommer et al., 1998). Dahle et al. (1990b) use $M_{s}$ because it is reasonably unbiased with respect to source dimensions and there is a globally consistent calculation method. Theodulidis and Papazachos (1992) mainly use $M_{s}$ but for the foreign earthquakes in their set they use $M_{w}$ or $M_{\mathrm{JMA}}$ which they state to be equivalent between 6.0 and 8.0. Ambraseys (1995) states that the conversion of $M_{L}$ to $M_{s}$ should not be done because of uncertainty in conversion which should be retained. This holds for all conversions between magnitude scales but because only $M_{w}$ can be found for all size earthquakes conversion from one scale to another is often necessary at small and large magnitudes, for example Dahle et al. (1990b) and Ambraseys et al. (1996) use some $M_{s}$ converted from other magnitude scales $\left(M_{L}, m_{b}\right.$, coda length magnitude). Japanese Meteorological Agency magnitude, $M_{\mathrm{JMA}}$, has been employed in many Japanese ground motion estimation relations (e.g. Kawashima et al., 1984; Kamiyama et al., 1992; Fukushima et al., 1995) although Kawashima et al. (1984) notes that it may not necessarily be the most suitable parameter to represent magnitude but it is the only one which exists for all earthquakes in their set of records. Peng et al. (1985) use Chinese surface-wave magnitude but also use $m_{b}$ and $M_{s}$ and find larger residuals. When using $M_{s}$ it is important that the measurements are corrected for focal depth, which significantly affects the estimates of $M_{s}$ 
for earthquakes with focal depths greater than $20 \mathrm{~km}$ (e.g. Herak et al., 2001).

Recently most equations have been derived using moment magnitude, $M_{w}$, (e.g. Boore et al., 1993; Lawson and Krawinkler, 1994; Sadigh et al., 1997; Kobayashi et al., 2000) which is directly related to the size of the source and the slip along the fault, unlike other magnitude scales which are empirically derived and have no physical meaning. The other major advantage of $M_{w}$ is that it does not saturate for large magnitudes, and can be calculated for small magnitudes, and hence provides a good measure of the energy released over the entire magnitude range. The size and slip of historical earthquakes can be found using geological data which can then be directly related to $M_{w}$ for use in assessing the design earthquake; this is more difficult to do for other magnitude scales (Boore, 1989). However, $M_{w}$ is not usually calculated for earthquakes with magnitudes less than about 5 and also it has only been uniformly calculated since 1977 and hence for earlier earthquakes estimates of $M_{w}$ are more difficult, if not impossible, to find. To overcome these difficulties some authors (e.g. Joyner and Boore, 1981; Xu et al., 1984; Crouse, 1991; Dahle et al., 1995) have used magnitudes from other scales (e.g. $\left.M_{L}, M_{s}\right)$ as estimates of $M_{w}$ for those earthquakes which do not have a published $M_{w}$ value. If only a few earthquakes in the set of data do not have a $M_{w}$ value, if the magnitude scale chosen to supplement $M_{w}$ is equivalent to moment magnitude for that size of earthquake and if the number of records associated with these earthquakes is small then this method is satisfactory.

The other main technique for providing a homogeneous magnitude scale for all sizes of earthquakes is to use one magnitude scale for small earthquakes, usually $M_{L}$ and one scale for larger earthquakes, usually $M_{s}$. Campbell (1981) introduced this idea to develop magnitude estimates that are generally con- 
sistent with $M_{w}$. He tried different division points, for the change from $M_{L}$ to $M_{s}$, between 5.5 and 6.5 and found that the magnitude is quite insensitive to choice, but he uses 6.0 as do Abrahamson and Litehiser (1989). Sabetta and Pugliese (1987) use 5.5 as the change-over point from $M_{L}$ to $M_{s}$ and find that this combined magnitude scale assures a linear relationship between logarithm of PGA and magnitude and avoids saturation effects of $M_{L}$. Niazi and Bozorgnia (1991) use 6.6 as the division point. Lee (1993) uses $M_{L}$ for $M \lesssim 6.5$ and other different (unspecified) magnitude scales for $M>6.5$. He does this because seismic hazard analysis often uses catalogues which do not specify magnitude scale and often the estimates are nonhomogeneous. Even though this may be so, increasing the uncertainty, associated with the ground motion estimation relation, by using a mixture of magnitude scales means that it can never be correctly used for seismic hazard analysis because there is no correct magnitude scale and the uncertainties are then increased unnecessarily.

Almost all studies include a factor which has an exponential dependence on magnitude, $\exp a M$, this is because the energy released by an earthquake is exponentially dependent on magnitude (Richter, 1958).

It has been proposed that strong ground motion does not increase without bound for increasing magnitudes and that as magnitude increases ground motion does not increase at a constant rate. This is known as magnitude saturation. Bolt and Abrahamson (1982) split their data into four broad magnitude groups and fit an equation which has no magnitude-dependent factors to the ground motion within each group. They find no systematic increase in near-source PGA as a function of magnitude although the derived equations predict lower PGA for larger magnitudes which, as Joyner and Boore (1983) point out, is not realistic. Hence this study may be biased by a lack 
of data for large magnitudes. Trifunac (1976) was the first to include a factor to model magnitude saturation, by using a factor that is exponentially dependent on the magnitude squared, i.e. $\exp b M^{2}$, in addition to the normal factor $\exp a M$. For a positive coefficient, $a$ and a negative coefficient $b$ it predicts a maximum ground motion which could occur however great the magnitude. Such factors have been included by, for example Trifunac (1980), Joyner and Fumal (1984), Huo and Hu (1991), Boore et al. (1993), Lee (1995), Lawson and Krawinkler (1994), Chapman (1999) and Abrahamson and Silva (1997). Other authors (Joyner and Boore, 1981; Kawashima et al., 1984; Crouse et al., 1988; Crouse, 1991) incorporate factors like $\exp b M^{2}$ into their equations but find that the coefficient $b$ is not statistically significant or that it does not improve the adjusted multiple correlation coefficient so remove the factor. Modelling quadratic dependence on magnitude requires records from large magnitude earthquakes that are often lacking (Trifunac, 1976). To overcome this lack of data Spudich et al. $(1996,1999)$ adopt coefficients, $a$ and $b$, from Boore et al. (1993). Lee (1995) uses only records with $M \geq 4.25$ so that $a$ and $b$ have the correct sign to give magnitude saturation for large magnitudes. Needing to apply such methods to force physically realistic coefficients suggests that magnitude saturation is not supported by the data used and that excluding the factor, $\exp b M^{2}$, would be preferable. However, magnitude saturation is supported theoretically, see for example Douglas (2002b).

Factors which are exponentially proportional to higher powers of magnitude have been incorporated into equations by Sadigh et al. (1997), who include a factor $\exp k_{1} M^{2.5}$, Abrahamson and Silva (1997) who include a factor exp $k_{2}(8.5-$ $M)^{3}$, and Youngs et al. (1997), who include a factor $\exp k_{3} M^{3}$, for the prediction of spectral acceleration. Campbell (1997) uses a non-linear magnitude 
dependent term, $\exp k_{4} \tanh M$.

Kamiyama et al. (1992) take the idea of magnitude saturation to its extreme by modelling PGA as completely independent of magnitude up to a distance which is exponentially dependent on magnitude. For distances greater than this near-source zone the predicted ground motion is exponentially dependent on magnitude.

An alternative method for modelling different magnitude dependence for small and large earthquakes is to derive separate equations for $M_{w}<6.5$ and for $M_{w} \geq 6.5$ (e.g. Sadigh et al., 1997; Sadigh and Egan, 1998). This technique relies on a large set of data that is well distributed in terms of magnitude so that there is enough data to derive reliable equations for the separate subsets, although Sadigh et al. (1997) constrain the predictions to be the same at $M_{w}=6.5$.

Ambraseys (1995) notes that because the conversion of $M_{s}$ to $M_{w}$ is non-linear there is a non-linear relationship between $M_{w}$ and ground motion prediction using an equation derived using $M_{s}$. Hence some degree of magnitude saturation is implicit in ground motion estimation relations based on $M_{s}$, even if only a factor $\exp a M_{s}$ is included, because $M_{s}$ saturates at large magnitudes and so the equation does not predict constantly increasing ground motion for increasing earthquake size (as measured by $M_{w}$ ). This form of magnitude saturation, however, is not constrained by the strong-motion data used to derive the equation.

Figure 2 compares the scaling of horizontal peak ground acceleration with $M_{w}$ for some recent equations derived using data from shallow crustal earthquakes. This figure shows the magnitude saturation of near-field PGA modelled in 
some recent studies (e.g. Sadigh et al., 1997; Campbell and Bozorgnia, 1994) and the implicit magnitude saturation of the equation by Ambraseys et al. (1996).

Some studies may implicitly account for source mechanism by including many shocks from the same area which have a similar mechanism, for example Trifunac (1976) notes that the large proportion of data from the San Fernando earthquake he uses may bias the results.

Campbell (1981) examines residuals from regression and finds reverse faulting PGA values are systematically higher (significant at the $10 \%$ level) than other motions but concludes this may be due to data from outside western N. America and so does not model the effect. Niazi and Bozorgnia (1991) also find evidence, by examining residuals, of higher ground motion from reverse faulting and lower motion from normal faulting as compared with the mean, but it is not modelled because the mechanisms of four earthquakes are unknown. Crouse et al. (1988) split data by fault mechanism and find no significant differences between thrust, normal and strike-slip. Spudich et al. (1999) find no significant difference between strike-slip and normal ground motions in extensional regimes.

Abrahamson and Litehiser (1989) include a simple multiplicative factor to model difference in ground motion between reverse (and reverse-oblique) and other source mechanisms. Boore et al. (1994a) find marginal statistical significance for the difference between strike-slip and reverse-slip ground motion, which they later model as a multiplicative factor (Boore et al., 1994b). Sadigh et al. (1997) also model this difference using a multiplicative factor (they include normal faulting ground motion in the strike-slip group because it was 
not found to be significantly different than strike-slip motion). Zhao et al. (1997) and Cousins et al. (1999) include a multiplicative factor to account for the difference between crustal reverse motion and other motions. Campbell and Bozorgnia (2002) incorporate factors to model difference between strikeslip (including normal), reverse and thrust ground motions. McVerry et al. (2000) include factors, in their crustal earthquake equation, to model differences between normal, reverse-oblique and reverse ground motions. Crouse and McGuire (1996) try a multiplicative factor, to predict the difference between reverse and strike-slip motion, in their equation but they find it is not significant and the inconsistency of the result between soil classes means it is difficult to attach significance to fault type.

More complex factors to model the differences in ground motion caused by different fault mechanisms have recently been included in ground motion estimation relations. Abrahamson and Silva (1997) include magnitude dependent fault mechanism factors and Campbell and Bozorgnia (1994) and Campbell (1997) include distance and magnitude dependent factors.

Sadigh and Egan (1998) provides different equations for reverse and strikeslip (including normal faulting) ground motion. This can incorporate complex multiplicative factors (dependent on magnitude, distance and soil category) relating ground motion associated with reverse faulting to that from strike-slip faulting but it requires much data to ensure that the predictions are realistic for all combinations of magnitude and distance.

Sharma (1998) does not attempt to include source mechanism factors because source mechanisms are not well defined for all earthquakes in his set of records , which come from the southern Himalayas, and including too many coefficients 
and a small amount of data may lead to errors.

Figure 3 compares the estimated ratio of horizontal peak ground acceleration and response spectral amplitudes between reverse and strike-slip faulting earthquakes using some recent equations derived using data from shallow crustal earthquakes. This figure shows that reverse faulting earthquakes are expected to show significantly larger response spectral amplitudes (up to a factor of 1.5) than strike-slip faulting earthquakes at short to intermediate periods $(T \leq 1 \mathrm{~s})$ and lower spectral amplitudes for longer periods. However there are considerable differences in the estimated ratios of reverse to strikeslip faulting ground motions between the different sets of equations. These differences are due to different definitions of reverse and strike-slip faulting, different sets of earthquakes and records used and different functional forms employed.

Recent attempts have been made to model differences in ground motion due to the general tectonic setting of the earthquake. Chiaruttini and Siro (1981) were the first to explicitly consider the tectonic setting (characterised by the earthquakes' geographical location) by developing separate equations for three different areas (Friuli, Italy; Ancona, Italy; and the rest of the Alpide belt) and also one equation which models the differences by a multiplicative factor. Fukushima and Tanaka (1990) allow different magnitude scaling for western N. American earthquakes than for Japanese shocks. Youngs et al. (1997) include a multiplicative factor to predict the significant difference between ground motion from interface and intraslab subduction zone earthquakes. Zhao et al. (1997) also include a factor to account for the difference between ground motion from interface subduction zone shocks and other types of earthquake. McVerry et al. (2000) include factors, in their subduction zone equation, to 
predict the difference between ground shaking from interface and deep slab shocks. Si and Midorikawa (2000) include two factors to model the difference between crustal, interplate and intraplate Japanese earthquakes. A recent study on modelling differences between ground motion due to the general tectonic setting is that by Parvez et al. (2001) who find large differences in ground motions between the eastern and western Himalayas.

Kobayashi et al. (2000) find their equation over predicts ground motion from interface earthquakes compared with intraslab motions. Crouse et al. (1988) find some differences between ground motion in different subduction zones but do not model them, partly because some differences may be because of site effects. Crouse et al. (1988) also try to find correlations between seismotectonic information (age, convergence, dip, contact width, maximum subduction depth, maximum historical earthquake, maximum rupture length, stress drop and seismic slip) and ground motion in each zone. They find weak correlations for stress drop and the maximum historical earthquake but lack confidence in the results because of uncertainty in stress drop estimates.

Other studies have found that the difference between strong ground motion in different seismotectonic regions is not significant. Sabetta and Pugliese (1987) exclude records from different seismotectonic and geological regions and repeat their analysis and find predicted PGA is similar. No significant difference is found between Guerrero (Mexico) ground motion and other Central American motion nor between subduction and shallow crustal strong ground motion by Dahle et al. (1995). Sharma (1998) neglects tectonic type because of a small set of records and because only small differences are expected. Atkinson (1997) checks for differences in ground motion between crustal, interface and intraslab shocks and finds no dependence on tectonic type. 
Azimuthal dependence of ground motion has been investigated in three studies. Sabetta and Pugliese (1987) find that some of their PGA values show azimuthal dependence although this is not modelled because it would require more coefficients and the direction of the azimuthal effect is different from region to region. Lungu et al. (1994, 1995b) split data into separate quadrants and find ground motion estimation equations for each subset; they find azimuthal dependence. The conclusions of this study are based on limited strong-motion data in each quadrant coming from only four earthquakes and hence special characteristics of these four earthquakes may explain the azimuthal dependence. This azimuthal dependence may also be partly due to differences in travel-paths.

\subsection{Characterisation of depth}

Incorporation of depth through selection criteria has been discussed in Section 4, this section describes how depth is included in the ground motion estimation equation.

The use of distance measures which contain information on the depth of the source, i.e. hypocentral distance, rupture distance, seismogenic distance, centroid distance, energy centre distance, equivalent hypocentral distance or surface projection distance with focal depth [as used by Ambraseys and Bommer (1991), Sigbjörnsson and Baldvinsson (1992) and Ambraseys (1995)] forces deeper earthquakes to predict smaller ground motions than shallower shocks. This is actually a path effect.

For sets of earthquakes with depths up to about $250 \mathrm{~km}$ (for example those 
from subduction zones) a factor which is exponentially dependent on depth is often included as well as using a distance measure which includes depth (hypocentral, centroid, energy centre or rupture distance) (Crouse, 1991; Lungu et al., 1994, 1995b; Molas and Yamazaki, 1995; Atkinson, 1997; Youngs et al., 1997; Zhao et al., 1997; Shabestari and Yamazaki, 1998; Cousins et al., 1999; Shabestari and Yamazaki, 2000; Si and Midorikawa, 2000). Annaka and Nozawa (1988), Molas and Yamazaki (1995) and Youngs et al. (1997) find it significantly increases coefficients of determination, $R^{2}$, or alternatively decreases the standard deviation. Kamiyama and Yanagisawa (1986) use such a factor but employ epicentral distance. Definitions of depth used to characterise the source have been focal depth (e.g. Atkinson, 1997), depth to top of fault (e.g. Molas and Yamazaki, 1995), centroid depth (e.g. Zhao et al., 1997) and average depth of fault plane (e.g. Si and Midorikawa, 2000).

Figure 4 compares the predicted effect of depth on horizontal peak ground acceleration for four equations derived for subduction zone earthquakes in different regions of the world. This figure shows that the effect of depth can be significant (for example the equation of Cousins et al. (1999) predicts about a factor of about four increase in PGA as the depth increases from 20 to $100 \mathrm{~km}$ ) and that the rate of increase in PGA with depth is similar in the different equations. There is a large difference, however, in the absolute size of the predicted PGAs between the different equations of over a factor of ten difference [compare, for example, the estimate PGA using the equation of Cousins et al. (1999) and that using the equation of Crouse (1991)].

Some studies (Kawashima et al., 1986; Crouse et al., 1988) have included such factors but have found that they do not significantly reduce errors associated with the equation. Campbell (1989) includes a factor exponentially dependent 
on depth and alternatively one linearly dependent on depth but although prediction is improved, and the residual plots no longer show a dependence on focal depth, he does not recommend the use of the equations because focal depths are associated with (possibly large) errors and hence the dependence may be false. Campbell (1989) uses a set of earthquakes with a limited range of focal depths (1.8 to $24.3 \mathrm{~km}$ ) over which focal depth dependence may not exist. Ambraseys (1995) also notes that focal depths are poorly determined and revises many focal depths using time between $\mathrm{P}$ and $\mathrm{S}$-wave arrivals. This uncertainty in focal depths means that focal depth dependence is difficult to test unless the range of depths is much greater than the errors associated with each depth estimate. Si and Midorikawa (2000) find that magnitude and depth are positively correlated so their associated coefficients may be incorrectly determined, especially when using rupture distance.

More complex depth dependent terms are tried by Kawashima et al. (1986), including factors which are dependent on depth and magnitude and depth and distance, but find there is no significant increase in the adjusted multiple correlation coefficient. A depth dependent anelastic attenuation factor is included and retained by Atkinson (1997).

Lungu et al. (1994, 1995b) find faster attenuation for deeper earthquakes compared with shallower shocks (this is based on attenuation rates for a few individual earthquakes) whereas Molas and Yamazaki (1995) group earthquakes by depth and find similar predictions for each group and for all the data together. 


\section{Characterisation of path}

The distance travelled from the source to the site, $d$, is the parameter used in all ground motion estimation relations to characterise the path, although many different definitions of this distance are used (see Section 9.1).

\subsection{Definitions of source-to-site distance}

Joyner and Boore (1981) state that the correct distance to use in ground motion estimation relations is the distance from the origin of the actual wave, which produced the measurement of ground motion (for example PGA or $\mathrm{SA}$ ), to the station but this is difficult to determine for past earthquakes and impossible to predict for future earthquakes. To overcome this difficulty ten different measures have been proposed to characterise the distance to the earthquake source:

Epicentral distance $d_{e}$ : Distance to the epicentre of the earthquake, i.e. the distance to the horizontal projection of the rupture's starting point.

This is the easiest distance measure to use because the epicentre is the location information given for all earthquakes.

The use of epicentral distance in hazard analysis is for small earthquakes reasonably straightforward because easily available catalogues of previous epicentres can be used as the future sources or if line or surface source zones are used then epicentres can be distributed on these source zones.

Hypocentral distance $d_{h}$ : Distance to the hypocentre of the earthquake, i.e. the distance to the rupture's starting point.

Like epicentres, hypocentres are reported for most earthquakes but ac- 
curate measures of focal depth are often difficult to obtain unless there is a good distribution of stations with distance from the source (Gubbins, 1990). Most damaging earthquakes occur within a shallow region of the crust (about the top $30 \mathrm{~km}$ ) and hence $d_{e}$ and $d_{h}$ become equal at intermediate and large distances.

Since focal depth becomes less important as the size of the earthquake increases (because the earthquake ruptures the entire seismogenic layer) and because focal depths of small earthquakes, for which depth is important, are likely to be associated with large errors, the use of hypocentral distance in ground motion estimation relations is unlikely to decrease the standard deviation of the final equation. This conclusion is only valid for shallow crustal earthquakes.

The use of hypocentral distance in ground motion estimation relations also means that further information needs to be gathered, compared with distance measures that do not include depth, during hazard assessment. However, available catalogues of previous earthquakes usually contain depth information.

Rupture centroid distance $d_{c}$ : Distance to the centroid of the rupture.

This distance measure requires an estimate of the dimensions of the rupture plane so that the centroid can be defined; it can be difficult to define this plane. However, because it is measured to a point source uncertainties in defining the exact location of the rupture plane will have less of an effect on rupture centroid distances than for line or surface measures.

Centre-of-energy-release distance $d_{E}$ : Distance to a point on the fault rupture where energy considered to be concentrated (Crouse et al., 1988; Crouse, 1991).

This distance is similar to rupture centroid distance. 


\section{Surface projection distance (also called Joyner-Boore or fault distance) $d_{f}$ :}

Distance to the surface projection of the rupture plane of the fault (Joyner and Boore, 1981); for a point within the projection $d_{f}=0$.

For line or surface distances (EHD, $D, d_{f}, d_{f, h}, d_{r}$ and $d_{s}$ ) and also the point distances $d_{c}$ and $d_{E}$ the location of the rupture plane must be known. The uncertainties and problems involved in finding rupture planes are discussed by workers developing relationships between magnitude and gross characteristics of faulting such as rupture length (e.g. Bonilla et al., 1984; Wells and Coppersmith, 1994). Techniques for defining the location of the probable rupture plane are discussed in Douglas (2001b).

Surface projection distances can have large uncertainties (up to $20 \mathrm{~km}$ for certain earthquakes and stations) because there are no published studies on the rupture plane or because there are several and no obvious way of deciding which is best. The errors in surface projection distances could be larger for earthquakes occurring during a sequence of similar sized shocks when aftershocks and geodetic data are likely to be difficult to use. Such earthquakes will probably have $M<6$ and hence rupture lengths of around $10 \mathrm{~km}$, so epicentral distance will be more reliable than surface projection distance. The current practice of quoting surface projection distances to one decimal place should not be taken as meaning that the distances are accurately known to $0.1 \mathrm{~km}$.

Surface projection distance with focal depth $d_{f, h}$ : Distance to the projection of the rupture on a plane at the focal depth.

The horizontal distance part of surface projection distance with focal depth are obviously associated with the same uncertainty as surface projection distance and errors in focal depths have already been discussed.

Rupture distance (also called source or fault distance) $d_{r}$ : Distance to 
rupture surface.

Estimates of this distance requires the same information as for $d_{f}$ together with the depth of rupture which like focal depth is difficult to obtain for many earthquakes. The vertical resolution of aftershock locations can be poor and so it is difficult to define the dip of the fault.

For future earthquakes, rupture distance can be estimated using mapped faults although it requires that the dip and depth of the faults are known.

Seismogenic distance $d_{s}$ : Distance to seismogenic rupture surface, assumes that the near-surface rupture in sediments is non-seismogenic (Campbell, 1997).

Marone and Scholz (1998) find that well-developed faults, i.e. faults that have undergone significant net displacement and as a result contain thick zones of wear material (gouge), display an absence of seismicity in about the top $3 \mathrm{~km}$. Therefore such faults may exhibit stable slip within this zone and unstable slip below this depth where the gouge becomes consolidated. On the other hand poorly-developed faults, i.e. faults with little or no net displacement and hence no appreciable gouge zone, display seismic failure throughout the upper zone. Seismogenic distance is measured to the part of fault where unstable slip occurs.

Campbell (1997) believes that seismogenic distance can be 'reliably and easily determined for most significant earthquakes' but, in fact, it has the same difficulties in its determination as rupture distance, which can be large, plus the requirement of defining depth to the seismogenic layer.

There will be little difference between rupture and seismogenic distance if rupture distances are defined to a rupture plane which is defined by: aftershock distribution, because aftershocks do not occur in stable slip zones; or fault slip inversion, which will define the part of the rupture plane where 
most slip occurred which correlates with the unstable zone (e.g. Archuleta, 1984; Marone and Scholz, 1998). Seismogenic distances are only likely to be significantly different to rupture distances for earthquakes with surface rupture which if it occurred for a well-developed fault, such as the Imperial Valley fault, would be considered to be the result of unstable slip at depth and not the stable slip in the gouge near the surface.

Campbell (1997) provides an equation for estimating the minimum seismogenic distance possible given $M_{w}$, rupture width, dip of rupture, depth to top of seismogenic zone and depth to bottom of seismogenic zone for a future earthquake, if no other information is available. However, the use of this equation in hazard assessment means that any reduction in uncertainty brought about by the use of seismogenic distance, compared with other distance measures, will be reintroduced.

\section{Elliptical distance $D$ or average site to rupture end distance ASRED:}

Mean of the distances to the extremities of the fault surface rupture (Bureau, 1978; Zhou et al., 1989), if no surface rupture occurred then the projection of the top of the rupture should be used.

No measurements of the width or depth of rupture are needed so elliptical distance has less uncertainty than either surface projection, rupture or seismogenic distances.

One consequence of using elliptical distance is that it automatically models near-field flattening of the attenuation curves without needing an equivalent depth term. For large magnitudes this flat area increases in size and elliptical distance use forces a nonlinear increase in acceleration with increase in magnitude. The consequence of using this distance is that the magnitude dependent terms included in the decay part of ground motion estimation equations by some authors (e.g. Campbell, 1981) do not need to 
be included separately (Douglas, 2001b).

As elliptical distance requires only the ends of a fault to be located it is easier to estimate for future earthquakes occurring along defined surface faults.

Equivalent hypocentral distance EHD: Distance from a virtual point source that provides the same energy to the site as does a finite-size fault (Ohno et al., 1993). Defined by: $1 / \mathrm{EHD}^{2}=\sum_{i=1}^{n} M_{0, i}^{2} X_{i}^{-2} / \sum_{i=1}^{n} M_{0, i}^{2}$, where $n$ is the number of segments on the rupture plane, $M_{0, i}$ is the seismic moment density on the $i$ th segment and $X_{i}$ is the distance between $i$ th segment and site.

It includes the effects of fault size, fault geometry and inhomogeneous slip distribution (Ohno et al., 1993). Ohno et al. (1996), Kawano et al. (2000) and Si and Midorikawa (2000) use EHD to derive their ground motion estimation equations.

To calculate EHD reliably requires much more information about an earthquake than other distance metrics used in ground motion estimation equations, namely it needs the distribution of displacement on the fault plane (assuming that the source time function is the same for all small segments on the fault plane) (Ohno et al., 1993). For large $(M \gtrsim 6.5)$, well recorded earthquakes maps of such distributions are being increasingly produced and published although for the same earthquake there are occasionally many different interpretations of the rupture for the same earthquake.

Figure 6 compares contours of equal EHD for uniform moment release along a horizontal line source to linearly increasing moment release along a horizontal line source.

EHD for faults with linearly increasing moment release predicts slower decay of ground motion at the end where most moment is released compared 
with the end where the moment release is least (Figure 6). As distance from the fault increases the contours of equal EHD for both uniform and linearly increasing ground motion become most circular and hence the decay of ground motion is modelled as if the energy was released from a point source. For uniform moment release the point source is at the centre of the fault and for linearly increasing moment it is near the end of the fault where most of the moment was released. This compares with surface projection distance and rupture distance where the contours of equal distance never become circular (see Figure 8) and so there is not one point source from which all the energy is assumed to be radiated.

Reliable determination of the fault slip that occurred during an earthquake, which is required for calculation of EHD, needs a large number of near-field accelerograms. Therefore it can only be estimated where there is a high density of accelerographs, such as California, Japan and Taiwan. Even when such data does exists the determined fault slip is still not precisely defined as can be demonstrated by comparing some of the different inversions of fault slip for the Imperial Valley earthquake (15/10/1979). The earthquake has been, and continues to be, intensely studied because of the wealth of high-quality near-field strong-motion data and there have been many different fault slip determinations made. Figure 7 shows a comparison of six of these inversions. From Figure 7 it can be seen that although there are similarities between the inversions, such as the area of large slip (about $2 \mathrm{~m})$ in the centre of the fault, there are also significant differences. These differences in slip translate into differences in the EHDs for the stations which recorded the earthquake.

When no inversions of the fault slip have been made, either uniform slip along the entire fault is assumed or hypocentral distance is used such as 
was done by Ohno et al. (1996) for some small magnitude earthquakes and for earthquakes with limited near-source recordings.

As short period ground motions (including PGA) is caused by local variations in the fault slip (Hanks and Johnson, 1976; McGarr, 1981; Boatwright and Boore, 1982; McGarr, 1982) EHD is unlikely to improve the modelling of such motions as it is an average of the moment release over the entire fault which does not have a large effect on short period motions. Therefore any possible improvement in modelling the variation due to distance by using EHD is probably likely to be for long period ground motions which are more dependent on the moment release over the entire fault. Ohno et al. (1996) and Si and Midorikawa (2000) have not found significantly lower standard deviations by using EHD rather than simpler distance metrics.

EHD is obviously much more difficult to calculate than the more common distance measures such as epicentral, hypocentral, surface projection or rupture distance.

At present the estimation of the pattern of fault slip in future earthquakes is impossible therefore the use of EHD in hazard analysis is also impossible except if uniform or simple slip patterns (see Figure 6) are assumed.

For all these reasons, although EHD, compared with simpler distance metrics, is a more physically-based distance metric and possibly has the ability to more adequately model the variations in long period ground motions, its use in ground motion estimation relations will not significantly reduce the associated uncertainty.

Idriss (1978) splits distance measurements into two groups: those measured to a point $\left(d_{e}, d_{h}, d_{c}\right.$ and $\left.d_{E}\right)$ and those measured to a line or surface $\left(d_{f}\right.$, $d_{f, h}, d_{r}, d_{s}, D$ and EHD). Some of these distance measures obey inequalities: 
$d_{f} \leq d_{r} \leq d_{s}\left(d_{f}=d_{r}\right.$ for vertical ruptures which reach the surface and for points on the foot wall of ruptures which reach the surface) and $d_{f} \leq d_{e} \leq D$. At large distances from the source all measures become almost equal, thus at great distances which is used is unimportant.

Figure 8 shows the contours of equal distance using the epicentral, surface projection, rupture and elliptical distances from a fault of length $50 \mathrm{~km}$, width $20 \mathrm{~km}$, dip $30^{\circ}$ which reached the surface, with the hypocentre at the bottom of the north eastern corner of the rupture. Only these four different distances are plotted because hypocentral, surface projection with focal depth and seismogenic distances all have similar characteristics to those contours for epicentral, surface projection and rupture distance respectively. Figure 8 shows the different assumptions, of how ground motion attenuates with distance, made when different distance metrics are used.

The most common form of decay term is a power law decay (which corresponds to geometric decay due to the spreading of waves from a source) using a modified distance, $R$, therefore the decay term is $R^{-\alpha}$. Distance is often modified through the addition of a constant, i.e. $R=d+\beta$ (e.g. Esteva, 1970), or by assuming that the source is at some depth, $h$, and then using the slant distance, $R=\sqrt{d^{2}+h^{2}}$ (e.g. Joyner and Boore, 1981). The actual distance, $d$, is not usually used, except when hypocentral distance (e.g. Caillot and Bard, 1993) or mainly far-field data (e.g. Singh et al., 1987) is used, because for small $d$ unrealistically high values of ground motion are predicted. The form $R=d+\beta$ does not correspond to a physical situation (even though Donovan and Bornstein (1978) suggest it does), unlike the form $R=\sqrt{d^{2}+h^{2}}$, and hence relating the decay rate, $\alpha$, found using this form to the real decay rate of different types of seismic waves is not correct. Often the calculated decay 
rate using $R=d+\beta$ as opposed to $R=\sqrt{d^{2}+h^{2}}$ is greater, for example McCann Jr. and Echezwia (1984) use one set of PGA values and fit both forms of distance dependence and find using the first form (with $\beta=25 \mathrm{~km}$ assigned) $\alpha=-1.915$ whereas using the second form (with $h=3.852 \mathrm{~km}$ found through regression) $\alpha=-0.913$. Only in the far field, $d \gg \beta$, does $(d+\beta)^{-\alpha}$ actually give a decay rate $\alpha$ against $d$ and hence only the decay rates where there is much data (usually $d \sim \beta$ ) should be compared.

The power, $\alpha$, which controls the decay rate is either fixed or found during the regression. Joyner and Boore (1981) constrain $\alpha$ to unity because this is the decay rate for body waves which they assume cause the peak ground acceleration; this choice of $\alpha$ has been followed by many other authors (e.g. Ambraseys and Bommer, 1991; Munson and Thurber, 1997). Garcia-Fernandez and Canas (1995) constrain $\alpha$ to $\frac{1}{2}$ because they assume their peak acceleration is associated with Lg waves. Ambraseys and Bommer (1991) also use $\alpha=0.83$ because they assume PGA is associated with the Airy phase. Campbell (1981) constrains $\alpha$ to 1.75 which he says is representative of far-field decay of PGA, although note this is for $R=d+\beta$ and hence it may be larger than if $R=\sqrt{d^{2}+h^{2}}$ was used. Kamiyama et al. (1992) and Kamiyama (1995) constrain the decay rate to -1.64 using results from other studies. Often though $\alpha$ is found during the regression which is better, since the equation would fit the data more closely, but requires a well distributed set of data in terms of distance and not too many other coefficients to find. Joyner and Boore (1983) state that they constrain $\alpha$ to 1 in Joyner and Boore (1981) because they believe their data did not permit a physically meaningful, simultaneous determination of a spreading coefficient and a coefficient of anelastic attenuation. If the data is insufficient then nonphysical coefficients can be found which 
although apparently match the data well, predict unrealistic ground motions at the edges of the data space.

Campbell (1981) introduces the concept of magnitude dependent $\beta$ or $h$, which means that the part of the attenuation curve (roughly the near field) with smaller decay rate than that in the far field is not constant for all sizes of earthquakes. This is known as distance saturation. Usually $\beta$ and $h$ are of the form $A \exp (B M)$, where $M$ is the magnitude, because this makes the flattened region of the curve proportional to the size of the fault rupture zone which has been found to be exponentially dependent on magnitude (e.g. Ambraseys and Jackson, 1998). Kamiyama et al. (1992) and Kamiyama (1995) give a model where PGA is completely independent of distance within a zone which is exponentially dependent on magnitude. Joyner and Boore (1981), Sabetta and Pugliese (1987), Boore et al. (1994a) and Ambraseys (1995) find no evidence for magnitude dependent $h$ for their data and distance definition (distance to surface projection of rupture), although Sabetta and Pugliese (1987) state that their experiment is not conclusive due to the distribution of data (there are only a few near-field records from large magnitude earthquakes in their set of records). Joyner and Boore (1981) prefer a magnitude independent $h$ because fewer coefficients need to be found.

Campbell (1997) models different decay for thrust(-oblique) and reverse(oblique) faults than that for other source mechanisms (strike-slip and normal). This effect must be due to different seismic waves being predominant in accelerograms from earthquakes with different source mechanisms because the travel path is independent of the source mechanism. 
Trifunac and Lee (1989) and Lee (1993) use an attenuation term that is dependent on focal depth, magnitude and correlation radius of source function (which can be approximated by shear-wave velocity).

Campbell (1997), Youngs et al. (1997) and Campbell and Bozorgnia (2002) model different decay rates for sites in different soil categories. This idea, although it may be supported by their data, only has a physical meaning (different local site amplifications) as a site effect and not as a path effect because although locally the soil may be known this does not mean such geology is constant along the travel path. Gaull (1988) and Yamabe and Kanai (1988) present models with magnitude dependent decay rates even in the far field. In the far field all earthquakes are seen by the site as point sources and hence the far-field decay rate should be independent of magnitude.

Recorded strong ground motion is composed of many types of seismic waves ( $\mathrm{P}, \mathrm{S}, \mathrm{Lg}$ and surface waves). These wave attenuate with individual rates, therefore different waves dominate at different distances, making the decay of peak ground motion complex. Trifunac and Brady $(1975,1976)$ and Trifunac (1976) model this by using the distance calibration function used for the calculation of $M_{L}$, derived by Richter (1958), which has a change of slope at $d=75 \mathrm{~km}$ because for $d<75 \mathrm{~km}$ body waves predominate, with decay $\sim d^{-1}$, where as for $d>75 \mathrm{~km}$ surface waves predominate, with decay $\sim d^{-1 / 2}$. Dahle et al. (1990b,a) also incorporate a change of slope into their decay term (although it is not a smooth transition from one decay rate to another) which models the change from spherical spreading, i.e. $d^{-1}$, of $\mathrm{S}$ waves to cylindrical spreading, i.e. $d^{-5 / 6}$, of $\operatorname{Lg}$ waves at $100 \mathrm{~km}$, although they note that the point where the slope changes depends on crustal structure and focal depth. Theoretical consideration of the importance of crustal structure on the rate 
of decay of seismic waves is contain within, for example, Burger et al. (1987) and Suhadolc and Chiaruttini (1987). McCann Jr. and Echezwia (1984) consider an expression of the near-field response of an elastic whole space which incorporates the first and second order geometrical spreading terms through an expression, $\left(A / d^{2}+B / d\right)^{C}$, which allows the peak ground motions to come from the combined effect of two different types of wave.

Joyner and Boore (1981) introduce a term, of form $\exp k R$, to model anelastic decay. This has been adopted by a number of subsequent authors (e.g. Ambraseys and Bommer, 1991; Sigbjörnsson and Baldvinsson, 1992) although often the geometrical decay power, $\alpha$, is fixed at unity so that a realistic, i.e. negative, anelastic coefficient is found. If $\alpha$ is not fixed then $k$ is often found to be positive (e.g. Ambraseys et al., 1996), which predicts increasing ground motion for increasing distance at large distances.

Abrahamson and Litehiser (1989) only include an anelastic term for interplate earthquakes. Atkinson (1997) includes a depth dependent anelastic decay term. Cousins et al. (1999) and McVerry et al. (2000) include a term to account for the higher anelastic decay due to the waves travelling through a volcanic region. Lee (1995) includes an anelastic decay term which becomes the only decay term for distances greater than a distance dependent on focal depth, magnitude and correlation radius of source function. Trifunac (1976) states that because the representative frequency of peak amplitudes varies with distance and because the relative digitisation noise also changes with distance it is difficult to include an anelastic decay term.

Abrahamson and Silva (1997) include a term, which is dependent on distance, for sites on the hanging wall of a fault rupture. Their term probably accounts 
for a site on the hanging wall seeing more of the rupture plane than a site on the foot wall but their complicated form for this term may not be justified by their limited amount of data.

Donovan and Bornstein (1978) use a complicated distance dependence, involving geometrical decay but also factors which model magnitude and distancedependent decay. Such a form of distance dependence, although it may be supported by their data, is unnecessarily complex, when it does not reduce the uncertainty associated with ground motion prediction, especially because they fit their non-linear equation, containing 6 coefficients, to only 59 records from 10 earthquakes.

Bolt and Abrahamson (1982) use a form of distance dependence which does not have a physical basis, i.e. they do not try to estimate geometrical decay or anelastic decay coefficients (Bolt and Abrahamson, 1983). Bolt and Abrahamson (1983) state the reason for their choice was to provide a form that will predict accelerations validly, particularly near the source.

\section{Characterisation of site}

Local site conditions at an accelerograph station can dramatically affect the strong ground motion recorded, for example Schenk (1984) relates the great variability in recorded ground motions up to $30 \mathrm{~km}$ to different site conditions. Therefore attempts are made in most ground motion estimation relations to model the effect of different near-surface ground conditions on strong motion. Some publications (e.g. Lungu et al., 1995b) however, use data from a wide variety of sites with different properties (ranging from stiff soil to very soft 
soil sites) and do not try to model or examine any differences. Equations that do not examine or model differences in site response are of limited value, especially when the equations are for intermediate- and long-period spectral ordinates, which can be significantly affected by local site conditions.

Data selection criteria, which seek to limit the accelerograms used to those recorded at stations with similar local site conditions, are the simplest techniques which have been employed. Esteva (1970), Faccioli (1978), Ohsaki et al. (1980b), Campbell (1989), Dahle et al. (1990b), Mohammadioun (1994a) and Xiang and Gao (1994) restrict their data to those from sites comparable to stiff clay or compact conglomerate, soft soil sites, bedrock sites, deep soil (depth greater than $10 \mathrm{~m}$ ) sites, rock sites, rock sites with $V_{s} \geq 750 \mathrm{~ms}^{-1}$ and basement rock sites respectively. Some studies do not select records from a homogeneous set of sites but only exclude those which are affected by significant soil amplification or non-linearity (usually soft soil sites) (e.g. McGuire, 1977; Campbell, 1981; Ohno et al., 1996; Sadigh et al., 1997; McVerry et al., 2000; Si and Midorikawa, 2000). Other studies (Iwasaki et al., 1980; Ohsaki et al., 1980a; Chiaruttini and Siro, 1981; Kawashima et al., 1986; Huo and Hu, 1991; Caillot and Bard, 1993; Crouse and McGuire, 1996; Sadigh et al., 1997) include data from different site categories but perform the regression on subsets of records with the same site classification. The advantage of this method is that non-linear soil behaviour is implicitly included, because the magnitude and distance scaling for each site category is independent of that for the other categories. Unless there are a lot of records and the distributions within each class are similar, differences between the predicted ground motion on different types of sites may not be significant and may be simply due to the lack of comparable data. 
Two studies have taken this idea to its extreme and only used records from a single station (Denham and Small, 1971; Singh et al., 1987). Niazi and Bozorgnia (1991) use records from the SMART-1 array, where the stations have essentially identical site conditions, but find that there is still much uncertainty. Such studies are of limited use for design because structures will not be built on the exact location of the instrument nor is it easy to decide whether another location has similar site conditions to the accelerograph station. However, such studies are of use for research about local site effects and also about the causes and properties of the scatter associated with equations for the estimation of strong ground motions.

The most commonly used technique to incorporate site effects into an ground motion estimation relation is to use multiplicative factors between ground motion at one type of site and that at another. Trifunac (1976) introduces this method; he uses three site categories and the multiplicative factor between basement rock and intermediate type rock is forced to be half the multiplicative factor between solid hard basement rock and alluvium sites thus limiting the generality of the method. The number of multiplicative factors used is usually one less than the number of site categories used, thus allowing different scalings amongst the site categories (e.g. Boore et al., 1993; Lawson and Krawinkler, 1994; Ambraseys et al., 1996; Sabetta and Pugliese, 1996; Chapman, 1999). Lee (1995) classifies stations into three geological site classes and two local soil classes, although the difference between geological and local scales is not clear, so there are six categories in total but only three factors. All the data is used to derive the magnitude and distance scaling, making the coefficients more robust, and removing bias from the amplification factors between the different site classes due to the distribution of the data. Possi- 
ble non-linear behaviour though cannot be modelled by these factors because they are equal throughout the dataspace. A combination of this method with the more general method explained above was used by Crouse and McGuire (1996), who compute multiplicative factors for two of their four soil categories because of the lack of data within the two categories. Caillot and Bard (1993) initially derive equations for each of their two site category subsets separately but find that the magnitude and distance coefficients of the two sets of equations are not significantly different so they employ a simple multiplicative factor. This shows that non-linear effects are probably not that important, although Caillot and Bard (1993) use a set of records with many weak motion time-histories so the non-linear effects may be masked.

Some studies have insufficient data to derive adequate site category multiplicative factors so they adopt multiplicative factors from previous studies (e.g. Atkinson, 1997; Spudich et al., 1999). If the site categories used in the two studies are similar enough then this is a valid procedure because true site coefficients should only depend on local site conditions at the stations.

Multiplicative factors between ground motion on different types of site are not always modelled as the same throughout the data space. McGuire (1978) attempts to include a distance dependent multiplicative factor but it is not statistically significant; a magnitude dependent factor, although statistically significant, does not reduce scatter and McGuire (1978) thinks it may be biased due to lack of rock records so it is not adopted. Campbell (1997) incorporates distance dependent site factors and Cousins et al. (1999), McVerry et al. (2000) and Campbell and Bozorgnia (2002) include distance and magnitudedependent site factors. Although Youngs et al. (1997) develop two separate equations for deep soil and rock sites they employ a joint regression method, 
because there is not enough data to apply regression to the individual subsets. Non-linear soil behaviour is explicitly accounted for in Abrahamson and Silva (1997) through the use of a factor which includes the predicted PGA on rock; a factor also included by McVerry et al. (2000) although they adopted the coefficients of Abrahamson and Silva (1997) because they have too few records to give realistic estimates of the coefficients. This problem highlights the main disadvantage of using such complicated factors, namely that a large, well distributed set of records is required to find robust estimates of coefficients in a non-linear equation.

Choices of site categories into which a station is placed is controlled by the quality of available site information. Complex classifications cannot be used, even if desired, unless there is adequate data for all the sites used (Spudich et al., 1999). Thus early studies (e.g. McGuire, 1978; Joyner and Boore, 1981) and some recent studies (e.g. Zhao et al., 1997; Spudich et al., 1999) simply use a binary classification of soil (or alluvium) and rock. Usually a site is classified as soil (or alluvium) if it has soil of more than between 4 (Joyner and Boore, 1981) and $20 \mathrm{~m}$ (Abrahamson and Silva, 1997) thick, because a shallow soil layer is not thought to greatly affect the ground motion. Some studies though have found that shallow soil sites have significantly higher ground motions than rock or stiff soil sites and that rock and deep soil sites have similar ground motion (Campbell, 1981; Sabetta and Pugliese, 1987; Campbell, 1989) although this is for PGA (a high frequency parameter) which is less affected by local site conditions. Ambraseys and Bommer (1991) attribute the apparent small dependence of horizontal PGA on site classification to the lack of available information which compelled them to use a simple binary system. As more site information on strong-motion stations has become available the 
number of site classes used has grown, so that there are three or more categories of increasing stiffness (roughly increasing shear-wave velocity) (e.g. Trifunac, 1976; Kawashima et al., 1986; Fukushima and Tanaka, 1990; Lawson and Krawinkler, 1994; Campbell, 1997; Chapman, 1999; Kobayashi et al., 2000). Some studies define the boundaries of the categories in terms of shearwave velocity (e.g. Boore et al., 1993; Ambraseys et al., 1996) but in fact there are no shear-wave velocity measurements for many of the stations they use, so a rough classification is made. Due to the difficulty of finding site information Theodulidis and Papazachos (1992) examined the PGV/PGA ratio for some of their Alaskan sites to decide whether they were rock or soil, which is based on empirical formulae which find differences in this ratio due to the local site conditions. There is some uncertainty in such formulae, due partly to the variability of ground motion and partly to the accelerogram correction method used to find PGV and hence classification based on PGV/PGA is unreliable. Sadigh and Egan (1998) show that PGV/PGA depends on magnitude, distance and source mechanism and not just site conditions and so care is needed in interpreting PGV/PGA ratios in terms of site conditions. However, Decanini et al. (2000) show that useful information on site conditions can be obtained from PGV/PGA and so it is a useful technique if no measured wave velocities are available. In an attempt to reduce the subjectivity of classifying Greek stations into rock or alluvium categories Theodulidis and Papazachos (1992) use the opinion of seven specialists and then use the average classification; this is a time-consuming process.

Examination of residuals for sites with different soil categories is a useful method for sets of records where site information is not complete, and hence cannot be included explicitly within the equation. This type of analysis was 
performed by Abrahamson and Litehiser (1989).

To overcome the subjectivity of soil categories some studies have used directly measured properties of the ground beneath the accelerograph station. The most commonly used measurement is the near-surface shear-wave velocity, $V_{s}$. Blume (1977) finds that the site impendence, $\rho V_{s}$ (where $\rho$ is the density of the ground which is approximately a constant), is the best measure of site condition and he uses it to derive site factors for his equation although the paper is not entirely clear how this is done. Joyner and Fumal (1984) use the average shear-wave velocity to one-quarter the wavelength of waves of period of concern (although often these shear-wave velocities are extrapolated using geological data); the basis of this choice is energy conservation along ray tubes. Shear-wave velocity is usually only measured down to shallow depths so $30 \mathrm{~m}$ is often used as the reference depth to which to compute the average shearwave velocity, although Boore et al. (1994a) state that ideally they would like to use depth to one quarter wavelength. Boore et al. (1994a) and Ambraseys (1995) include site factors based on average shear-wave velocity to $30 \mathrm{~m}$ in their equations. Unlike other formulations to incorporate site conditions into ground motion estimation relations, directly using shear-wave velocity has the advantage of being physically based so the coefficients can be examined to check that they are reasonable. Also it is better because there is no need for subjective categories (Ambraseys, 1995). This has two advantages: firstly no decisions need to be made about the categories to use or which category a particular station is in and secondly when the equation is used for design the shear-wave velocity at the site can be measured and used directly in the formula, removing the need for more subjective judgement on the part of the designer who does not know exactly how site classifications were originally 
done. The major problem with using $V_{s}$ is that there are no published measurements at most strong-motion stations, especially those outside California or Japan (Ambraseys, 1995; Spudich et al., 1999). Different choices of the reference depth to compute the average $V_{s}$ can lead to different results (Ambraseys, 1995) so subjectivity is not completely removed although Boore et al. (1994a) believe one-quarter wavelength depth is the best to use but for long periods this is hundreds of metres for which the data is currently unavailable. Another disadvantage of this method is that surface waves could be important (Joyner and Fumal, 1984; Boore et al., 1994a), especially for long periods, and their amplifications are not modelled by using $V_{s}$ directly in the equation like it is at present (Joyner and Fumal, 1984). Also it does not model the effect of the thickness of attenuating material (Boore et al., 1994a) or resonance effects (Joyner and Fumal, 1984).

Some studies have used site factors based on other measurements which can possibly overcome some of the disadvantages of shear-wave velocity, although not all have a physical basis. Joyner and Fumal (1984) include site factors based on $V_{s}$ and depth to underlying rock, $H$, and find correlation for long periods but no correlation for short periods although they state it is inappropriate to use depth to rock at present because the San Fernando strong-motion data does not show any significant correlation. Trifunac (1980) and Trifunac and Lee (1989) include a multiplicative factor which is exponentially dependent on the depth of sedimentary deposit although Trifunac and Lee (1989) note that this is not always known at every location so they also provide an equation using simple site categories. A combination of depth to rock and site categories is employed by Lee (1993) and Campbell (1997) although Campbell uses a complex depth scaling factor. Combinations of depth to rock and 
site categories are not the most efficient site parameters because they are not strictly independent, for example if a site is classified as rock then the depth to rock must be zero. This correlation could cause problems when coefficients of both these factors are sought.

A single parameter which is a rough combination of shear-wave velocity and depth to bedrock is the natural period of the site, $T$, which for a single layer equals $4 H / V_{s}$. The need to include a term reflecting explicitly local amplification dependent on natural period of the soil is noted by Benito et al. (1992) because they find little correlation between simple soil categories and ground motion. A factor exponentially dependent on natural period is included by Tong and Katayama (1988) and Sun and Peng (1993), although Tong and Katayama (1988) find that it has little effect on estimation. Using natural period explicitly rather than depth to rock and shear-wave velocity reduces generality because if both $H$ and $V_{s}$ are included there are more coefficients to be determined, allowing modelling of attenuation effects through the soil layer (which depends on depth) and also impedance (which depends on shear-wave velocity). Also the natural period of the site is less available for strong-motion recording sites than is shear-wave velocity and hence it is easier to use shearwave velocity than natural period of the site.

The most site specific procedure is to use individual coefficients for each station. This idea was introduced by Kamiyama and Yanagisawa (1986) (although Kobayashi and Midorikawa (1982) developed a method which is similar) and has since been adopted in many Japanese studies (Kamiyama et al., 1992; Fukushima et al., 1995; Molas and Yamazaki, 1995; Shabestari and Yamazaki, 1998; Kawano et al., 2000; Shabestari and Yamazaki, 2000). Its two advantages are that no site information is required about the stations included in 
the set of records, hence eliminating subjective soil categories or the need to measure shear-wave velocity or similar quantities, and all site effects should be modelled through the use of automatically derived transfer functions. To use this method a large number of records are required for each station, hence its use in Japan where there is an abundance of data, otherwise the station coefficients are not adequately determined. For example, if each station recorded only one earthquake then the standard deviation of the ground motion estimation equation would be zero because the individual site coefficients would equal the residuals from the regression without any site factors. This though would not be correct because the derived coefficients cannot be related to site response but could be due to either source, path or site effects. A number of records at each station are required, with different source and path conditions, before the site coefficients tend to the true values, which gives the correct transfer function for each site. Kamiyama and Yanagisawa (1986) find a good agreement between the site coefficients (transformed to amplification spectra) and the amplification spectra predicted using the shear-wave velocity profiles of the stations. Molas and Yamazaki (1995) find weak correlation between station coefficients and soil categories although there is much scatter. Unless the individual site coefficients can be related to the theoretical transfer function at each station or to some other feature of the site, ground motion estimation relations including these individual factors are impossible to use for the prediction of ground motion at a site which is not within the original set of records. Even if a relation could be found between site characteristics and the coefficients, the use of such equations in seismic hazard analysis, where many sites are considered, would require detailed information on all those under investigation. 
The most computational intensive method for including local site effects within an ground motion estimation study is to convert all the recorded time-histories from sites with a variety of properties to time-histories which would have been recorded on a site with given properties. This procedure was adopted by Annaka and Nozawa (1988), who use 1D propagation theory to transform records from sites with $V_{s}<300 \mathrm{~ms}^{-1}$ to records from sites with $V_{s}>300 \mathrm{~ms}^{-1}$, and Kawano et al. (2000), who strip off the effects of the uppermost layers of ground under a station to get a record which comes from a site with $0.5 \leq V_{s} \leq 2.7 \mathrm{kms}^{-1}$. Altering the recorded time-history in this way could lead to increased uncertainty because the ground motion is not simply affected by the ground directly under the station (1D effect) but by the ground within an undefined area (2D and 3D effects).

No published ground motion estimation relation considers topographical effects except those which exclude records believed to be affected by topography, see Section 4, and Zhao et al. (1997) who include in their rock category records from stations where topographic effects are expected.

Figure 5 compares the estimated ratio of horizontal peak ground acceleration and response spectral amplitudes between soft soil sites and hard rock sites and between stiff soil sites and hard rock sites using some recent equations. This figure shows that soil sites are expected to show significantly larger response spectral amplitudes (up to a factor of 2.5) than rock sites at almost all periods of engineering interest with the maximum ratio occurring around $T=1 \mathrm{~s}$. However there are considerable differences in the estimated ratios of soil and rock ground motions between the different sets of equations. Compare, for example, the estimated ratios using the equations of Campbell and Bozorgnia (2002), which predict large ratios (up to a factor of 2.5 for soft and stiff soil), 
and those of Lussou et al. (2001), which predict much smaller ratios (up to a factor of 1.3 for stiff soil and 1.6 for soft soil). These differences are due to different site classifications, different sets of sites and records used and different functional forms employed.

\section{Analysis techniques}

The majority of ground motion estimation studies use the ordinary least squares method (or an unspecified procedure) to derive the coefficients of their equation. However, more complex procedures have been developed to overcome problems encountered due to the inhomogeneity, in terms of independent parameters, of most strong-motion sets. These inhomogeneities are listed below.

- In most strong-motion sets, unless they are specially selected, there is a strong correlation between magnitude and distance of the records, because larger earthquakes can be detected at greater distances than smaller earthquakes.

- There is an abundance of accelerograms from large distances (from between about 50 and $200 \mathrm{~km}$ ) and there still is a lack of near-field data from large earthquakes which are most important for seismic design.

- Some earthquakes (for example San Fernando) occur within a region with a large number of accelerographs so there are many available records.

Regression techniques have been developed to counteract the ill effect on the estimated coefficients (and hence predictions) caused by each of these characteristics. 
Donovan (1973) was the first to find that correlation between magnitude and distance leads to changes in the derived coefficients. The regression method most often used to reduce the effect of magnitude and distance correlation is the two-stage technique introduced by Joyner and Boore (1981). In this method, the distance dependent coefficients are derived first, using individual amplitude scaling factors for each earthquake. In the second stage the magnitude-dependent coefficients are derived by fitting a curve to these amplitude scaling factors. Fukushima and Tanaka (1990) conduct simple numerical experiments to show that for sets with a strong correlation between magnitude and distance the distance dependence is reduced, when ordinary least squares is used, compared with the decay associated with an individual earthquake. They find the two-stage method yields distance coefficients similar to those associated with individual earthquakes. This usefulness of the two-stage method has also been demonstrated by Abrahamson and Litehiser (1989), Fukushima et al. (1995), Molas and Yamazaki (1995), Sharma (1998) and Sharma (2000) for their highly correlated (correlation coefficients up to 0.63) magnitude and distance values. Sabetta and Pugliese (1987), Boore et al. (1994a), Ambraseys (1995), Ambraseys et al. (1996) and Sabetta and Pugliese (1996) have found that one-stage and two-stage methods yield similar predictions, especially at intermediate distances where there is most of the data. Ambraseys and Bommer (1991) prefer a one-stage method because more than half the earthquakes in their set of records were only recorded by one instrument and in the second stage these are excluded from the calculation of the magnitude dependence, thereby omitting a large proportion of their data from the regression. Spudich et al. (1999) also use a one-stage method because two-stage methods underestimate the earthquake-to-earthquake component of variation for sets of records like theirs with many singly-recorded earthquakes. Caillot and Bard (1993) 
state that the two-stage method may be misleading because for some spectral periods it does not reduce the variance; they also find significant changes in predictions between one and two-stage methods. A similar technique is applied by Orphal and Lahoud (1974), who use data from the well-recorded San Fernando earthquake to find the distance dependent coefficient and then the rest of the data, from other less well-recorded earthquakes, to define the magnitude scaling. Gaull (1988) applied a variation of this method. This method assumes that the distance decay is the same for all earthquakes; an assumption which is not necessarily justified. McCue et al. (1988) implemented the reverse of this idea, firstly finding the magnitude dependence by examining PGA for many events recorded at the same distance and then using all data to find the distance dependence.

A more complex procedure to overcome the effect of a strong correlation between magnitude and distance (correlation coefficient 0.84) was developed by Tong and Katayama (1988). It is based on a 'reliability' parameter for each earthquake, it is the product of the number of records from that earthquake and the coefficient of determination of a regression equation, derived for each earthquake individually, which estimates the geometrical decay rate. Using earthquakes with 'reliability' values greater than unity they find that a weighted average, using the 'reliability' values, leads to a distance dependence coefficient which is not affected by the correlation between magnitude and distance.

A method was introduced by Trifunac (1976), where the set of records is split up into 24 different magnitude, site and component (horizontal or vertical) intervals. The magnitude, site, component and confidence interval dependent coefficients are calculated using one PGA value from each interval. This method 
reduces the possible bias in the coefficients due to a large number of records with similar magnitudes. Another procedure to reduce this bias was used by Blume (1980). The data is divided into distance dependent bands and within each band a regression equation dependent on magnitude is found which is used to calculate the predicted ground motion at a single point within the interval. Each of these points is used to find the overall distance dependent coefficient.

By far the most common technique for minimizing possible bias, due to a many records with similar associated distances and magnitudes, is weighted regression. Huo and $\mathrm{Hu}$ (1991) divide their dataspace into magnitude-distance intervals within which each record has a weight equal to the reciprocal of the number of records within that interval and then all subdivisions have equal weight. Similar schemes have been implemented by Caillot and Bard (1993) and Crouse and McGuire (1996). Si and Midorikawa (2000) give nearsource records much higher weight than those from large distances. Caillot and Bard (1993) and Munson and Thurber (1997) find that weighting can have a significant effect on the predictions.

To give more weight to near-field PGA values, which are more important for engineering design, Bolt and Abrahamson (1982) use non-linear regression on the untransformed PGA rather than on the logarithm of PGA. They believe that the equation derived by Joyner and Boore (1981) is not strongly affected by the near-field data, limiting its usefulness. The statistical assumption behind the analysis of Bolt and Abrahamson (1982) is that the uncertainty associated with PGA is the same for all levels of ground motion (Draper and Smith, 1981, pp. 237-238). This assumption must be false because otherwise using the standard deviation associated with the equation, to derive predicted 
ground motion for percentiles less than $50 \%$, would lead to the prediction of negative PGA (by definition a positive quantity). Also working directly on the untransformed PGA violates the requirement of the standard least-squares method that the residuals be homoscedastic, i.e. that the residuals are similarly distributed with respect to the predicted value and the independent parameters.

The problem of well-recorded earthquakes (for example San Fernando, Imperial Valley and Northridge) having an unwanted strong influence on the regression [as noted by Trifunac (1976)] is also usually reduced through a weighting scheme; an idea first introduced by Campbell (1981). Campbell (1981) divides the dataspace into a number of distance intervals within which each record is weighted by a relative weighting factor equal to the reciprocal of the number of records within that interval from the earthquake with which the record is associated. Variations on this procedure have been adopted by McCann Jr. and Echezwia (1984), Abrahamson and Litehiser (1989), Campbell (1989), Niazi and Bozorgnia (1991), Sun and Peng (1993), Campbell (1997) and Sharma (1998). The two-stage method of Joyner and Boore (1981) also reduces the bias due to well-recorded shocks. The opposite weighting is applied by Si and Midorikawa (2000) who give more weighting to the well-recorded earthquakes. Donovan and Bornstein (1978) find that, although $32 \%$ of their data is from one earthquake (San Fernando), no bias is introduced

Campbell (1997) tries to reduce the bias due to a number of recordings being made at close sites during the same earthquake [the same possible bias that Boore et al. (1993) reduce by including only one record from similar sites which were less than $1 \mathrm{~km}$ apart] through a weighting scheme. 
Ambraseys and Bommer (1991) choose not to apply weights with their regression analysis because it involves assumptions which are difficult to verify. The ordinary least-squares method is applied by Xu et al. (1984), who justify its use by the small number of records they employ. Campbell and Bozorgnia (2002) do not apply weights for their regression because of the relatively uniform distribution of their recordings with respect to magnitude and distance.

The final reason for not using the ordinary least-squares technique is so that the coefficients obtained are physically realistic. For highly non-linear forms of the equation, where a small change in one coefficient strongly affects another coefficient's value, special techniques need to be employed. Dahle et al. (1995) use a Bayesian one-stage method to yield physically possible coefficients. Crouse and McGuire (1996) apply constraints to their coefficients so that predicted ground motion is an increasing function magnitude and decreasing function of distance. Kamiyama et al. (1992) obtain one of their coefficients, which controls how far the flat part of the attenuation curve (where there is no decay with distance) extends, by a trial and error process so it is consistent with empirical estimates of fault length. If the unconstrained coefficients are nonphysical then it means that the data used is insufficient for the complexity of equation employed. This is a problem with McVerry et al. (2000) who use a very complex functional form for their ground motion estimation relation and then must use many coefficients from Abrahamson and Silva (1997) because their set is insufficient to derive realistic coefficients. Campbell (1997) notes that his adopted functional form has too many coefficients so it is necessary to perform the analysis in many steps finding different sets of coefficients at each stage to ensure a stable result is obtained. Yamabe and Kanai (1988) apply a two-stage regression, which removes the problems 
caused by products of independent variables because the two stages consist of ordinary linear regression. This method though cannot be used for the vast majority of non-linear functional forms which have been proposed.

The other method for obtaining physically realistic coefficients is by using subsets of the data for different parts of the analysis. This is especially useful for data which is dominated by far-field records but where the adopted equation involves coefficients which are only important in the near field. Donovan and Bornstein (1978) divide their data according to distance and find the equation by least squares (no details of this process are provided in the paper). Abrahamson and Litehiser (1989) group their data into 0.5 magnitude unit intervals and fit simple equations to each subset, the coefficients of which are then used to find the overall functional form and coefficients of their nonlinear distance saturation term, which controls the predicted ground motion in the near field. A similar technique is employed by Huo and Hu (1991) and Si and Midorikawa (2000) to find the coefficients of their distance saturation terms although they use the data from a selection of earthquakes rather than magnitude-binned data. Only the earthquakes associated with the most reliable information (those with $M_{s}>6.0$ ) are used by Theodulidis and Papazachos (1992) to find distance coefficients which forces them to adopt a four-stage regression technique to incorporate all the other data.

Schenk $(1982,1984)$ fits the equation to PGA values by eye and not through regression analysis. Schenk (1982) does this because the least squares method is often highly dependent on marginal observations, meaning that certain points can have a large influence on the derived coefficients. Although this is true, fitting an equation by eye is not an objective method, and so cannot be repeated by another person and get the same result, and it is impossible to use 
for complicated functional forms where the data cannot be visualised easily.

Only one published ground motion estimation relation (Huo and $\mathrm{Hu}, 1991$ ) makes the important observation that the independent variables used in ground motion estimation relations (for example magnitude and distance) are associated with their own uncertainties. They develop a method based on weighted consistent least-squares which takes the uncertainties in magnitude and distance into account when deriving the equation. The equations and standard derivations derived by Huo and Hu (1991) using this method and using a standard method that assumes the independent parameters are exact are similar. For prediction purposes it is best to assume that there are no errors in the independent parameters because the standard method gives the equation that minimises the least-squares error in prediction. However, if the coefficients in the equation are of interest, for example to compare with coefficients predicted on a theoretical basis, then a regression method that assumes there are errors in the independent parameters is better.

Brillinger and Preisler $(1984,1985)$ introduce the maximum-likelihood method for deriving equations for the estimation of strong ground motion. The method is also known as the random effects method (Abrahamson and Youngs, 1992). In the random-effects technique the error is assumed to consist of two parts: an earthquake-to-earthquake component, which is the same for all records from the same earthquake, and a record-to-record component, which expresses the variability between each record not expressed by the earthquake-to-earthquake component. The standard deviation of these two errors is found along with the coefficients. This method is thought to take better account of the fact that each record from the same earthquake is not strictly independent. Joyner and Boore (1993) provides a good discussion of this method. This regression 
method has become the most commonly used method and is used by, for example, Boore et al. (1993), Abrahamson and Silva (1997) and Spudich et al. (1999).

\section{Conclusions}

From the above discussion it can be seen that little agreement has been reached in the past thirty years of ground motion estimation relation studies, in terms of data selection; characterisation of source, path or site; or regression techniques employed. Workers have chosen their techniques based on the available data, which varies greatly with geographical region.

The method chosen must also depend on the purpose to which the equations are to be used. For example, if the equations are to be used for seismic hazard analysis of a large region for which only crude site information is available deriving an equation using complex site factors which are difficult to correlate with the crude site information would make the hazard analysis more complicated, although the derived equations with the complex site factors may model the physics of the problem better. If, however, the equation was to be used for a specific site for which detailed soil and wave velocity profiles are available including complex site response modelling in the equation would be justified and useful.

The ground motion recorded during a particular earthquake at a particular site is the the result of a nonlinear combination of many factors. As has been shown above many different choices have been made in deriving equations for the estimation of strong ground motion therefore it is difficult to corre- 
late apparent differences in the estimated ground motions the seismotectonic conditions of the areas where the accelerograms used were recorded. This is because of differences in magnitude scale, distance metric and site classifications used, functional form adopted and, probably mainly, because of the distribution of the data used in terms of magnitude and distance.

Estimated ground motions from recent equations for most combinations of magnitude and distance match closely, see Figure 2. Estimated ground motions from early equations, however, show a large dispersion, see Figure 9 which shows differences of up to a factor of ten in predicted PGA for a $M_{w}=4.5$ earthquake at $d_{f}=50 \mathrm{~km}$ using the equations of Trifunac (1976) and Esteva and Villaverde (1973). The large differences in early equations to estimate ground motions are because of a lack of data, especially near-field data from large earthquakes, a lack of detailed source, path and site information and the simple techniques used to derive the equations. As strong-motion data has become more quantiful and of higher quality and the techniques used to derive the equations more sophisticated the predicted ground motions have become more similar.

There are, however, a number of important questions in ground motion estimation on which there is disagreement. Examples of these are given below.

- For which regions of the world are strong ground motions significantly different than ground motions in other regions? If ground motions in certain regions of the world are sufficiently similar to those in other regions data from these different areas can be combined to improve the robustness of the derived equations.

- How do near-field ground motion amplitudes scale with magnitude? 
- What is the most appropriate distance metric to use? This will depend on the type of data available (it is impossible to use a complex metric where information on the fault rupture is not available) and also on the type of earthquakes under consideration (focal depth has been shown to significantly affect ground motion amplitudes and hence its inclusion for areas affected by deep earthquakes is important).

- What is the best way to include site effects into the equations?

Many factors are known to affect ground motions recorded at a site (Boore, 1983; Joyner, 1987; Joyner and Boore, 1988; Anderson, 1991; Douglas, 2001b) that are neglected in currently used equations for the estimation of earthquake ground motions. These factors include: stress conditions in the crust including stress drop (both static and dynamic), rupture propagation leading to directivity effects, radiation pattern, differing decay rates for different types of wave, variations in subsurface topography (basin effects), focussing and topography. Neglecting these factors leads to large standard deviations when such equations are used. These large standard deviations mean that earthquake engineers must include large factors of safety into their designs. Figure 10 shows the uncertainty (defined in as a factor of one standard deviation) of published equations for the estimation of horizontal peak ground acceleration against the date when the equation was first published. It shows that in the past thirty years there has been little or no decrease in the associated standard deviations of the calculated equations to estimate strong ground motions. This article has showed, however, that each step of the procedure followed in deriving these equations has been scrutinised and improvements suggested.

In order to improve the precision of ground motion estimates new independent parameters, such as more sophisticated site characterisation, need to be 
included into the equations. Examples of such independent parameters that should be included in future equations, because they can be measured before an earthquake occurs, are: static stress drop and crustal structure, both of which are regionally dependent; the effect of basins, which is especially important for long-period ground motions; resonance and impedance effects in the soil deposits beneath the site; and non-linear site response. To include these effects needs, however, detailed information which, unfortunately, is currently lacking, especially in Europe and the Middle East.

Ground motion estimation using strong-motion records is still an rapidly evolving subject and every year about five new sets of equations are derived and published. Therefore a future review such as this will probably emphasise different points than considered here. Future studies should concentrate on trying to answer the still outstanding issues mentioned above and should make full use of the available data.

\section{Acknowledgements}

This study was funded by EPSRC grant no. GR/L87385 and EC grant no. EVR1-CT-1999-40008; I thank both funding agencies for their support. I thank Prof. N.N. Ambraseys, Dr J.J. Bommer, Dr P.M. Smit, Anna Baba, Julian Garcia-Mayordomo, Marco Pagani, Jorge Prieto-Salazar, Carlos Rodriguez, Tizi Rossetto and Iain Tromans for references and their enthusiasm towards the original reports. I thank Dr A. Dahle for sending me a copy of Dahle et al. (1991). Also I thank Dr S.K. Sarma and Prof. P. Suhadolc for examining me for my Ph.D.; my thesis and consequently this paper were improved significantly by their comments. In addition, critical reviews by Prof. P. Fajfar, 
Dr K. W. Campbell and Prof. G. Panza were helpful and lead to significant improvements to the article.

\section{References}

Abrahamson, N. A., Litehiser, J. J., Jun 1989. Attenuation of vertical peak acceleration. Bulletin of the Seismological Society of America 79 (3), 549580.

Abrahamson, N. A., Silva, W. J., Jan/Feb 1997. Empirical response spectral attenuation relations for shallow crustal earthquakes. Seismological Research Letters 68 (1), 94-127.

Abrahamson, N. A., Youngs, R. R., Feb 1992. A stable algorithm for regression analyses using the random effects model. Bulletin of the Seismological Society of America 82 (1), 505-510.

Alfaro, C. S., Kiremidjian, A. S., White, R. A., 1990. Seismic zoning and ground motion parameters for El Salvador. Tech. Rep. 93, The John A. Blume Earthquake Engineering Center, Stanford University, not seen. Reported in Bommer et al. (1996).

Algermissen, S. T., Hansen, S. L., Thenhaus, P. C., 1988. Seismic hazard evaluation for El Salvador. Tech. rep., Report for the US Agency for International Development, not seen. Reported in Bommer et al. (1996).

Ambraseys, N., Douglas, J., Aug 2000. Reappraisal of the effect of vertical ground motions on response. ESEE Report 00-4, Department of Civil and Environmental Engineering, Imperial College, London, also available on internet at: http://www.esee.cv.ic.ac.uk/reports.htm.

Ambraseys, N. N., 1975. Trends in engineering seismology in Europe. In: Proceedings of Fifth European Conference on Earthquake Engineering. Vol. 3. 
pp. 39-52.

Ambraseys, N. N., Jan 1990. Uniform magnitude re-evaluation of European earthquakes associated with strong-motion records. Earthquake Engineering and Structural Dynamics 19 (1), 1-20.

Ambraseys, N. N., Apr 1995. The prediction of earthquake peak ground acceleration in Europe. Earthquake Engineering and Structural Dynamics 24 (4), $467-490$.

Ambraseys, N. N., Bommer, J. J., 1991. The attenuation of ground accelerations in Europe. Earthquake Engineering and Structural Dynamics 20 (12), 1179-1202.

Ambraseys, N. N., Bommer, J. J., 1992. On the attenuation of ground accelerations in Europe. In: Proceedings of Tenth World Conference on Earthquake Engineering. Vol. 2. pp. 675-678.

Ambraseys, N. N., Bommer, J. J., 1995. Attenuation relations for use in Europe: An overview. In: Elnashai, A. S. (Ed.), Proceedings of Fifth SECED Conference on European Seismic Design Practice. pp. 67-74.

Ambraseys, N. N., Bommer, J. J., Sarma, S. K., Nov 1992. A review of seismic ground motions for UK design. ESEE Report 92-8, Department of Civil Engineering, Imperial College, London.

Ambraseys, N. N., Jackson, J. A., 1998. Faulting associated with historical and recent earthquakes in the Eastern Mediterranean region. Geophysical Journal International 133 (2), 390-406.

Ambraseys, N. N., Simpson, K. A., 1996. Prediction of vertical response spectra in Europe. Earthquake Engineering and Structural Dynamics 25 (4), $401-412$.

Ambraseys, N. N., Simpson, K. A., Bommer, J. J., 1996. Prediction of horizontal response spectra in Europe. Earthquake Engineering and Structural 
Dynamics 25 (4), 371-400.

Anderson, J. G., Apr 1991. Strong motion seismology. Reviews of Geophysics 29, 700-720, part 2 .

Annaka, T., Nozawa, Y., 1988. A probabilistic model for seismic hazard estimation in the Kanto district. In: Proceedings of Ninth World Conference on Earthquake Engineering. Vol. II. pp. 107-112.

Aptikaev, F., Kopnichev, J., 1980. Correlation between seismic vibration parameters and type of faulting. In: Proceedings of Seventh World Conference on Earthquake Engineering. Vol. 1. pp. 107-110.

Archuleta, R. J., Jun 1984. A faulting model for the 1979 Imperial Valley earthquake. Journal of Geophysical Research 89 (B6), 4559-4585.

Atkinson, G. M., Jul-Dec 1990. A comparison of eastern North American ground motion observations with theoretical predictions. Seismological Research Letters 61 (3-4), 171-180.

Atkinson, G. M., 1997. Empirical ground motion relations for earthquakes in the Cascadia region. Canadian Journal of Civil Engineering 24, 64-77.

Benito, B., Rinaldis, D., Gorelli, V., Paciello, A., 1992. Influence of the magnitude, distance and natural period of soil in the strong ground motion. In: Proceedings of Tenth World Conference on Earthquake Engineering. Vol. 2. pp. $773-779$.

Blume, J. A., 1977. The SAM procedure for site-acceleration-magnitude relationships. In: Proceedings of Sixth World Conference on Earthquake Engineering. Vol. I. pp. 416-422.

Blume, J. A., 1980. Distance partitioning in attenuation studies. In: Proceedings of Seventh World Conference on Earthquake Engineering. Vol. 2. pp. $403-410$.

Boatwright, J., Boore, D. M., Dec 1982. Analysis of the ground accelerations 
radiated by the 1980 Livermore Valley earthquakes for directivity and dynamic source characteristics. Bulletin of the Seismological Society of America $72(6), 1843-1865$.

Bolt, B. A., Abrahamson, N. A., Dec 1982. New attenuation relations for peak and expected accelerations of strong ground motion. Bulletin of the Seismological Society of America 72 (6), 2307-2321.

Bolt, B. A., Abrahamson, N. A., Oct 1983. Reply to W. B. Joyner and D. M. Boore's "Comments on 'New attenuation relations for peak and expected accelerations of strong ground motion'". Bulletin of the Seismological Society of America 73 (5), 1481-1483.

Bommer, J. J., Elnashai, A. S., Chlimintzas, G. O., Lee, D., Mar 1998. Review and development of response spectra for displacement-based seismic design. ESEE Report 98-3, Department of Civil Engineering, Imperial College, London.

Bommer, J. J., Hernández, D. A., Navarrete, J. A., Salazar, W. M., 1996. Seismic hazard assessments for El Salvador. Geofísica Internacional 35 (3), $227-244$.

Bonilla, M. G., Mark, R. K., Lienkaemper, J. J., Dec 1984. Statistical relations among earthquake magnitude, surface rupture length, and surface fault displacement. Bulletin of the Seismological Society of America 74 (6), $2379-2411$.

Boore, D. M., Jul 1983. Strong-motion seismology. Reviews of Geophysics and Space Physics 21 (6), 1308-1318.

Boore, D. M., Sep 1989. The Richter scale: Its development and use for determining earthquake source parameters. Tectonophysics 166 (1-3), 1-14.

Boore, D. M., Joyner, W. B., Dec 1982. The empirical prediction of ground motion. Bulletin of the Seismological Society of America 72 (6), S43-S60, 
part B.

Boore, D. M., Joyner, W. B., Fumal, T. E., 1993. Estimation of response spectra and peak accelerations from western North American earthquakes: An interim report. Open-File Report 93-509, U.S. Geological Survey.

Boore, D. M., Joyner, W. B., Fumal, T. E., 1994a. Estimation of response spectra and peak accelerations from western North American earthquakes: An interim report. Part 2. Open-File Report 94-127, U.S. Geological Survey.

Boore, D. M., Joyner, W. B., Fumal, T. E., 1994b. Ground motion estimates for strike- and reverse-slip faults, provided to the Southern California Earthquake Center and widely distributed as an insert in Boore et al. (1994a). Not seen. Reported in Boore et al. (1997).

Boore, D. M., Joyner, W. B., Fumal, T. E., Jan/Feb 1997. Equations for estimating horizontal response spectra and peak acceleration from western North American earthquakes: A summary of recent work. Seismological Research Letters 68 (1), 128-153.

Bouhadad, Y., Laouami, N., Bensalem, R., Larbes, S., 1998. Seismic hazard estimation in the central Tell Atlas of Algeria (Algiers-Kabylia). In: Proceedings of Eleventh European Conference on Earthquake Engineering.

Bozorgnia, Y., Campbell, K. W., Niazi, M., 2000. Observed spectral characteristics of vertical ground motion recorded during worldwide earthquakes from 1957 to 1995. In: Proceedings of Twelfth World Conference on Earthquake Engineering. Paper No. 2671.

Brillinger, D. R., Preisler, H. K., 1984. An exploratory analysis of the JoynerBoore attenuation data. Bulletin of the Seismological Society of America 74 (4), 1441-1450.

Brillinger, D. R., Preisler, H. K., 1985. Further analysis of the Joyner-Boore attenuation data. Bulletin of the Seismological Society of America 75 (2), 
$611-614$.

Bureau, G. J., Jun 1978. Influence of faulting on earthquake attenuation. In: Proceedings of the ASCE Geotechnical Engineering Division Speciality Conference: Earthquake Engineering and Soil Dynamics. Vol. I. pp. 290-307. Burger, R. W., Somerville, P. G., Barker, J. S., Herrmann, R. B., Helmberger, D. V., Apr 1987. The effect of crustal structure on strong ground motion attenuation relations in eastern North America. Bulletin of the Seismological Society of America 77 (2), 420-439.

Caillot, V., Bard, P. Y., 1993. Magnitude, distance and site dependent spectra from Italian accelerometric data. European Earthquake Engineering VII (1), $37-48$.

Camacho, E., Lindholm, C., Dahle, A., Bungum, H., 1997. Seismic hazard assessment in Panama. Engineering Geology 48 (1-2), 1-6.

Campbell, K. W., Dec 1981. Near-source attenuation of peak horizontal acceleration. Bulletin of the Seismological Society of America 71 (6), 2039-2070.

Campbell, K. W., Aug 1985. Strong motion attenuation relations: A ten-year perspective. Earthquake Spectra 1 (4), 759-804.

Campbell, K. W., Oct 1989. The dependence of peak horizontal acceleration on magnitude, distance, and site effects for small-magnitude earthquakes in California and eastern North America. Bulletin of the Seismological Society of America 79 (5), 1311-1346.

Campbell, K. W., Sep 1990. Empirical prediction of near-source soil and softrock ground motion for the Diablo Canyon power plant site, San Luis Obispo county, California. Tech. rep., Dames \& Moore, Evergreen, Colorado, prepared for Lawrence Livermore National Laboratory. Not seen. Reported in Idriss (1993).

Campbell, K. W., Jan 1993. Empirical prediction of near-source ground motion 
from large earthquakes. In: Proceedings of the International Workshop on Earthquake Hazard and Large Dams in the Himalaya. Indian National Trust for Art and Cultural Heritage, New Delhi, India.

Campbell, K. W., Jan/Feb 1997. Empirical near-source attenuation relationships for horizontal and vertical components of peak ground acceleration, peak ground velocity, and pseudo-absolute acceleration response spectra. Seismological Research Letters 68 (1), 154-179.

Campbell, K. W., 2002a. A contemporary guide to strong-motion attenuation relations. In: Lee, W. H. K., Kanamori, H., Jennings, P. C., Kisslinger, C. (Eds.), International Handbook of Earthquake and Engineering Seismology. Academic Press, London.

Campbell, K. W., 2002b. Engineering models of strong ground motion. In: Chen, W. F., Scawthorn, C. (Eds.), Handbook of Earthquake Engineering. CRC Press, Boca Raton, FL, USA, Ch. 5.

Campbell, K. W., 2002c. Strong-motion attenuation relations. In: Lee, W. H. K., Kanamori, H., Jennings, P. C., Kisslinger, C. (Eds.), International Handbook of Earthquake and Engineering Seismology. Academic Press, London, Ch. 60.

Campbell, K. W., Bozorgnia, Y., Jul 1994. Near-source attenuation of peak horizontal acceleration from worldwide accelerograms recorded from 1957 to 1993. In: Proceedings of the Fifth U.S. National Conference on Earthquake Engineering. Vol. III. pp. 283-292.

Campbell, K. W., Bozorgnia, Y., Nov 2000. New empirical models for predicting near-source horizontal, vertical, and $V / H$ response spectra: Implications for design. In: Proceedings of the Sixth International Conference on Seismic Zonation.

Campbell, K. W., Bozorgnia, Y., 2002. Mutually consistent near-source at- 
tenuation relations for the horizontal and vertical components of PGA and acceleration response spectra. Bulletin of the Seismological Society of America Submitted.

Chang, T.-Y., Cotton, F., Angelier, J., Oct 2001. Seismic attenuation and peak ground acceleration in Taiwan. Bulletin of the Seismological Society of America 91 (5), 1229-1246.

Chapman, M. C., Nov 1999. On the use of elastic input energy for seismic hazard analysis. Earthquake Spectra 15 (4), 607-635.

Chiaruttini, C., Siro, L., Dec 1981. The correlation of peak ground horizontal acceleration with magnitude, distance, and seismic intensity for Friuli and Ancona, Italy, and the Alpide belt. Bulletin of the Seismological Society of America 71 (6), 1993-2009.

Chopra, A. K., 1995. Dynamics of Structures - Theory and Application to Earthquake Engineering. Prentice Hall International, Inc.

Chou, C.-C., Uang, C.-M., Oct 2000. Establishing absorbed energy spectra an attenuation approach. Earthquake Engineering and Structural Dynamics $29(10), 1441-1455$.

Climent, A., Taylor, W., Ciudad Real, M., Strauch, W., Villagrán, M., Dahle, A., Bungum, H., 1994. Spectral strong motion attenuation in Central America. Tech. Rep. 2-17, NORSAR, not seen. Reported in Camacho et al. (1997) and Bommer et al. (1996).

Cornell, C. A., Oct 1968. Engineering seismic risk analysis. Bulletin of the Seismological Society of America 58 (5), 1583-1606.

Cornell, C. A., Banon, H., Shakal, A. F., Jul-Aug 1979. Seismic motion and response prediction alternatives. Earthquake Engineering and Structural Dynamics 7 (4), 295-315.

Cousins, W. J., Zhao, J. X., Perrin, N. D., Dec 1999. A model for the atten- 
uation of peak ground acceleration in New Zealand earthquakes based on seismograph and accelerograph data. Bulletin of the New Zealand Society for Earthquake Engineering 32 (4), 193-220.

Crouse, C. B., 1991. Ground-motion attenuation equations for earthquakes on the Cascadia subduction zones. Earthquake Spectra 7 (2), 201-236.

Crouse, C. B., McGuire, J. W., Aug 1996. Site response studies for purpose of revising NEHRP seismic provisions. Earthquake Spectra 12 (3), 407-439.

Crouse, C. B., Vyas, Y. K., Schell, B. A., Feb 1988. Ground motion from subduction-zone earthquakes. Bulletin of the Seismological Society of America $78(1), 1-25$.

Dahle, A., Bugum, H., Kvamme, L. B., 1990a. Attenuation modelling based on intraplate earthquake recordings. In: Proceedings of Ninth European Conference on Earthquake Engineering. Vol. 4-A. pp. 121-129.

Dahle, A., Bungum, H., Kvamme, L. B., Nov 1990b. Attenuation models inferred from intraplate earthquake recordings. Earthquake Engineering and Structural Dynamics 19 (8), 1125-1141.

Dahle, A., Bungum, H., Kvamme, L. B., 1991. Empirically derived PSV spectral attenuation models for intraplate conditions. European Earthquake Engineering $3,42-52$.

Dahle, A., Climent, A., Taylor, W., Bungum, H., Santos, P., Ciudad Real, M., Linholm, C., Strauch, W., Segura, F., 1995. New spectral strong motion attenuation models for Central America. In: Proceedings of the Fifth International Conference on Seismic Zonation. Vol. II. pp. 1005-1012.

Decanini, L., Mollaioli, F., F., P. G., Romanelli, F., Vaccari, F., Dec 2000. Pericolosità sismica della Sicilia sud orientale. Terremoti di scenario per Augusta, Siracusa e Noto. In: Decanini, L., Panza, G. F. (Eds.), Scenari di pericolosità sismica ad Augusta, Siracusa e Noto. CNR-Gruppo Nazionale 
per la Difesa dai Terremoti, Rome, Italy, pp. 80-151, in Italian.

Denham, D., Small, G. R., Mar 1971. Strong motion data centre: Bureau of mineral resources, Canada. Bulletin of the New Zealand Society for Earthquake Engineering 4 (1), 15-30.

Denham, D., Small, G. R., Everingham, I., 1973. Some strong-motion results from Papua New Guinea 1967-1972. In: Proceedings of Fifth World Conference on Earthquake Engineering. Vol. 2. pp. 2324-2327.

Devillers, C., Mohammadioun, B., 1981. French methodology for determining site-adapted SMS (Séisme Majoré de Sécurité) spectra. In: Transactions of the 6th International Conference on Structural Mechanics in Reactor Technology. Vol. K(a). K 1/9.

Donovan, N. C., 1973. A statistical evaluation of strong motion data including the February 9, 1971 San Fernando earthquake. In: Proceedings of Fifth World Conference on Earthquake Engineering. Vol. 1. pp. 1252-1261.

Donovan, N. C., Bornstein, A. E., Jul 1978. Uncertainties in seismic risk analysis. Journal of The Geotechnical Engineering Division, ASCE 104 (GT7), 869-887.

Douglas, J., Jan 2001a. A comprehensive worldwide summary of strong-motion attenuation relationships for peak ground acceleration and spectral ordinates (1969 to 2000). ESEE Report 01-1, Department of Civil and Environmental Engineering, Imperial College, London.

Douglas, J., Oct 2001b. A critical reappraisal of some problems in engineering seismology. Ph.D. thesis, University of London.

Douglas, J., May 2002a. Errata of and additions to ESEE Report No. 01-1: 'A comprehensive worldwide summary of strong-motion attenuation relationships for peak ground acceleration and spectral ordinates (1969 to 2000)'. SM Report 02-1, Department of Civil and Environmental Engineering, Im- 
perial College, London.

Douglas, J., 2002b. Note on scaling of peak ground acceleration and peak ground velocity with magnitude. Geophysical Journal International 148 (2), $336-339$.

Draper, N. R., Smith, H., 1981. Applied Regression Analysis, 2nd Edition. John Wiley \& Sons.

Ekström, G., Dziewonski, A. M., Mar 1988. Evidence of bias in estimations of earthquake size. Nature 332, 319-323.

Esteva, L., 1970. Seismic risk and seismic design. In: Hansen, R. (Ed.), Seismic Design for Nuclear Power Plants. The M.I.T. Press, pp. 142-182.

Esteva, L., Villaverde, R., 1973. Seismic risk, design spectra and structural reliability. In: Proceedings of Fifth World Conference on Earthquake Engineering. Vol. 2. pp. 2586-2596.

Faccioli, E., Jun 1978. Response spectra for soft soil sites. In: Proceedings of the ASCE Geotechnical Engineering Division Speciality Conference: Earthquake Engineering and Soil Dynamics. Vol. I. pp. 441-456.

Free, M. W., 1996. The attenuation of earthquake strong-motion in intraplate regions. Ph.D. thesis, University of London.

Free, M. W., Ambraseys, N. N., Sarma, S. K., Feb 1998. Earthquake groundmotion attenuation relations for stable continental intraplate regions. ESEE Report 98-1, Department of Civil Engineering, Imperial College, London.

Fukushima, Y., Gariel, J.-C., Tanaka, R., 1994. Prediction relations of seismic motion parameters at depth using borehole data. In: Proceedings of Tenth European Conference on Earthquake Engineering. Vol. 1. pp. 417-422.

Fukushima, Y., Gariel, J.-C., Tanaka, R., Dec 1995. Site-dependent attenuation relations of seismic motion parameters at depth using borehole data. Bulletin of the Seismological Society of America 85 (6), 1790-1804. 
Fukushima, Y., Tanaka, T., 1990. A new attenuation relation for peak horizontal acceleration of strong earthquake ground motion in Japan. Bulletin of the Seismological Society of America 80 (4), 757-783.

Fukushima, Y., Tanaka, T., Kataoka, S., 1988. A new attenuation relationship for peak ground acceleration derived from strong-motion accelerograms. In: Proceedings of Ninth World Conference on Earthquake Engineering. Vol. II. pp. $343-348$.

Garcia-Fernandez, M., Canas, J., 1995. Regional peak ground acceleration estimates in the Iberian peninsula. In: Proceedings of the Fifth International Conference on Seismic Zonation. Vol. II. pp. 1029-1034.

Gariel, J.-C., Archuleta, R. J., Bouchon, M., Aug 1990. Rupture process of an earthquake with kilometric size fault inferred from the modeling of nearsource records. Bulletin of the Seismological Society of America 80 (4), $870-888$.

Gaull, B. A., 1988. Attenuation of strong ground motion in space and time in southwest Western Australia. In: Proceedings of Ninth World Conference on Earthquake Engineering. Vol. II. pp. 361-366.

Gubbins, D., 1990. Seismology and Plate Tectonics. Cambridge University Press.

Hanks, T. C., Johnson, D. A., Jun 1976. Geophysical assessment of peak accelerations. Bulletin of the Seismological Society of America 66 (3), 959968.

Hartzell, S., Helmberger, D. V., Apr 1982. Strong-motion modeling of the Imperial Valley earthquake of 1979. Bulletin of the Seismological Society of America 72 (2), 571-596.

Hartzell, S. H., Heaton, T. H., Dec 1983. Inversion of strong ground motion and teleseismic waveform data for the fault rupture history of the 1979 
Imperial Valley, California, earthquake. Bulletin of the Seismological Society of America 73 (6), 1553-1583.

Herak, M., Panza, G. F., Costa, G., 2001. Theoretical and observed depth correction for $m_{s}$. Pure and Applied Geophysics 158 (8), 1517-1530.

Huo, J., Hu, Y., 1991. Attenuation laws considering the randomness of magnitude and distance. Earthquake Research in China 5 (1), 17-36.

Idriss, I. M., Jun 1978. Characteristics of earthquake ground motions. In: Proceedings of the ASCE Geotechnical Engineering Division Speciality Conference: Earthquake Engineering and Soil Dynamics. Vol. III. pp. 1151-1265.

Idriss, I. M., 1993. Procedures for selecting earthquake ground motions at rock sites. Tech. Rep. NIST GCR 93-625, National Institute of Standards and Technology.

Iwasaki, T., Kawashima, K., Saeki, M., 1980. Effects of seismic and geotechnical conditions on maximum ground accelerations and response spectra. In: Proceedings of Seventh World Conference on Earthquake Engineering. Vol. 2. pp. 183-190.

Jacob, K. H., Gariel, J.-C., Armbruster, J., Hough, S., Friberg, P., Tuttle, M., May 1990. Site-specific ground motion estimates for New York city. In: Proceedings of the Fourth U.S. National Conference on Earthquake Engineering. Vol. 1. pp. 587-596.

Jain, S. K., Roshan, A. D., Arlekar, J. N., Basu, P. C., Nov 2000. Empirical attenuation relationships for the Himalayan earthquakes based on Indian strong motion data. In: Proceedings of the Sixth International Conference on Seismic Zonation.

Johnson, R. A., Aug 1973. An earthquake spectrum prediction technique. Bulletin of the Seismological Society of America 63 (4), 1255-1274.

Joyner, W. B., Jul 1987. Strong-motion seismology. Reviews of Geophysics 
25 (6), 1149-1160.

Joyner, W. B., Boore, D. M., Dec 1981. Peak horizontal acceleration and velocity from strong-motion records including records from the 1979 Imperial Valley, California, earthquake. Bulletin of the Seismological Society of America 71 (6), 2011-2038.

Joyner, W. B., Boore, D. M., Oct 1983. Comments on "New attenuation relations for peak and expected accelerations of strong ground motion," by B.A. Bolt and N.A. Abrahamson. Bulletin of the Seismological Society of America 73 (5), 1479-1480.

Joyner, W. B., Boore, D. M., Jun 1988. Measurement, characterization, and prediction of strong ground motion. In: Proceedings of Earthquake Engineering \& Soil Dynamics II. Geotechnical Division, ASCE, pp. 43-102.

Joyner, W. B., Boore, D. M., Apr 1993. Methods for regression analysis of strong-motion data. Bulletin of the Seismological Society of America 83 (2), $469-487$.

Joyner, W. B., Boore, D. M., Aug 1996. Recent developments in strong motion attenuation relationships. In: Proceedings of the 28th Joint Meeting of the U.S.-Japan Cooperative Program in Natural Resource Panel on Wind and Seismic Effects. pp. 101-116.

Joyner, W. B., Fumal, T. E., 1984. Use of measured shear-wave velocity for predicting geologic site effects on strong ground motion. In: Proceedings of Eighth World Conference on Earthquake Engineering. Vol. II. pp. 777-783. Kamiyama, M., Oct 1989. Regression analyses of strong-motion spectra in terms of a simplified faulting source model. In: Proceedings of the Fourth International Conference on Soil Dynamics and Earthquake Engineering. pp. $113-126$.

Kamiyama, M., 1995. An attenuation model for the peak values of strong 
ground motions with emphasis on local soil effects. In: Proceedings of the First International Conference on Earthquake Geotechnical Engineering. Vol. 1. pp. 579-585.

Kamiyama, M., O’Rourke, M., Flores-Berrones, R., Sep 1992. A semi-empirical analysis of strong-motion peaks in terms of seismic source, propagation path and local site conditions. Tech. Rep. NCEER-92-0023, National Center for Earthquake Engineering Research.

Kamiyama, M., Yanagisawa, E., Jun 1986. A statisical model for estimating response spectra of strong earthquake ground motions with emphasis on local soil conditions. Soils and Foundations 26 (2), 16-32.

Kawano, H., Takahashi, K., Takemura, M., Tohdo, M., Watanabe, T., Noda, S., 2000. Empirical response spectral attenuations on the rocks with VS = 0.5 to $3.0 \mathrm{~km} / \mathrm{s}$ in Japan. In: Proceedings of Twelfth World Conference on Earthquake Engineering. Paper No. 0953.

Kawashima, K., Aizawa, K., Takahashi, K., 1984. Attenuation of peak ground motion and absolute acceleration response spectra. In: Proceedings of Eighth World Conference on Earthquake Engineering. Vol. II. pp. 257-264. Kawashima, K., Aizawa, K., Takahashi, K., Oct 1985. Attenuation of peak ground motions and absolute acceleration response spectra of vertical earthquake ground motion. Proceedings of JSCE Structural Engineering/Earthquake Engineering 2 (2), 415-422.

Kawashima, K., Aizawa, K., Takahashi, K., Mar-Apr 1986. Attenuation of peak ground acceleration, velocity and displacement based on multiple regression analysis of Japanese strong motion records. Earthquake Engineering and Structural Dynamics 14 (2), 199-215.

Kobayashi, H., Midorikawa, S., 1982. A semi-empirical method for estimating response spectra of near-field ground motions with regard to fault rupture. 
In: Proceedings of Seventh European Conference on Earthquake Engineering. Vol. 2. pp. 161-168.

Kobayashi, H., Nagahashi, S., 1977. Response spectra on seismic bedrock during earthquake. In: Proceedings of Sixth World Conference on Earthquake Engineering. Vol. I. pp. 516-522.

Kobayashi, S., Takahashi, T., Matsuzaki, S., Mori, M., Fukushima, Y., Zhao, J. X., Somerville, P. G., 2000. A spectral attenuation model for Japan using digital strong motion records of JMA87 type. In: Proceedings of Twelfth World Conference on Earthquake Engineering. Paper No. 2786.

Lawson, R. S., Krawinkler, H., 1994. Cumulative damage potential of seismic ground motion. In: Proceedings of Tenth European Conference on Earthquake Engineering. Vol. 2. pp. 1079-1086.

Lee, V. W., Jan 1993. Scaling PSV from earthquake magnitude, local soil, and geologic depth of sediments. Journal of The Geotechnical Engineering Division, ASCE 119 (1), 108-126.

Lee, V. W., 1995. Pseudo relative velocity spectra in former Yugoslavia. European Earthquake Engineering IX (1), 12-22.

Lee, V. W., Manić, M., 1994. Empirical scaling of response spectra in former Yugoslavia. In: Proceedings of Tenth European Conference on Earthquake Engineering. Vol. 4. pp. 2567-2572.

Lee, V. W., Trifunac, M. D., May 1995. Pseudo relative velocity spectra of strong earthquake ground motion in California. Tech. Rep. CE 95-04, Department of Civil Engineering, University of Southern California, Los Angeles, California, U.S.A.

Lee, V. W., Trifunac, M. D., Todorovska, M. I., Novikova, E. I., Apr 1995. Empirical equations describing attenuation of peak of strong ground motion, in terms of magnitude, distance, path effects and site conditions. Tech. Rep. 
CE 95-02, Department of Civil Engineering, University of Southern California, Los Angeles, California, U.S.A.

Lungu, D., Coman, O., Moldoveanu, T., Aug 1995a. Hazard analysis for Vrancea earthquakes. Application to Cernavoda NPP site in Romania. In: Proceedings of the 13th International Conference on Structural Mechanics in Reactor Technology. Division K, Paper No. 538.

Lungu, D., Cornea, T., Craifaleanu, I., Aldea, A., 1995b. Seismic zonation of Romania based on uniform hazard response ordinates. In: Proceedings of the Fifth International Conference on Seismic Zonation. Vol. I. pp. 445-452.

Lungu, D., Cornea, T., Craifaleanu, I., Demetriu, S., Jun 1996. Probabilistic seismic hazard analysis for inelastic structures on soft soils. In: Proceedings of Eleventh World Conference on Earthquake Engineering.

Lungu, D., Demetriu, S., Radu, C., Coman, O., 1994. Uniform hazard response spectra for Vrancea earthquakes in Romania. In: Proceedings of Tenth European Conference on Earthquake Engineering. Vol. 1. pp. 365-370.

Lussou, P., Bard, P. Y., Cotton, F., Fukushima, Y., Jan 2001. Seismic design regulation codes: Contribution of K-Net data to site effect evaluation. Journal of Earthquake Engineering 5 (1), 13-33.

Manic, M. I., 1998. A new site dependent attenuation model for prediction of peak horizontal acceleration in Northwestern Balkan. In: Proceedings of Eleventh European Conference on Earthquake Engineering.

Marone, C., Scholz, C. H., Jun 1998. The depth of seismic faulting and the upper transition from stable to unstable slip regimes. Geophysical Research Letters 15 (6), 621-624.

McCann Jr., M. W., Echezwia, H., 1984. Investigating the uncertainty in ground motion prediction. In: Proceedings of Eighth World Conference on Earthquake Engineering. Vol. II. pp. 297-304. 
McCue, K., Dec 1986. Strong motion attenuation in eastern Australia. In: Earthquake Engineering Symposium. National Conference Publication 86/15. Institution of Engineers Australia, not seen. Reported in Free (1996).

McCue, K., Gibson, G., Wesson, V., 1988. Intraplate recording of strong motion in southeastern Australia. In: Proceedings of Ninth World Conference on Earthquake Engineering. Vol. II. pp. 355-360.

McGarr, A., May 1981. Analysis of peak ground motion in terms of a model of inhomogenous faulting. Journal of Geophysical Research 86 (B5), 39013912.

McGarr, A., Dec 1982. Upper bounds on near-source peak ground motion based on a model of inhomogeneous faulting. Bulletin of the Seismological Society of America 72 (6), 1825-1841.

McGuire, R. K., 1977. Seismic design spectra and mapping procedures using hazard analysis based directly on oscillator response. Earthquake Engineering and Structural Dynamics 5, 211-234.

McGuire, R. K., Apr 1978. Seismic ground motion parameter relations. Journal of The Geotechnical Engineering Division, ASCE 104 (GT4), 481-490.

McVerry, G. H., Dowrick, D. J., Sritharan, S., Cousins, W. J., Porritt, T. E., 1993. Attenuation of peak ground accelerations in New Zealand. In: Proceedings of the International Workshop on Strong Motion Data. Vol. 2. pp. 23-38, not seen. Cited in McVerry et al. (1995).

McVerry, G. H., Dowrick, D. J., Zhao, J. X., November 1995. Attenuation of peak ground accelerations in New Zealand. In: Pacific Conference on Earthquake Engineering. Vol. 3. pp. 287-292.

McVerry, G. H., Zhao, J. X., Abrahamson, N. A., Somerville, P. G., 2000. Crustal and subduction zone attenuation relations for New Zealand earthquakes. In: Proceedings of Twelfth World Conference on Earthquake Engi- 
neering. Paper No. 1834.

Milne, W. G., 1977. Seismic risk maps for Canada. In: Proceedings of Sixth World Conference on Earthquake Engineering. Vol. I. p. 930, 2-508.

Milne, W. G., Davenport, A. G., Apr 1969. Distribution of earthquake risk in Canada. Bulletin of the Seismological Society of America 59 (2), 729-754.

Mohammadioun, B., 1991. The prediction of response spectra for the antiseismic design of structures specificity of data from intracontinential environments. European Earthquake Engineering V (2), 8-17.

Mohammadioun, B., 1994a. Prediction of seismic motion at the bedrock from the strong-motion data currently available. In: Proceedings of Tenth European Conference on Earthquake Engineering. Vol. 1. pp. 241-245.

Mohammadioun, G., 1994b. Calculation of site-adapted reference spectra from the statistical analysis of an extensive strong-motion data bank. In: Proceedings of Tenth European Conference on Earthquake Engineering. Vol. 1. pp. $177-181$.

Molas, G. L., Yamazaki, F., Oct 1995. Attenuation of earthquake ground motion in Japan including deep focus events. Bulletin of the Seismological Society of America 85 (5), 1343-1358.

Molas, G. L., Yamazaki, F., Mar 1996. Attenuation of response spectra in Japan using new JMA records. Bulletin of Earthquake Resistant Structure Research Center 29, 115-128.

Monguilner, C. A., Ponti, N., Pavoni, S. B., 2000a. Relationships between basic ground motion parameters for earthquakes of the Argentine western region. In: Proceedings of Twelfth World Conference on Earthquake Engineering. Paper no. 1195.

Monguilner, C. A., Ponti, N., Pavoni, S. B., Richarte, D., 2000b. Statistical characterization of the response spectra in the Argentine Republic. In: Pro- 
ceedings of Twelfth World Conference on Earthquake Engineering. Paper no. 1825 .

Munson, C. G., Thurber, C. H., Aug 1997. Analysis of the attenuation of strong ground motion on the island of Hawaii. Bulletin of the Seismological Society of America 87 (4), 945-960.

Musson, R. M. W., Marrow, P. C., Winter, P. W., May 1994. Attenuation of earthquake ground motion in the UK. Tech. Rep. AEA/CS/16422000/ZJ745/004, AEA Technology Consultancy Services (SRD) and British Geological Survey.

Niazi, M., Bozorgnia, Y., Jun 1991. Behaviour of near-source peak horizontal and vertical ground motions over SMART-1 array, Taiwan. Bulletin of the Seismological Society of America 81 (3), 715-732.

Niazi, M., Bozorgnia, Y., 1992. Behaviour of near-source vertical and horizontal response spectra at SMART-1 array, Taiwan. Earthquake Engineering and Structural Dynamics 21, 37-50.

Ohno, S., Ohta, T., Ikeura, T., Takemura, M., 1993. Revision of attenuation formula considering the effect of fault size to evaluate strong motion spectra in near field. Tectonophysics 218, 69-81.

Ohno, S., Takemura, M., Niwa, M., Takahashi, K., 1996. Intensity of strong ground motion on pre-quaternary stratum and surface soil amplifications during the 1995 Hyogo-ken Nanbu earthquake, Japan. Journal of Physics of the Earth 44 (5), 623-648.

Ohsaki, Y., Sawada, Y., Hayashi, K., Ohmura, B., Kumagai, C., 1980a. Spectral characteristics of hard rock motions. In: Proceedings of Seventh World Conference on Earthquake Engineering. Vol. 2. pp. 231-238.

Ohsaki, Y., Watabe, M., Tohdo, M., 1980b. Analyses on seismic ground motion parameters including vertical components. In: Proceedings of Seventh World 
Conference on Earthquake Engineering. Vol. 2. pp. 97-104.

Olson, A. H., Apsel, R. J., Dec 1982. Finite faults and inverse theory with applications to the 1979 Imperial Valley earthquake. Bulletin of the Seismological Society of America 72 (6), 1969-2001.

Orphal, D. L., Lahoud, J. A., Oct 1974. Prediction of peak ground motion from earthquakes. Bulletin of the Seismological Society of America 64 (5), $1563-1574$.

Parvez, I. A., Gusev, A. A., Panza, G. F., Petukhin, A. G., 2001. Preliminary determination of the interdependence among strong-motion amplitude, earthquake magnitude and hypocentral distance for the Himalayan region. Geophysical Journal International 144 (3), 577-596.

Peng, K.-Z., Wu, F. T., Song, L., May-Jun 1985. Attenuation characteristics of peak horizontal acceleration in northeast and southwest China. Earthquake Engineering and Structural Dynamics 13 (3), 337-350.

Perea, T., Sordo, E., 1998. Direct response spectrum prediction including local site effects. In: Proceedings of Eleventh European Conference on Earthquake Engineering.

Petrovski, D., Marcellini, A., 1988. Prediction of seismic movement of a site: Statisical approach. In: Proc. UN Sem. on Predict. of Earthquakes. Lisbon, Portugal, 14-18 November. Not seen. Reported in Ambraseys and Bommer (1995).

PML, 1982. British earthquakes. Tech. Rep. 115/82, Principia Mechanica Ltd., London, not seen. Reported in Ambraseys et al. (1992).

PML, 1985. Seismological studies for UK hazard analysis. Tech. Rep. 346/85, Principia Mechanica Ltd., London, not seen. Reported in Ambraseys et al. (1992).

Radu, C., Lungu, D., Demetriu, S., Coman, O., Sep 1994. Recurrence, atten- 
uation and dynamic amplification for intermediate depth Vrancea earthquakes. In: Proceedings of the XXIV General Assembly of the ESC. Vol. III. pp. $1736-1745$.

Ramazi, H. R., Schenk, V., Sep 1994. Preliminary results obtained from strong ground motion analzses [sic] of Iranian earthquakes. In: Proceedings of the XXIV General Assembly of the ESC. Vol. III. pp. 1762-1770.

Richter, C. F., 1958. Elementary Seismology. Freeman and Co., San Francisco, USA.

Rinaldis, D., Berardi, R., Theodulidis, N., Margaris, B., 1998. Empirical predictive models based on a joint Italian \& Greek strong-motion database: I, peak ground acceleration and velocity. In: Proceedings of Eleventh European Conference on Earthquake Engineering.

Sabetta, F., Pugliese, A., Oct 1987. Attenuation of peak horizontal acceleration and velocity from Italian strong-motion records. Bulletin of the Seismological Society of America 77 (5), 1491-1513.

Sabetta, F., Pugliese, A., Apr 1996. Estimation of response spectra and simulation of nonstationary earthquake ground motions. Bulletin of the Seismological Society of America 86 (2), 337-352.

Sadigh, K., Chang, C.-Y., Abrahamson, N. A., Chiou, S. J., Power, M. S., Mar 1993. Specification of long-period ground motions: Updated attenuation relationships for rock site conditions and adjustment factors for near-fault effects. In: Proceedings of ATC-17-1 Seminar on Seismic Isolation, Passive Energy Dissipation, and Active Control. pp. 59-70.

Sadigh, K., Chang, C.-Y., Egan, J. A., Makdisi, F., Youngs, R. R., Jan/Feb 1997. Attenuation relationships for shallow crustal earthquakes based on California strong motion data. Seismological Research Letters 68 (1), 180189. 
Sadigh, R. K., Egan, J. A., 1998. Updated relationships for horizontal peak ground velocity and peak ground displacement for shallow crustal earthquakes. In: Proceedings of the Sixth U.S. National Conference on Earthquake Engineering.

Sarma, S. K., Free, M. W., November 1995. The comparision of attenuation relationships for peak horizontal acceleration in intraplate regions. In: Pacific Conference on Earthquake Engineering. Vol. 2. pp. 175-184.

Sarma, S. K., Srbulov, M., Aug 1996. A simplified method for prediction of kinematic soil-foundation interaction effects on peak horizontal acceleration of a rigid foundation. Earthquake Engineering and Structural Dynamics $25(8), 815-836$.

Sarma, S. K., Srbulov, M., 1998. A uniform estimation of some basic ground motion parameters. Journal of Earthquake Engineering 2 (2), 267-287.

Schenk, V., 1982. Peak particle ground motions in earthquake near-field. In: Proceedings of Seventh European Conference on Earthquake Engineering. Vol. 2. pp. 211-217.

Schenk, V., Mar 1984. Relations between ground motions and earthquake magnitude, focal distance and epicentral intensity. Engineering Geology $20(1 / 2), 143-151$.

Sen, M. K., May 1990. Deep structural complexity and site response in Los Angeles basin. In: Proceedings of the Fourth U.S. National Conference on Earthquake Engineering. Vol. 1. pp. 545-553.

Shabestari, K. T., Yamazaki, F., 2000. Attenuation relation of response spectra in Japan considering site-specific term. In: Proceedings of Twelfth World Conference on Earthquake Engineering. Paper No. 1432.

Shabestari, T. K., Yamazaki, F., 1998. Attenuation of JMA seismic intensity using recent JMA records. In: Proceedings of the 10th Japan Earth- 
quake Engineering Symposium. Vol. 1. pp. 529-534, not seen. Reported in Shabestari and Yamazaki (2000).

Sharma, M. L., Aug 1998. Attenuation relationship for estimation of peak ground horizontal acceleration using data from strong-motion arrays in India. Bulletin of the Seismological Society of America 88 (4), 1063-1069.

Sharma, M. L., 2000. Attenuation relationship for estimation of peak ground vertical acceleration using data from strong motion arrays in India. In: Proceedings of Twelfth World Conference on Earthquake Engineering. Paper No. 1964.

Si, H., Midorikawa, S., 2000. New attenuation relations for peak ground acceleration and velocity considering effects of fault type and site condition. In: Proceedings of Twelfth World Conference on Earthquake Engineering. Paper No. 0532.

Sigbjörnsson, R., 1990. Strong motion measurements in Iceland and seismic risk assessment. In: Proceedings of Ninth European Conference on Earthquake Engineering. Vol. 10-A. pp. 215-222.

Sigbjörnsson, R., Baldvinsson, G. I., 1992. Seismic hazard and recordings of strong ground motion in Iceland. In: Proceedings of Tenth World Conference on Earthquake Engineering. Vol. 1. pp. 419-424.

Simpson, K. A., 1996. Attenuation of strong ground-motion incorporating near-surface foundation conditions. Ph.D. thesis, University of London.

Singh, R. P., Aman, A., Prasad, Y. J. J., 1996. Attenuation relations for strong seismic ground motion in the Himalayan region. Pure and Applied Geophysics 147 (1), 161-180.

Singh, S. K., Gutierreez, C., Arboleda, J., Ordaz, M., 1993. Peligro sísmico en El Salvador. Tech. rep., Universidad Nacional Autónoma de México, México, not seen. Reported in Bommer et al. (1996). 
Singh, S. K., Mena, E., Castro, R., Carmona, C., Oct 1987. Empirical prediction of ground motion in Mexico City from coastal earthquakes. Bulletin of the Seismological Society of America 77 (5), 1862-1867.

Smit, P., Sep 1998. Strong motion attenuation model for central Europe. In: Proceedings of Eleventh European Conference on Earthquake Engineering. Smisma.

Smit, P., Dec 2000. Personal communication 4/12/2000.

Smit, P., Arzoumanian, V., Javakhishvili, Z., Arefiev, S., Mayer-Rosa, D., Balassanian, S., Chelidze, T., 2000. The digital accelerograph network in the Caucasus. In: Balassanian, S. (Ed.), Earthquake Hazard and Seismic Risk Reduction - Advances in Natural and Technological Hazards Research. Kluwer Academic Publishers, presented at 2nd International Conference on Earthquake Hazard and Seismic Risk Reduction, Yerevan, Armenia, 15/9/1998-21/9/1998.

Spudich, P., Fletcher, J., Hellweg, M., Boatwright, J., Sullivan, C., Joyner, W., Hanks, T., Boore, D., McGarr, A., Baker, L., Lindh, A., 1996. Earthquake ground motions in extensional tectonic regimes. Open-File Report 96-292, U.S. Geological Survey, not seen. Reported in Spudich et al. (1997).

Spudich, P., Fletcher, J. B., Hellweg, M., Boatwright, J., Sullivan, C., Joyner, W. B., Hanks, T. C., Boore, D. M., McGarr, A., Baker, L. M., Lindh, A. G., Jan/Feb 1997. SEA96 - A new predictive relation for earthquake ground motions in extensional tectonic regimes. Seismological Research Letters 68 (1), 190-198.

Spudich, P., Joyner, W. B., Lindh, A. G., Boore, D. M., Margaris, B. M., Fletcher, J. B., Oct 1999. SEA99: A revised ground motion prediction relation for use in extensional tectonic regimes. Bulletin of the Seismological Society of America 89 (5), 1156-1170. 
Suhadolc, P., Chiaruttini, C., 1987. A theoretical study of the dependence of the peak ground acceleration on source and structure parameters. In: Erdik, M., Toksöz, M. (Eds.), Strong Ground Motion Seismology. D. Reidel Publishing Company, pp. 143-183.

Sun, F., Peng, K., 1993. Attenuation of strong ground motion in western U.S.A. Earthquake Research in China 7 (1), 119-131.

Takahashi, T., Kobayashi, S., Fukushima, Y., Zhao, J. X., Nakamura, H., Somerville, P. G., Nov 2000. A spectral attenuation model for Japan using strong motion data base. In: Proceedings of the Sixth International Conference on Seismic Zonation.

Tamura, K., Sasaki, Y., Aizawa, K., May 1990. Attenuation characteristics of ground motions in the period range of 2 to 20 seconds - for application to the seismic design of long-period structures. In: Proceedings of the Fourth U.S. National Conference on Earthquake Engineering. Vol. 1. pp. 495-504.

Taylor Castillo, W., Santos Lopez, P., Dahle, A., Bungum, H., 1992. Digitization of strong-motion data and estimation of PGA attenuation. Tech. Rep. 2-4, NORSAR, not seen. Reported in Bommer et al. (1996).

Tento, A., Franceschina, L., Marcellini, A., 1992. Expected ground motion evaluation for Italian sites. In: Proceedings of Tenth World Conference on Earthquake Engineering. Vol. 1. pp. 489-494.

Theodulidis, N. P., Papazachos, B. C., 1992. Dependence of strong ground motion on magnitude-distance, site geology and macroseismic intensity for shallow earthquakes in Greece: I, peak horizontal acceleration, velocity and displacement. Soil Dynamics and Earthquake Engineering 11, 387-402.

Theodulidis, N. P., Papazachos, B. C., 1994. Dependence of strong ground motion on magnitude-distance, site geology and macroseismic intensity for shallow earthquakes in Greece: II horizontal pseudovelocity. Soil Dynamics 
and Earthquake Engineering 13 (5), 317-343.

Tong, H., Katayama, T., 1988. Peak acceleration attenuation by eliminating the ill-effect of the correlation between magnitude and epicentral distance. In: Proceedings of Ninth World Conference on Earthquake Engineering. Vol. II. pp. 349-354.

Trifunac, M. D., Feb 1976. Preliminary analysis of the peaks of strong earthquake ground motion - dependence of peaks on earthquake magnitude, epicentral distance, and recording site conditions. Bulletin of the Seismological Society of America 66 (1), 189-219.

Trifunac, M. D., 1977. Forecasting the spectral amplitudes of strong earthquake ground motion. In: Proceedings of Sixth World Conference on Earthquake Engineering. Vol. I. pp. 139-152.

Trifunac, M. D., Oct 1978. Response spectra of earthquake ground motions. Journal of The Engineering Mechanics Division, ASCE 104 (EM5), 10811097.

Trifunac, M. D., 1980. Effects of site geology on amplitudes of strong motion. In: Proceedings of Seventh World Conference on Earthquake Engineering. Vol. 2. pp. 145-152.

Trifunac, M. D., Anderson, J. G., 1978. Preliminary empirical models for scaling pseudo relative velocity spectra. Tech. Rep. 78-04, Department of Civil Engineering, University of Southern California, Los Angeles, California, U.S.A., not seen. Cited in Lee et al. (1995).

Trifunac, M. D., Brady, A. G., 1975. On the correlation of peak acceleration of strong motion with earthquake magnitude, epicentral distance and site conditions. In: Proceedings of the U.S. National Conference on Earthquake Engineering. pp. $43-52$.

Trifunac, M. D., Brady, A. G., Jul-Sep 1976. Correlations of peak acceleration, 
velocity and displacement with earthquake magnitude, distance and site conditions. Earthquake Engineering and Structural Dynamics 4 (5), 455471.

Trifunac, M. D., Lee, V. W., 1979. Dependence of pseudo relative velocity spectra of strong motion acceleration on depth of sedimentary deposits. Tech. Rep. 79-10, Department of Civil Engineering, University of Southern California, Los Angeles, California, U.S.A., not seen. Cited in Lee et al. (1995).

Trifunac, M. D., Lee, V. W., 1985. Preliminary empirical model for scaling pseudo relative velocity spectra of strong earthquake acceleration in terms of magnitude, distance, site intensity and recording site condition. Tech. Rep. 85-04, Department of Civil Engineering, University of Southern California, Los Angeles, California, U.S.A., not seen. Cited in Trifunac and Lee (1979). Trifunac, M. D., Lee, V. W., Jul 1989. Empirical models for scaling pseudo relative velocity spectra of strong earthquake accelerations in terms of magnitude, distance, site intensity and recording site conditions. Soil Dynamics and Earthquake Engineering 8 (3), 126-144.

Tromans, I. J., Bommer, J. J., Sep 2002. The attenuation of strong-motion peaks in Europe. In: Proceedings of Twelfth European Conference on Earthquake Engineering. Paper no. 394.

Tsai, Y. B., Brady, F. W., Cluff, L. S., May 1990. An integrated approach for characterization of ground motions in PG\&E's long term seismic program for Diablo Canyon. In: Proceedings of the Fourth U.S. National Conference on Earthquake Engineering. Vol. 1. pp. 597-606.

Wang, B.-Q., Wu, F. T., Bian, Y.-J., 1999. Attenuation characteristics of peak accele-ration in north China and comparison with those in the eastern part of North America. Acta Seismologica Sinica 
12 (1), on internet at: http://www.chinainfo.gov.cn/periodical/dizhenE/dzxb99/dzxb9901/990104.htm.

Wang, G., Tao, X., Nov 2000. A new two-stage procedure for fitting attenuation relationship of strong ground motion. In: Proceedings of the Sixth International Conference on Seismic Zonation.

Wells, D. L., Coppersmith, K. J., Aug 1994. New empirical relationships among magnitude, rupture length, rupture width, rupture area, and surface displacement. Bulletin of the Seismological Society of America 84 (4), $974-1002$.

Xiang, J., Gao, D., 1994. The attenuation law of horizontal peak acceleration on the rock site in Yunnan area. Earthquake Research in China 8 (4), 509516.

Xu, Z., Shen, X., Hong, J., 1984. Attenuation relation of ground motion in northern China. In: Proceedings of Eighth World Conference on Earthquake Engineering. Vol. II. pp. 335-342.

Yamabe, K., Kanai, K., 1988. An empirical formula on the attenuation of the maximum acceleration of earthquake motions. In: Proceedings of Ninth World Conference on Earthquake Engineering. Vol. II. pp. 337-342.

Yokota, H., Shiba, K., Okada, K., 1988. The characteristics of underground earthquake motions observed in the mud stone layer in Tokyo. In: Proceedings of Ninth World Conference on Earthquake Engineering. Vol. II. pp. $429-434$.

Youngs, R. R., Chiou, S.-J., Silva, W. J., Humphrey, J. R., Jan/Feb 1997. Strong ground motion attenuation relationships for subduction zone earthquakes. Seismological Research Letters 68 (1), 58-73.

Youngs, R. R., Day, S. M., Stevens, J. L., Jun 1988. Near field ground motions on rock for large subduction earthquakes. In: Proceedings of Earthquake 
Engineering \& Soil Dynamics II. Geotechnical Division, ASCE, pp. 445462.

Zhao, J. X., Dowrick, D. J., McVerry, G. H., Jun 1997. Attenuation of peak ground acceleration in New Zealand earthquakes. Bulletin of the New Zealand National Society for Earthquake Engineering 30 (2), 133-158.

Zhou, X., Su, J., Wang, G., 1989. A modification of the fault-rupture model and its application in seismic hazard analysis. Earthquake Research in China $3(4), 351-365$. 


\section{A General characteristics of published equations for estimating peak ground acceleration}

Table A.1 gives the general characteristics of published equations for estimating peak ground acceleration. The columns are:

H Number of horizontal records (if both horizontal components are used then multiply by two to get total number)

$\mathrm{V}$ Number of vertical components

E Number of earthquakes

$M_{\min }$ Magnitude of smallest earthquake

$M_{\max }$ Magnitude of largest earthquake

$M$ scale Magnitude scale (scales in brackets refer to those scales which the main $M$ values were sometimes converted from, or used without conversion, when no data existed), where:

$m_{b}$ Body-wave magnitude

$M_{C}$ Chinese surface wave magnitude

$M_{C L}$ Coda length magnitude

$M_{D}$ Duration magnitude

$M_{\text {JMA }}$ Japanese Meteorological Agency magnitude

$M_{L}$ Local magnitude

$M_{b L g}$ Magnitude calculated using Lg amplitudes on short-period, vertical seismographs

$M_{s}$ Surface-wave magnitude

$M_{w}$ Moment magnitude

$d_{\min }$ Shortest source-to-site distance

$d_{\max }$ Longest source-to-site distance 
$d$ scale Distance measure, where:

$d_{c}$ Distance to rupture centroid

$d_{e}$ Epicentral distance

$d_{E}$ Distance to energy centre

$d_{f}$ Distance to projection of rupture plane on surface (Joyner and Boore, 1981)

$d_{h}$ Hypocentral (or focal) distance

$d_{q}$ Equivalent hypocentral distance (EHD) (Ohno et al., 1993)

$d_{r}$ Distance to rupture plane

$d_{s}$ Distance to seismogenic rupture plane (assumes near-surface rupture in sediments is non-seismogenic) (Campbell, 1997)

S Number of different site conditions modelled, where:

C Continuous classification

I Individual classification for each site

C Use of the two horizontal components of each accelerogram, where:

B Both components

C Randomly chosen component

G Geometric mean

L Larger component

M Mean (not stated what type)

O Randomly oriented component

R Resolved component

U Unknown

V Vectorially resolved component, i.e. square root of sum of squares of the two components

R Regression method used, where:

1 Ordinary one-stage 
1B Bayesian one-stage

1M Maximum likelihood one-stage (Joyner and Boore, 1993)

1W Weighted one-stage

2 Two-stage (Joyner and Boore, 1981)

2M Maximum likelihood two-stage (Joyner and Boore, 1993)

2W Two-stage with second staged weighted as described in Joyner and Boore (1988)

O Other method

U Unknown

M Source mechanisms (and tectonic type) of earthquakes (letters in brackets refer to those mechanism which are separately modelled), where:

A All (this is assumed if no information is given in the reference)

B Interslab

F Interface

I Intraplate

N Normal

O Oblique

R Reverse

S Strike-slip

T Thrust

'+' refers to extra records from outside region used to supplement data. (...) refer either to magnitudes of supplementing records or to those used for part of analysis. ${ }^{*}$ means information is approximate because either read from graph or found in another way. 
Table A.1: Characteristics of published equations for estimating peak ground acceleration.

\begin{tabular}{|c|c|c|c|c|c|c|c|c|c|c|c|c|c|c|}
\hline Reference & Area & $\mathrm{H}$ & $\mathrm{V}$ & $\mathrm{E}$ & $M_{\min }$ & $M_{\max }$ & $M$ scale & $d_{\min }$ & $d_{\max }$ & $d$ scale & $\mathrm{S}$ & $\mathrm{C}$ & $\mathrm{R}$ & M \\
\hline $\begin{array}{l}\text { Milne and Daven- } \\
\text { port }(1969)\end{array}$ & W. USA & $\mathrm{U}$ & - & $\mathrm{U}$ & $\mathrm{U}$ & $\mathrm{U}$ & $\mathrm{U}$ & $\mathrm{U}$ & $\mathrm{U}$ & $d_{e}$ & 1 & $\mathrm{U}$ & $\mathrm{U}$ & $\mathrm{A}$ \\
\hline Esteva (1970) & W. USA & $\mathrm{U}$ & - & $\mathrm{U}$ & $\mathrm{U}$ & $\mathrm{U}$ & $\mathrm{U}$ & $15^{*}$ & $500^{*}$ & $d_{h}$ & 1 & $\mathrm{U}$ & $\mathrm{U}$ & $\mathrm{A}$ \\
\hline $\begin{array}{l}\text { Denham and } \\
\text { Small (1971) }\end{array}$ & $\begin{array}{l}\text { Yonki, } \quad \text { New } \\
\text { Guinea }\end{array}$ & 8 & - & 8 & $\mathrm{U}$ & $\mathrm{U}$ & $M_{L}^{2}$ & $\mathrm{U}$ & $\mathrm{U}$ & $d_{h}$ & 1 & $\mathrm{U}$ & $\mathrm{U}$ & $\mathrm{A}$ \\
\hline $\begin{array}{l}\text { Denham et al. } \\
(1973)\end{array}$ & $\begin{array}{l}\text { Papua } \\
\text { Guinea }\end{array}$ & 25 & - & 25 & 5.2 & 8.0 & $M_{L}$ & $80^{*}$ & 300 & $\mathrm{U}$ & 1 & $\mathrm{U}$ & 1 & $\mathrm{~A}$ \\
\hline Donovan (1973) & $\begin{array}{l}\text { Mostly W. } \\
\text { USA but } 100+ \\
\text { foreign }\end{array}$ & 678 & - & $\mathrm{U}$ & $<5$ & $>8$ & $\mathrm{U}$ & $3^{*}$ & $450^{*}$ & $d_{h}$ & 1 & $\mathrm{U}$ & $\mathrm{U}$ & $\mathrm{A}$ \\
\hline $\begin{array}{l}\text { Esteva and } \\
\text { Villaverde (1973) }\end{array}$ & W. USA & $\mathrm{U}$ & - & $\mathrm{U}$ & $\mathrm{U}$ & $\mathrm{U}$ & $\mathrm{U}$ & $15^{*}$ & $150 *$ & $d_{h}$ & 1 & $\mathrm{~B}$ & $\mathrm{U}$ & $\mathrm{A}$ \\
\hline $\begin{array}{l}\text { Orphal and La- } \\
\text { houd }(1974)\end{array}$ & California & 140 & - & 31 & 4.1 & 7.0 & $M_{L}$ & 15 & 350 & $d_{h}$ & 1 & $\mathrm{U}$ & $\mathrm{O}$ & $\mathrm{A}$ \\
\hline Ambraseys (1975) & Europe & 58 & - & $\mathrm{U}^{3}$ & 3.5 & 5.0 & $M_{L}$ & 5 & 35 & $d_{h}$ & 1 & $\mathrm{U}^{4}$ & $\mathrm{U}$ & $\mathrm{A}$ \\
\hline
\end{tabular}

continued on next page

$\overline{2}$ State that it is Richter magnitude which assume to be $M_{L}$

3 Ambraseys and Bommer (1995) state that uses 38 earthquakes.

4 Ambraseys and Bommer (1995) state that uses larger component. 
Table A.1: continued

\begin{tabular}{|c|c|c|c|c|c|c|c|c|c|c|c|c|c|c|}
\hline Reference & Area & $\mathrm{H}$ & $\mathrm{V}$ & $\mathrm{E}$ & $M_{\min }$ & $M_{\max }$ & $M$ scale & $d_{\min }$ & $d_{\max }$ & $d$ scale & $\mathrm{S}$ & $\mathrm{C}$ & $\mathrm{R}$ & $\mathrm{M}$ \\
\hline $\begin{array}{l}\text { Trifunac and } \\
\text { Brady (1975), Tri- } \\
\text { funac (1976) \& } \\
\text { Trifunac and } \\
\text { Brady (1976) }\end{array}$ & W. USA & 181 & 181 & 57 & 3.8 & 7.7 & $\begin{array}{l}\text { Mostly } \\
M_{L}\end{array}$ & $6^{5 *}$ & $400^{6}$ & $* d_{e}$ & 3 & $\mathrm{~B}$ & $\mathrm{O}$ & $\mathrm{A}$ \\
\hline Blume (1977) & $\begin{array}{l}\text { California \& } \\
\text { W. Nevada }\end{array}$ & $795^{7}$ & - & $\mathrm{U}$ & $\mathrm{U}$ & $\mathrm{U}$ & $M_{L}$ & $\mathrm{U}$ & $\mathrm{U}$ & $d_{h}$ & $\begin{array}{l}2 \\
(1)\end{array}$ & B & $\mathrm{U}$ & $\mathrm{A}$ \\
\hline McGuire (1977) & W. USA & 34 & - & 22 & 5.3 & 7.6 & $M_{L}$ & 14 & 125 & $d_{h}$ & 1 & B & $\mathrm{U}$ & $\mathrm{A}$ \\
\hline Milne (1977) & W. USA & $200^{*}$ & - & $\mathrm{U}$ & 3.5 & 7.7 & $\mathrm{U}$ & 1 & 380 & $d_{h}$ & 1 & $\mathrm{U}$ & $\mathrm{U}$ & $\mathrm{A}$ \\
\hline $\begin{array}{l}\text { Donovan and } \\
\text { Bornstein (1978) }\end{array}$ & W. USA & 59 & - & 10 & 5.0 & 7.7 & $\mathrm{U}^{8}$ & 0.1 & 321 & $\begin{array}{l}d_{E}, \quad d_{r} \\
\text { and } d_{h}\end{array}$ & 1 & $\mathrm{~B}$ & $\mathrm{O}$ & $\mathrm{A}$ \\
\hline
\end{tabular}

continued on next page

\footnotetext{
5 Note only valid for $R \geq 20 \mathrm{~km}$

6 Note only valid for $R \leq 200 \mathrm{~km}$

7 Total earthquake components (does not need to be multiplied by two) for magnitude and distance dependence. Uses 2713 underground nuclear explosion records for site dependence.

8 Idriss (1978) finds magnitudes to be mixture of $M_{L}$ and $M_{s}$.
} 
Table A.1: continued

\begin{tabular}{|c|c|c|c|c|c|c|c|c|c|c|c|c|c|c|}
\hline Reference & Area & $\mathrm{H}$ & $\mathrm{V}$ & $\mathrm{E}$ & $M_{\min }$ & $M_{\max }$ & $M$ scale & $d_{\min }$ & $d_{\max }$ & $d$ scale & $\mathrm{S}$ & $\mathrm{C}$ & $\mathrm{R}$ & $\mathrm{M}$ \\
\hline Faccioli (1978) & $\begin{array}{l}\text { Mostly W. } \\
\text { USA \& Japan, } \\
\text { some foreign }\end{array}$ & $47^{9}$ & - & 23 & 4.9 & 7.8 & $\mathrm{U}^{10}$ & 15 & 342 & $d_{h}$ & 1 & $\mathrm{~B}$ & $\mathrm{U}$ & $\mathrm{A}$ \\
\hline McGuire (1978) & W. USA & 70 & - & $17+^{*}$ & $4.5^{*}$ & 7.7 & $\mathrm{U}^{11}$ & $11^{*}$ & $210^{*}$ & $d_{h}$ & 2 & $\mathrm{~B}$ & $\mathrm{U}$ & $\mathrm{A}$ \\
\hline $\begin{array}{l}\text { A. Patwardhan et } \\
\text { al. }(1978)^{12}\end{array}$ & Worldwide & $63(32)$ & - & $\begin{array}{l}25 \\
(23)\end{array}$ & $4(5.3)$ & $\begin{array}{l}7.7 \\
(7.8)\end{array}$ & $M_{s}$ & $\mathrm{U}$ & $\mathrm{U}$ & $d_{r}$ & 2 & B & $\mathrm{U}$ & $\mathrm{A}$ \\
\hline $\begin{array}{l}\text { Cornell et al. } \\
(1979)\end{array}$ & W. USA & 70 & - & $\mathrm{U}$ & $\mathrm{U}$ & $\mathrm{U}$ & $M_{L}$ & $\mathrm{U}$ & $\mathrm{U}$ & $d_{h}$ & 1 & $\mathrm{C}$ & $\mathrm{U}$ & A \\
\hline $\begin{array}{lr}\text { Aptikaev and } \\
\text { Kopnichev (1980) }\end{array}$ & Worldwide & $\begin{array}{l}\text { Many } \\
100 \mathrm{~s}\end{array}$ & - $\left(70^{*}\right)$ & $\begin{array}{l}\mathrm{U} \\
(59)\end{array}$ & $\overline{\mathrm{U}}$ & $\mathrm{U}$ & $\mathrm{U}$ & $\overline{\mathrm{U}}$ & $\mathrm{U}$ & $d_{h}$ & 1 & $\mathrm{U}$ & $\mathrm{U}$ & $\begin{array}{lr}\text { A } & (\mathrm{T}, \\
\text { TS, } & \text { S, } \\
\text { SN, } & \\
\text { N) }{ }^{13} & \end{array}$ \\
\hline Blume (1980) & W. USA & 816 & - & $\mathrm{U}$ & 2.1 & 7.6 & $\mathrm{U}$ & 0 & 449 & $d_{h}$ & 1 & $\mathrm{~B}$ & $\begin{array}{l}1 \\
\mathrm{O}\end{array}$ & $\mathrm{A}$ \\
\hline
\end{tabular}

continued on next page

$\overline{9}$ Total earthquake components (does not need to be multiplied by two)

${ }^{10}$ Idriss (1978) believes majority are $M_{s}$.

${ }^{11}$ Idriss (1978) finds magnitudes to be mixture of $M_{L}, m_{b}$ and $M_{s}$.

${ }^{12}$ Reported in Idriss (1978).

${ }^{13}$ Assume dip-slip means normal mechanism. 
Table A.1: continued

\begin{tabular}{|c|c|c|c|c|c|c|c|c|c|c|c|c|c|}
\hline Reference & Area & $\mathrm{H}$ & $\mathrm{V}$ & $\mathrm{E}$ & $M_{\min }$ & $M_{\max }$ & $M$ scale & $d_{\min }$ & $d_{\max } d$ scale & $\mathrm{S}$ & $\mathrm{C}$ & $\mathrm{R}$ & M \\
\hline $\begin{array}{l}\text { Iwasaki et al. } \\
(1980)\end{array}$ & Japan & 301 & - & 51 & $>5.0$ & $<7.9$ & $M_{L}^{14}$ & $<20$ & $>200 d_{e}$ & 4 & $\mathrm{U}$ & 1 & $\mathrm{~A}$ \\
\hline $\begin{array}{l}\text { Ohsaki et al. } \\
(1980 b)\end{array}$ & Japan & 75 & 75 & $\mathrm{U}$ & 4 & 7.4 & $\mathrm{U}$ & 6 & $500 \quad d_{h}$ & 1 & $\mathrm{U}$ & 1 & $\mathrm{~A}$ \\
\hline Campbell (1981) & $\begin{array}{l}\text { W. USA+8 } \\
\text { foreign }\end{array}$ & 116 & - & 27 & 5.0 & 7.7 & $\begin{array}{l}M_{L} \text { for } \\
M<6.0 \\
\text { and } M_{s} \\
\text { other- } \\
\text { wise }\end{array}$ & 0.08 & $47.7 \quad d_{r}$ & 1 & M & $\mathrm{O}$ & $\mathrm{A}$ \\
\hline $\begin{array}{l}\text { Chiaruttini and } \\
\text { Siro (1981) }\end{array}$ & $\begin{array}{l}\text { Europe \& Mid. } \\
\text { East }\end{array}$ & 224 & - & 117 & 2.7 & 7.8 & $M_{L}\left(m_{b}\right)$ & 3 & $480 \quad d_{h}$ & 1 & $\mathrm{~L}$ & 1 & $\mathrm{~A}$ \\
\hline $\begin{array}{l}\text { Joyner and Boore } \\
\text { (1981) }\end{array}$ & W. N. America & 182 & - & 23 & 5.0 & 7.7 & $\begin{array}{l}M_{w} \\
\left(M_{L}\right)\end{array}$ & 0.5 & $370 \quad d_{f}$ & 2 & $\mathrm{~L}$ & 2 & $\mathrm{~A}$ \\
\hline $\begin{array}{l}\text { Bolt and Abra- } \\
\text { hamson }(1982)\end{array}$ & W. N. America & 182 & - & 23 & 5.0 & 7.7 & $\begin{array}{l}M_{w} \\
\left(M_{L}\right)\end{array}$ & 0.5 & $370 \quad d_{f}$ & 1 & $\mathrm{~L}$ & $\mathrm{O}$ & $\mathrm{A}$ \\
\hline PML (1982) & $\begin{array}{l}\text { Europe + USA } \\
+ \text { others }\end{array}$ & 113 & - & 32 & 4.3 & 8 & $M_{s}$ & 0.1 & $330 \quad d_{e}$ or $d_{f}$ & 1 & $\mathrm{U}$ & $\mathrm{U}$ & $\mathrm{A}$ \\
\hline Schenk (1982) & Unknown & 3500 & - & $\mathrm{U}$ & 2.5 & 6.5 & $M_{s}$ & 2 & $600 \quad d_{h}$ & 1 & $\mathrm{U}$ & $\mathrm{O}$ & $\mathrm{A}$ \\
\hline
\end{tabular}

continued on next page

$\overline{{ }^{14} \text { State }}$ that it is Richter magnitude which assume to be $M_{L}$ 
Table A.1: continued

\begin{tabular}{|c|c|c|c|c|c|c|c|c|c|c|c|c|c|c|}
\hline Reference & Area & $\mathrm{H}$ & $\mathrm{V}$ & $\mathrm{E}$ & $M_{\min }$ & $M_{\max }$ & $M$ scale & $d_{\min }$ & $d_{\max }$ & $d$ scale & $\mathrm{S}$ & $\mathrm{C}$ & $\mathrm{R}$ & M \\
\hline $\begin{array}{l}\text { Joyner and Fumal } \\
(1984)\end{array}$ & W. N. America & 182 & - & 23 & 5.0 & 7.7 & $\begin{array}{l}M_{w} \\
\left(M_{L}\right)\end{array}$ & 0.5 & 370 & $d_{f}$ & $\mathrm{C}$ & $\mathrm{L}$ & 2 & $\mathrm{~A}$ \\
\hline $\begin{array}{l}\text { Kawashima } \\
\text { et al. (1984) \& } \\
\text { Kawashima et al. } \\
(1986)\end{array}$ & Japan & 197 & - & 90 & 5.0 & 7.9 & $M_{\mathrm{JMA}}$ & $5^{*}$ & $550^{*}$ & $d_{e}$ & 3 & $\mathrm{R}$ & 1 & $\mathrm{~A}$ \\
\hline $\begin{array}{l}\text { McCann Jr. and } \\
\text { Echezwia (1984) }\end{array}$ & $\begin{array}{l}\text { N. America + } \\
\text { foreign }\end{array}$ & 83 & - & 18 & $5.0+$ & $\mathrm{U}$ & $M_{w}$ & $\mathrm{U}$ & $\mathrm{U}$ & $d_{r}$ & 1 & $\mathrm{U}$ & $\mathrm{O}$ & $\mathrm{A}$ \\
\hline Schenk (1984) & Unknown & 3500 & - & $\mathrm{U}$ & 2.5 & 6.5 & $\mathrm{U}$ & 2 & 600 & $d_{h}$ & 1 & $\mathrm{U}$ & $\mathrm{O}$ & $\mathrm{A}$ \\
\hline Xu et al. (1984) & N. China & 19 & - & 10 & 4.5 & 7.8 & $\begin{array}{l}M_{w}\left(M_{L}\right. \\
\text { for } M< \\
6.0, \quad M_{s} \\
\text { for } M \geq \\
6.0)\end{array}$ & 10.1 & 157 & $d_{e}$ & 1 & $\mathrm{~L}$ & 1 & $\mathrm{~A}$ \\
\hline $\begin{array}{l}\text { Kawashima et al. } \\
(1985)\end{array}$ & Japan & - & 119 & $90^{*}$ & $5.0^{*}$ & $7.5^{*}$ & $M_{\mathrm{JMA}}$ & $5^{*}$ & $500^{*}$ & $d_{e}$ & 3 & - & 1 & $\mathrm{~A}$ \\
\hline Peng et al. (1985) & N.E. China & 73 & - & 20 & 3.7 & 7.8 & $M_{C}$ & 2 & 442.5 & $d_{e}$ & 1 & $\mathrm{U}$ & 1 & $\mathrm{~A}$ \\
\hline PML (1985) & $\begin{array}{l}\text { USA + Europe } \\
+ \text { others }\end{array}$ & 203 & - & 46 & 3.1 & 6.9 & $M_{s}$ & 0.1 & 40 & $d_{r}$ & 1 & $\mathrm{U}$ & $\mathrm{U}$ & $\mathrm{A}(\mathrm{S}, \mathrm{T})$ \\
\hline
\end{tabular}


Table A.1: continued

\begin{tabular}{|c|c|c|c|c|c|c|c|c|c|c|c|c|c|c|}
\hline Reference & Area & $\mathrm{H}$ & $\mathrm{V}$ & $\mathrm{E}$ & $M_{\min }$ & $M_{\max }$ & $M$ scale & $d_{\min }$ & $d_{\max }$ & $d$ scale & $\mathrm{S}$ & $\mathrm{C}$ & $\mathrm{R}$ & $\mathrm{M}$ \\
\hline McCue (1986) & E. Australia & $\mathrm{U}$ & - & $\mathrm{U}$ & 1.7 & 5.4 & $M_{L}$ & 2.5 & 134 & $d_{h}$ & 1 & $\mathrm{U}$ & $\mathrm{U}$ & $\mathrm{A}$ \\
\hline $\begin{array}{ll}\text { C.B. } & \text { Crouse } \\
(1987)^{15} & \end{array}$ & S. California & $\mathrm{U}$ & - & $\mathrm{U}$ & $\mathrm{U}$ & $\mathrm{U}$ & $M_{s}$ & $\mathrm{U}$ & $\mathrm{U}$ & $d_{r}$ & 1 & B & $\mathrm{U}$ & $\mathrm{A}$ \\
\hline $\begin{array}{l}\text { Sabetta and } \\
\text { Pugliese (1987) }\end{array}$ & Italy & 95 & - & 17 & 4.6 & 6.8 & $\begin{array}{l}M_{s} \quad \text { for } \\
M \quad \geq \\
5.5, \quad M_{L} \\
\text { other- } \\
\text { wise }\end{array}$ & $\begin{array}{l}1.5 \\
1.5\end{array}$ & $\begin{array}{l}179 \\
180\end{array}$ & $\begin{array}{l}\text { Both } d_{f} \\
\& d_{e}\end{array}$ & 2 & $\mathrm{~L}$ & 1 & $\mathrm{~A}$ \\
\hline $\begin{array}{ll}\text { K. } & \text { Sadigh } \\
(1987)^{16} & \\
\end{array}$ & $\begin{array}{l}\text { W. USA + } \\
\text { others }\end{array}$ & $\mathrm{U}$ & - & $\mathrm{U}$ & $\mathrm{U}$ & $\mathrm{U}$ & $M_{w}$ & $\mathrm{U}$ & $\mathrm{U}$ & $d_{r}$ & 2 & B & $\mathrm{U}$ & $\mathrm{A}(\mathrm{S}, \mathrm{R})$ \\
\hline Singh et al. (1987) & Mexico & 16 & - & 16 & 5.6 & 8.1 & $M_{s}$ & 282 & 466 & $d_{r}$ & 1 & $\mathrm{U}$ & 1 & $\mathrm{~A}$ \\
\hline $\begin{array}{l}\text { Algermissen et al. } \\
(1988)\end{array}$ & $\begin{array}{l}\text { Vicinity of San } \\
\text { Salvador }\end{array}$ & 82 & - & $\mathrm{U}$ & $\mathrm{U}$ & $\mathrm{U}$ & $M_{s}$ & $\mathrm{U}$ & $\mathrm{U}$ & $d_{h}$ & 1 & M & $\mathrm{U}$ & $\mathrm{A}$ \\
\hline $\begin{array}{l}\text { Annaka and } \\
\text { Nozawa (1988) }\end{array}$ & Japan & $\mathrm{U}$ & - & 45 & $\mathrm{U}$ & $\mathrm{U}$ & $\mathrm{U}$ & $\mathrm{U}$ & $\mathrm{U}$ & $\overline{\mathrm{U}}$ & 1 & $\mathrm{U}$ & 1 & $\mathrm{~A}$ \\
\hline
\end{tabular}

$\overline{15}$ Reported in Joyner and Boore (1988).

${ }^{16}$ Reported in Joyner and Boore (1988). 
Table A.1: continued

\begin{tabular}{|c|c|c|c|c|c|c|c|c|c|c|c|c|c|c|}
\hline Reference & Area & $\mathrm{H}$ & $\mathrm{V}$ & $\mathrm{E}$ & $M_{\min }$ & $M_{\max }$ & $M$ scale & $d_{\min }$ & $d_{\max }$ & $d$ scale & $\mathrm{S}$ & $\mathrm{C}$ & $\mathrm{R}$ & M \\
\hline $\begin{array}{l}\text { K.W. Campbell } \\
(1988)^{17}\end{array}$ & Worldwide & $\mathrm{U}$ & - & $\mathrm{U}$ & $\geq 5$ & $\mathrm{U}$ & $\begin{array}{l}M_{L} \text { for } \\
M<6.0 \\
\text { and } M_{s} \\
\text { other- } \\
\text { wise }\end{array}$ & $\mathrm{U}$ & $<50$ & $d_{s}$ & 2 & $\mathrm{M}$ & $\mathrm{U}$ & $\mathrm{A}(\mathrm{S}, \mathrm{R})$ \\
\hline $\begin{array}{l}\text { Fukushima } \\
\text { et al. (1988) } \\
\text { \& Fukushima and } \\
\text { Tanaka (1990) }\end{array}$ & $\begin{array}{l}\text { Japan+200 W. } \\
\text { USA }\end{array}$ & $486+200$ & - & $28+15$ & $4.6(5.0)$ & $8.2(7.7)$ & $\begin{array}{l}M_{s} \\
\left(M_{\mathrm{JMA}}\right)\end{array}$ & $\begin{array}{l}16 \\
(0.1)\end{array}$ & $\begin{array}{l}303 \\
(48)\end{array}$ & $\begin{array}{l}d_{h}, \\
d_{r} \text { for } 2 \\
\text { Japanese } \\
\& \text { all US }\end{array}$ & 4 & $\mathrm{G}$ & 2 & $\mathrm{~A}$ \\
\hline Gaull (1988) & $\begin{array}{l}\text { S.W. W. Aus- } \\
\text { tralia }\end{array}$ & $25+$ & - & $12+$ & 2.6 & 6.9 & $M_{L}$ & 2.5 & 175 & $d_{h}$ & 1 & $\mathrm{U}$ & $\mathrm{O}$ & $\mathrm{A}$ \\
\hline $\begin{array}{l}\text { Joyner and Boore } \\
(1988)\end{array}$ & W. N. America & 182 & - & 23 & 5.0 & 7.7 & $\begin{array}{l}M_{w} \\
\left(M_{L}\right) \\
\end{array}$ & 0.5 & 370 & $d_{f}$ & 2 & $\begin{array}{l}\mathrm{L}, \\
\mathrm{O}\end{array}$ & $2 \mathrm{~W}$ & A \\
\hline $\begin{array}{l}\text { McCue et al. } \\
(1988)\end{array}$ & S.E. Australia & 62 & - & $\mathrm{U}$ & $0.5^{*}$ & $6^{*}$ & $M_{L}$ & $5^{*}$ & 833 & $d_{e}$ & 1 & $\mathrm{U}$ & $\mathrm{O}$ & $\mathrm{A}$ \\
\hline $\begin{array}{l}\text { Petrovski and } \\
\text { Marcellini (1988) }\end{array}$ & Europe & 120 & - & 46 & 3 & 7 & $\mathrm{U}$ & 8 & 200 & $d_{h}$ & 1 & $\mathrm{~L}$ & $\mathrm{U}$ & $\mathrm{A}$ \\
\hline
\end{tabular}

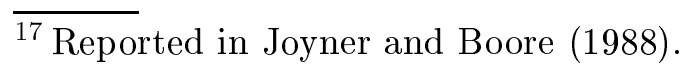


Table A.1: continued

\begin{tabular}{|c|c|c|c|c|c|c|c|c|c|c|c|c|c|c|}
\hline Reference & Area & $\mathrm{H}$ & $\mathrm{V}$ & $\mathrm{E}$ & $M_{\min }$ & $M_{\max }$ & $M$ scale & $d_{\min }$ & $d_{\max }$ & $d$ scale & $\mathrm{S}$ & $\mathrm{C}$ & $\mathrm{R}$ & M \\
\hline $\begin{array}{l}\text { Tong and } \\
\text { Katayama (1988) }\end{array}$ & Kanto (Japan) & $<227$ & - & $<27$ & $4.5^{*}$ & $7.9^{*}$ & $\mathrm{U}$ & $10^{*}$ & $750^{*}$ & $d_{e}$ & $\mathrm{C}$ & $\mathrm{L}$ & $\mathrm{O}$ & $\mathrm{A}$ \\
\hline $\begin{array}{l}\text { Yamabe and } \\
\text { Kanai (1988) }\end{array}$ & Japan & $\mathrm{U}$ & - & 22 & 5.3 & 7.9 & $\mathrm{U}$ & $\mathrm{U}$ & $\mathrm{U}$ & $d_{h}$ & 1 & $\mathrm{U}$ & $\mathrm{O}$ & $\mathrm{A}$ \\
\hline $\begin{array}{l}\text { Youngs et al. } \\
(1988)\end{array}$ & $\begin{array}{l}\text { Worldwide } \\
\text { subduction } \\
\text { zones }\end{array}$ & $197+389$ & - & 60 & 5 & $\begin{array}{l}8.1 \\
(8.2)^{18}\end{array}$ & $\begin{array}{l}M_{w}\left(M_{s},\right. \\
\left.m_{b}\right)\end{array}$ & $\begin{array}{l}15^{*} \\
\left(20^{*}\right) \\
\end{array}$ & $\begin{array}{l}450^{*} \\
\left(450^{*}\right.\end{array}$ & $\begin{array}{l}d_{r}, d_{h} \text { for } \\
M_{w} \lesssim \\
7.5\end{array}$ & 1 & $\mathrm{G}$ & $1 \mathrm{~W}$ & $\mathrm{~A}(\mathrm{~B}, \mathrm{~F})$ \\
\hline $\begin{array}{l}\text { Abrahamson and } \\
\text { Litehiser (1989) }\end{array}$ & $\begin{array}{l}75 \%+\text { Califor- } \\
\text { nia, rest for- } \\
\text { eign }\end{array}$ & 585 & 585 & 76 & 5.0 & 8.1 & $\begin{array}{l}M_{s} \quad \text { for } \\
M_{s} \quad \geq \\
6.0, \quad M_{L} \\
\left(m_{b}\right) \\
\text { other- } \\
\text { wise }\end{array}$ & 0.08 & 400 & $d_{r}$ & 1 & $\mathrm{~L}$ & $\mathrm{O}$ & $\begin{array}{l}\mathrm{A}(\mathrm{R} \& \\
\mathrm{RO}, \mathrm{I})\end{array}$ \\
\hline Campbell (1989) & $\begin{array}{l}\text { W. N. America } \\
+3 \text { from Man- } \\
\text { agua }\end{array}$ & 190 & - & 91 & 2.9 & 5.0 & $M_{L}$ & 0.6 & 18.3 & $d_{e}$ & 1 & M & $\mathrm{O}$ & $\mathrm{A}$ \\
\hline $\begin{array}{l}\text { Alfaro et al. } \\
(1990)\end{array}$ & $\begin{array}{l}\text { Guatemala, } \\
\text { Nicaragua \& } \\
\text { El Salvador }\end{array}$ & 20 & - & 12 & 4.1 & 7.5 & $M_{s}$ & 1 & 27 & $d_{e}$ & 1 & $\mathrm{~L}$ & $\mathrm{U}$ & $\mathrm{A}$ \\
\hline
\end{tabular}

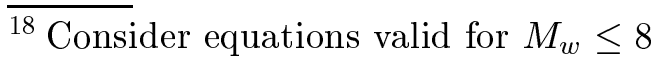


Table A.1: continued

\begin{tabular}{|c|c|c|c|c|c|c|c|c|c|c|c|c|c|c|}
\hline Reference & Area & $\mathrm{H}$ & $\mathrm{V}$ & $\mathrm{E}$ & $M_{\min }$ & $M_{\max }$ & $M$ scale & $d_{\min }$ & $d_{\max }$ & $d$ scale & $\mathrm{S}$ & $\mathrm{C}$ & $\mathrm{R}$ & $\mathrm{M}$ \\
\hline Ambraseys (1990) & W. N. America & 182 & - & 23 & 5.03 & 7.7 & $\begin{array}{l}M_{w} \\
\left(M_{L}\right)\end{array}$ & 0.5 & 370 & $d_{f}$ & 2 & $\mathrm{~L}$ & 2 & $\mathrm{~A}$ \\
\hline Campbell (1990) & Unknown & $\mathrm{U}$ & - & $\mathrm{U}$ & $\mathrm{U}$ & $\mathrm{U}$ & $\begin{array}{l}M_{L} \text { for } \\
M<6 \\
M_{s} \text { for } \\
M \geq 6\end{array}$ & $\mathrm{U}$ & $\mathrm{U}$ & $d_{s}$ & 1 & $\mathrm{U}$ & $\mathrm{U}$ & $\mathrm{A}$ \\
\hline $\begin{array}{l}\text { Dahle et al. } \\
\text { (1990b) \& Dahle } \\
\text { et al. (1990a) }\end{array}$ & $\begin{array}{l}\text { Worldwide } \\
\text { intraplate } \\
\text { regions }\end{array}$ & 87 & - & 56 & 2.9 & 7.8 & $\begin{array}{l}M_{s}\left(M_{L},\right. \\
m_{b} \\
\left.M_{C L}\right)\end{array}$ & 6 & 1300 & $d_{h}$ & 1 & $\mathrm{~L}$ & 2 & A \\
\hline $\begin{array}{lll}\text { Jacob } & \text { et } & \text { al. } \\
(1990) & & \end{array}$ & E. N. America & $\mathrm{U}$ & - & 8 & 1.8 & 6.4 & $m_{b}$ & $\begin{array}{l}\leq \\
20\end{array}$ & 820 & $\mathrm{U}^{19}$ & 1 & $\mathrm{U}$ & $\mathrm{O}$ & $\mathrm{A}$ \\
\hline Sen (1990) & $\begin{array}{l}\text { Whittier Nar- } \\
\text { rows area }\end{array}$ & $72^{*}$ & - & 11 & 2.2 & 3.5 & $M_{L}$ & $12^{*}$ & $21^{*}$ & $d_{h}$ & 1 & $\mathrm{U}$ & $1 \mathrm{M}$ & $\mathrm{A}(\mathrm{T})$ \\
\hline $\begin{array}{l}\text { Sigbjörnsson } \\
(1990)\end{array}$ & Iceland & $\mathrm{U}$ & - & $\mathrm{U}$ & $\mathrm{U}$ & $5.8^{20}$ & $\mathrm{U}$ & $\mathrm{U}$ & $\mathrm{U}$ & $d_{f}$ & 1 & $\mathrm{U}$ & $\mathrm{U}$ & $\mathrm{A}$ \\
\hline Tsai et al. (1990) & Worldwide & $<217$ & - & $<51$ & $4.9^{*}$ & 7.4 & $M_{w}$ & $3^{*}$ & $150^{*}$ & $d_{r}$ & 1 & $\mathrm{M}$ & $\mathrm{U}$ & $\mathrm{T}(\mathrm{S}, \mathrm{O})$ \\
\hline
\end{tabular}

continued on next page

$\overline{19}$ Free (1996) believes it is $d_{h}$.

${ }^{20}$ This is $M_{s}$. 
Table A.1: continued

\begin{tabular}{|c|c|c|c|c|c|c|c|c|c|c|c|c|c|c|}
\hline Reference & Area & $\mathrm{H}$ & $\mathrm{V}$ & $\mathrm{E}$ & $M_{\min }$ & $M_{\max }$ & $M$ scale & $d_{\min }$ & $d_{\max }$ & $d$ scale & $\mathrm{S}$ & $\mathrm{C}$ & $\mathrm{R}$ & $\mathrm{M}$ \\
\hline $\begin{array}{l}\text { Ambraseys and } \\
\text { Bommer (1991) } \\
\text { \& Ambraseys and } \\
\text { Bommer (1992) }\end{array}$ & $\begin{array}{l}\text { Europe \& Mid. } \\
\text { East }\end{array}$ & 529 & 459 & $\begin{array}{l}\mathrm{H}: 219, \\
\mathrm{~V}: 191\end{array}$ & 4 & 7.34 & $M_{s}$ & 1 & $\begin{array}{l}\mathrm{H}: 313 \\
\mathrm{~V}: 214 \\
\end{array}$ & $\begin{array}{l}3, d_{f} \quad \text { for } \\
4 M_{s} \quad \gtrsim \\
6.0, \quad d_{e} \\
\text { other- } \\
\text { wise }\end{array}$ & 1 & $\mathrm{~L}$ & $\begin{array}{l}1, \\
2\end{array}$ & $\mathrm{~A}$ \\
\hline Crouse (1991) & $\begin{array}{l}\text { Worldwide } \\
\text { subduction } \\
\text { zones }\end{array}$ & $697^{21}$ & - & $\mathrm{U}$ & 4.8 & 8.2 & $\begin{array}{l}M_{w}\left(M_{s}\right. \\
\left.M_{\mathrm{JMA}}\right)\end{array}$ & $>8$ & $>866$ & $\begin{array}{l}d_{E}, \\
d_{h} \quad \text { for } \\
M<7.5\end{array}$ & 1 & $\mathrm{~B}$ & 1 & $\mathrm{~A}$ \\
\hline $\begin{array}{l}\text { Huo and } \mathrm{Hu} \\
(1991)\end{array}$ & $\begin{array}{l}\text { W. USA with } \\
25 \text { foreign }\end{array}$ & $383+25$ & - & $14+2$ & 5.0 & $\begin{array}{l}7.4 \\
(7.3)\end{array}$ & $\begin{array}{l}M_{L} \quad \text { or } \\
m_{b} \text { for } \\
M<6.0 \\
\text { and } M_{s} \\
\text { other- } \\
\text { wise }\end{array}$ & 0.1 & $\begin{array}{l}227 \\
(265)\end{array}$ & $d_{f}$ & 2 & B & $\mathrm{O}$ & $\mathrm{A}$ \\
\hline $\begin{array}{l}\text { I.M. Idriss (1991) } \\
\text { reported in Idriss } \\
(1993)\end{array}$ & Unknown & 572 & - & $30^{*}$ & 4.6 & 7.4 & $\begin{array}{l}M_{L} \text { for } \\
M<6 \\
M_{s} \quad \text { for } \\
M \geq 6\end{array}$ & 1 & 100 & $\begin{array}{l}d_{r}, d_{h} \text { for } \\
M<6\end{array}$ & 1 & $\mathrm{U}$ & $\mathrm{U}$ & $\mathrm{A}$ \\
\hline
\end{tabular}

continued on next page

$\overline{{ }^{21} \text { Total }}$ number of components, does not need to be multiplied by two. 
Table A.1: continued

\begin{tabular}{|c|c|c|c|c|c|c|c|c|c|c|c|c|c|}
\hline Reference & Area & $\mathrm{H}$ & $\mathrm{V}$ & $\mathrm{E}$ & $M_{\min }$ & $M_{\max }$ & $M$ scale & $d_{\min }$ & $d_{\max } d$ scale & $\mathrm{S}$ & $\mathrm{C}$ & $\mathrm{R}$ & M \\
\hline $\begin{array}{l}\text { Niazi and Bozorg- } \\
\text { nia (1991) }\end{array}$ & $\begin{array}{l}\text { SMART-1 ar- } \\
\text { ray, Taiwan }\end{array}$ & 236 & 234 & 12 & 3.6 & 7.8 & $\begin{array}{l}M_{L} \\
\left(M_{D}\right) \\
\text { for } \\
M_{L} \quad< \\
6.6, \text { else } \\
M_{s}\end{array}$ & $3.1^{22}$ & $119.7^{2} z_{h}$ & 1 & $\mathrm{M}$ & $2 \mathrm{~W}$ & $\mathrm{~A}$ \\
\hline $\begin{array}{l}\text { Ambraseys et al. } \\
(1992)\end{array}$ & $\begin{array}{l}\text { USA }+ \text { Europe } \\
+ \text { others }\end{array}$ & 504 & - & 45 & 3.1 & 6.87 & $M_{s}$ & 0.5 & $\begin{array}{l}d_{f}, d_{e} \text { for } \\
\text { some }\end{array}$ & 1 & $\mathrm{~L}$ & 1 & $\mathrm{~A}$ \\
\hline $\begin{array}{l}\text { Kamiyama } \\
\text { et al. (1992) } \\
\& \quad \text { Kamiyama } \\
(1995)\end{array}$ & Japan & 357 & - & 82 & 4.1 & 7.9 & $M_{\mathrm{JMA}}$ & 3.4 & $413.3 d_{h}$ & $\mathrm{I}$ & B & $\mathrm{O}$ & $\mathrm{A}$ \\
\hline $\begin{array}{l}\text { Sigbjörnsson } \\
\text { and Baldvinsson } \\
(1992)\end{array}$ & Iceland & 262 & - & 39 & 2.0 & 6.0 & $\mathrm{U}$ & 2 & 80 & 2 & $\mathrm{~B}, \mathrm{~L}$ & 2 & $\mathrm{~A}$ \\
\hline $\begin{array}{l}\text { Taylor Castillo } \\
\text { et al. (1992) }\end{array}$ & $\begin{array}{ll}\text { Nicaragua, } & \text { El } \\
\text { Salvador } & \& \\
\text { Costa Rica } & \end{array}$ & 89 & - & 27 & 3.0 & 7.6 & $M_{s}$ & 6 & $210 \quad d_{h}$ & 1 & $\mathrm{~L}$ & $\mathrm{U}$ & $\mathrm{A}$ \\
\hline
\end{tabular}

$\overline{{ }^{22} \text { Distance to centre of array }}$ 
Table A.1: continued

\begin{tabular}{|c|c|c|c|c|c|c|c|c|c|c|c|c|c|c|}
\hline Reference & Area & $\mathrm{H}$ & $\mathrm{V}$ & $\mathrm{E}$ & $M_{\min }$ & $M_{\max }$ & $M$ scale & $d_{\min }$ & $d_{\max }$ & $d$ scale & $\mathrm{S}$ & $\mathrm{C}$ & $\mathrm{R}$ & M \\
\hline $\begin{array}{l}\text { Tento et al. } \\
(1992)\end{array}$ & Italy & 137 & - & 40 & 4 & 6.6 & $M_{L}$ & 3.2 & 170 & $\begin{array}{l}d_{f} \quad \text { for } \\
M_{L} \quad \geq \\
5.7, \quad d_{e} \\
\text { other- } \\
\text { wise }\end{array}$ & 1 & $\mathrm{~L}$ & 2 & $\mathrm{~A}$ \\
\hline $\begin{array}{l}\text { Theodulidis } \\
\text { and Papazachos } \\
(1992)\end{array}$ & $\begin{array}{l}\text { Greece+16 for- } \\
\text { eign }\end{array}$ & $105+16^{23}$ & & $36+4$ & $\begin{array}{l}4.5 \\
(7.2)\end{array}$ & $\begin{array}{l}7.0 \\
(7.5)\end{array}$ & $\begin{array}{l}M_{s}, M_{w}, \\
M_{\mathrm{JMA}}\end{array}$ & $\begin{array}{l}1 \\
(48)\end{array}$ & $\begin{array}{l}128 \\
(236)\end{array}$ & $d_{e}$ & 2 & $\mathrm{~B}$ & $\mathrm{O}$ & $\mathrm{A}$ \\
\hline $\begin{array}{l}\text { Boore et al. } \\
(1993) \& \text { Boore } \\
\text { et al. }(1997)\end{array}$ & W. N. America & 271 & - & 20 & $5.1^{24}$ & 7.7 & $M_{w}$ & 0 & 118.2 & $d_{f}$ & 3 & $\begin{array}{l}\mathrm{L}, \\
\mathrm{G}\end{array}$ & $2 \mathrm{M}$ & $\mathrm{A}$ \\
\hline Campbell (1993) & Worldwide & $\mathrm{U}$ & - & $\mathrm{U}$ & $\mathrm{U}^{25}$ & $\mathrm{U}$ & $\begin{array}{l}M_{L} \quad \text { for } \\
M<6.0 \\
\text { and } M_{s} \\
\text { other- } \\
\text { wise }\end{array}$ & $\mathrm{U}$ & $\mathrm{U}^{26}$ & $d_{s}$ & 2 & M & $\mathrm{O}$ & $\mathrm{A}(\mathrm{T}, \mathrm{S})$ \\
\hline
\end{tabular}

continued on next page

$\overline{23}$ Total number of components does not need to be multiplied by two

${ }^{24}$ Boore et al. (1997) revise this magnitude to 5.87. New minimum magnitude is 5.2.

${ }^{25}$ Considers equation valid for $M \geq 4.7$.

${ }^{26}$ Considers equation valid for $d \leq 300 \mathrm{~km}$. 
Table A.1: continued

\begin{tabular}{|c|c|c|c|c|c|c|c|c|c|c|c|c|c|c|}
\hline Reference & Area & $\mathrm{H}$ & $\mathrm{V}$ & $\mathrm{E}$ & $M_{\min }$ & $M_{\max }$ & $M$ scale & $d_{\text {min }}$ & $d_{\max }$ & $d$ scale & S & $\mathrm{C}$ & $\mathrm{R}$ & $\mathrm{M}$ \\
\hline $\begin{array}{llr}\text { McVerry } & \text { et } & \text { al. } \\
(1993) & & \& \\
\text { McVerry } & \text { et } & \text { al. } \\
(1995) & & \end{array}$ & New Zealand & 256 & - & $31^{*}$ & 5.1 & 7.3 & $M_{w}$ & 13 & 312 & $d_{c}$ or $d_{h}$ & 1 & $\mathrm{~L}$ & 1 & $\mathrm{~A}, \mathrm{R}$ \\
\hline $\begin{array}{l}\text { Sadigh et al. } \\
\text { (1993) \& Sadigh } \\
\text { et al. (1997) }\end{array}$ & $\begin{array}{l}\text { California with } \\
4 \text { foreign }\end{array}$ & $960+4$ & $\mathrm{U}$ & $119+2$ & $\begin{array}{l}3.8 \\
(6.8)\end{array}$ & $\begin{array}{l}7.4 \\
(7.4)\end{array}$ & $M_{w}$ & $\begin{array}{l}0.1 \\
(3)\end{array}$ & $\begin{array}{l}305 \\
(172)\end{array}$ & $\begin{array}{l}d_{r} \quad \text { for } \\
\text { 25ome, } d_{h} \\
\text { for small } \\
\text { ones }\end{array}$ & 2 & $\mathrm{G}$ & $\mathrm{U}$ & $\mathrm{A}(\mathrm{R}, \mathrm{S})$ \\
\hline Singh et al. (1993) & $\begin{array}{ll}\text { Nicaragua, } & \text { El } \\
\text { Salvador } & \& \\
\text { Costa Rica } & \end{array}$ & 89 & - & 27 & 3.0 & 7.6 & $M_{s}$ & 6 & 210 & $d_{h}$ & 1 & $\mathrm{~V}$ & $\mathrm{O}$ & $\mathrm{A}$ \\
\hline $\begin{array}{l}\text { Sun and Peng } \\
(1993)\end{array}$ & $\begin{array}{l}\text { W. USA with } 1 \\
\text { foreign }\end{array}$ & $150+1$ & - & $42+1$ & 4.1 & 7.7 & $\begin{array}{l}M_{L} \text { for } \\
M<6 \\
\text { else } M_{s}\end{array}$ & $2^{*}$ & $150^{*}$ & $d_{e}$ & $\mathrm{C}$ & $\mathrm{R}$ & 1 & $\mathrm{~A}$ \\
\hline $\begin{array}{l}\text { Boore et al. } \\
(1994 a) \& \text { Boore } \\
\text { et al. (1997) }\end{array}$ & W. N. America & $\begin{array}{l}271 \\
(70)\end{array}$ & - & $20(9)$ & $\begin{array}{l}5.1^{28} \\
(5.3)\end{array}$ & $\begin{array}{l}7.7 \\
(7.4)\end{array}$ & $M_{w}$ & 0 & $\begin{array}{l}118.2 \\
(109)\end{array}$ & & $\mathrm{C}$ & $\begin{array}{l}\mathrm{L}, \\
\mathrm{G}\end{array}$ & $\begin{array}{l}1 \mathrm{M}, \\
2 \mathrm{M}\end{array}$ & $\begin{array}{l}\mathrm{A} \\
(\mathrm{R}, \mathrm{S})^{29}\end{array}$ \\
\hline
\end{tabular}

continued on next page

${ }^{27}$ Equations stated to be for distances up to $100 \mathrm{~km}$

${ }^{28}$ Boore et al. (1997) revise this magnitude to 5.87. New minimum magnitude is 5.2.

${ }^{29}$ Coefficients given in Boore et al. (1994b) 
Table A.1: continued

\begin{tabular}{|c|c|c|c|c|c|c|c|c|c|c|c|c|c|}
\hline Reference & Area & $\mathrm{H}$ & $\mathrm{V}$ & $\mathrm{E}$ & $M_{\min }$ & $M_{\max }$ & $M$ scale & $d_{\min }$ & $d_{\max } d$ scale & $\mathrm{S}$ & $\mathrm{C}$ & $\mathrm{R}$ & $\mathrm{M}$ \\
\hline $\begin{array}{l}\text { Fukushima } \\
\text { et al. (1994) } \\
\text { \& Fukushima } \\
\text { et al. (1995) }\end{array}$ & $\begin{array}{l}3 \text { vertical ar- } \\
\text { rays in Japan }\end{array}$ & 285 & 284 & 42 & 5.0 & 7.7 & $M_{\mathrm{JMA}}$ & $60^{*}$ & $400^{*} \quad d_{h}$ & $\mathrm{I}$ & $\mathrm{B}$ & 1,2 & $\mathrm{~A}$ \\
\hline $\begin{array}{l}\text { Lawson } \quad \text { and } \\
\text { Krawinkler } \\
(1994)\end{array}$ & W. USA & $250+$ & - & 11 & 5.8 & 7.4 & $M_{w}$ & $\mathrm{U}$ & $100 \quad d_{f}$ & 3 & $\mathrm{U}$ & $1 \mathrm{M}$ & $\mathrm{A}$ \\
\hline $\begin{array}{l}\text { Lungu et al. } \\
(1994)\end{array}$ & Romania & $\approx 300$ & 125 & 4 & 6.3 & 7.4 & $M_{w}$ & $\mathrm{U}$ & $d_{h}$ & 1 & $\mathrm{U}$ & 1 & $\mathrm{~A}$ \\
\hline $\begin{array}{l}\text { Musson et al. } \\
(1994)\end{array}$ & $\begin{array}{l}\mathrm{UK}+30^{*} \text { for- } \\
\text { eign }\end{array}$ & $\begin{array}{l}15 \\
30^{*}\end{array}$ & - & $4+16$ & $3(3.7)$ & $\begin{array}{l}3.5 \\
(6.4)\end{array}$ & $M_{L}$ & $\begin{array}{l}70^{*} \\
(>1.3\end{array}$ & $\begin{array}{l}>477.4 l_{h} \\
\left(200^{*}\right)\end{array}$ & 1 & $\mathrm{U}^{30}$ & $\mathrm{O}$ & $\mathrm{A}$ \\
\hline $\begin{array}{l}\text { Radu et al. } \\
(1994), \quad \text { Lungu } \\
\text { et al. (1995a) } \\
\& \text { Lungu et al. } \\
(1996)\end{array}$ & Romania & 106 & - & 3 & $\begin{array}{l}6.7\left(M_{L}\right) \\
\text { or } \\
7.0\left(M_{w}\right)\end{array}$ & $\begin{array}{l}7.2\left(M_{L}\right) \\
\text { or } \\
7.5\left(M_{w}\right)\end{array}$ & $\mathrm{U}^{31}$ & $90^{*}$ & $320^{*} \quad d_{h}$ & 1 & $\mathrm{~L}$ & 1 & $\mathrm{~A}$ \\
\hline
\end{tabular}

continued on next page

$\overline{{ }^{30} \text { Free }}(1996)$ believes it is largest horizontal component.

${ }^{31} \mathrm{It}$ is not clear whether use Richter magnitude $\left(M_{L}\right)$ or $M_{w}$. 
Table A.1: continued

\begin{tabular}{|c|c|c|c|c|c|c|c|c|c|c|c|c|c|c|}
\hline Reference & Area & $\mathrm{H}$ & $\mathrm{V}$ & $\mathrm{E}$ & $M_{\min }$ & $M_{\max }$ & $M$ scale & $d_{\min }$ & $d_{\max }$ & $d$ scale & $\mathrm{S}$ & $\mathrm{C}$ & $\mathrm{R}$ & $\mathrm{M}$ \\
\hline $\begin{array}{l}\text { Ramazi and } \\
\text { Schenk (1994) }\end{array}$ & Iran & 83 & 83 & 20 & 5.1 & 7.7 & $M_{s}{ }^{32}$ & $\leq 8$ & $\begin{array}{l}\geq \\
180\end{array}$ & $\begin{array}{l}d_{h} \quad \text { for } \\
\text { most, } d_{r} \\
\text { for } 19^{33}\end{array}$ & 2 & $\mathrm{U}$ & $\mathrm{U}$ & $\mathrm{A}$ \\
\hline $\begin{array}{l}\text { Xiang and Gao } \\
(1994)\end{array}$ & $\begin{array}{l}\text { Yunnan, } \\
\text { China }+114 \\
\text { W. N. America }\end{array}$ & $131+114$ & - & $\mathrm{U}$ & $2.5^{*}$ & $7.6^{*}$ & $\begin{array}{l}M_{s} \\
\left(M_{L}\right)\end{array}$ & $2^{*}$ & $120^{*}$ & $d_{e}$ & 1 & $\mathrm{~L}$ & $\mathrm{U}$ & $\mathrm{A}$ \\
\hline Ambraseys (1995) & $\begin{array}{l}\text { Europe and } \\
\text { Mid. East }\end{array}$ & 830 & 620 & 334 & 4.0 & 7.3 & $M_{s}$ & $0^{*}$ & $260^{*}$ & $\begin{array}{l}d_{f} \quad \text { for } \\
M_{s} \quad> \\
6.0, \quad d_{e} \\
\text { other- } \\
\text { wise }\end{array}$ & 1 & $\mathrm{~L}$ & $2 \mathrm{~W}$ & A \\
\hline $\begin{array}{l}\text { Dahle et } \quad \text { al. } \\
(1995)\end{array}$ & Cen. America & 280 & - & 72 & $3^{*}$ & $8^{*}$ & $\begin{array}{l}M_{w}\left(M_{s},\right. \\
\left.m_{b}, M_{D}\right)\end{array}$ & $6^{*}$ & $490^{*}$ & $d_{h}$ & 2 & $\mathrm{~L}$ & $1 \mathrm{~B}$ & $\mathrm{~A}$ \\
\hline $\begin{array}{l}\text { Garcia-Fernandez } \\
\text { and Canas (1995) }\end{array}$ & Iberian Pen. & 57 & 367 & $\mathrm{U}$ & 3.1 & 5.0 & $M_{b L g}$ & $\mathrm{U}$ & $\mathrm{U}$ & $d_{e}$ & 1 & $\mathrm{U}$ & $\mathrm{U}$ & $\mathrm{A}$ \\
\hline
\end{tabular}

continued on next page

$\overline{32}$ Some may be $m_{b}$ because in their Table 1 some earthquakes to not have $M_{s}$ given but do have $m_{b}$. If so new minimum is 5.0 .

${ }^{33}$ They state it is 'closest distance from the exposure of ruptured part of the fault, instead of focal distances' so may not be rupture distance. 
Table A.1: continued

\begin{tabular}{|c|c|c|c|c|c|c|c|c|c|c|c|c|c|c|}
\hline Reference & Area & $\mathrm{H}$ & $\mathrm{V}$ & $\mathrm{E}$ & $M_{\min }$ & $M_{\max }$ & $M$ scale & $d_{\min }$ & $d_{\max }$ & $d$ scale & $\mathrm{S}$ & $\mathrm{C}$ & $\mathrm{R}$ & $\mathrm{M}$ \\
\hline Lee et al. (1995) & W. N. America & 1926 & 1926 & 297 & 1.7 & 7.7 & $\begin{array}{l}\text { Usually } \\
M_{L} \text { for } \\
M \leq 6.5 \\
\text { and } \\
M_{s} \text { for } \\
M>6.5\end{array}$ & 2 & $200+$ & $-d_{h}$ & $\begin{array}{l}9, \\
3 \\
\times \\
\mathrm{C}\end{array}$ & $\mathrm{U}$ & 1 & $\mathrm{~A}$ \\
\hline $\begin{array}{l}\text { Lungu } \\
(1995 b)\end{array}$ et al. & Romania & 106 & - & 3 & $\begin{array}{l}6.7\left(M_{L}\right) \\
\text { or } \\
7.0\left(M_{w}\right)\end{array}$ & $\begin{array}{l}7.2\left(M_{L}\right) \\
\text { or } \\
7.5\left(M_{w}\right)\end{array}$ & $\mathrm{U}^{34}$ & $\mathrm{U}$ & $\mathrm{U}$ & $d_{h}$ & 1 & $\mathrm{~L}$ & 1 & $\mathrm{~A}$ \\
\hline $\begin{array}{l}\text { Molas and Ya- } \\
\text { mazaki (1995) }\end{array}$ & Japan & 2166 & - & 387 & $4.1^{*}$ & $7.8^{*}$ & $M_{\mathrm{JMA}}$ & $8^{*}$ & $1000^{*}$ & $\begin{array}{l}* d_{r} \text { for } 2 \\
\text { earth- } \\
\text { quakes, } \\
d_{h} \text { oth- } \\
\text { erwise }\end{array}$ & $\mathrm{I}$ & $\mathrm{L}$ & $\mathrm{O}$ & $\mathrm{A}$ \\
\hline $\begin{array}{l}\text { Sarma and Free } \\
(1995)\end{array}$ & $\begin{array}{l}\text { E. N. Amer- } \\
\text { ica }\end{array}$ & 77 & - & 33 & 2.8 & 5.9 & $\begin{array}{l}M_{w}\left(m_{b}\right. \\
\left.M_{L}, M_{s}\right)\end{array}$ & 0 & 820 & $d_{f}$ or $d_{e}$ & 2 & $\mathrm{U}$ & 1 & $\mathrm{~A}$ \\
\hline
\end{tabular}

continued on next page

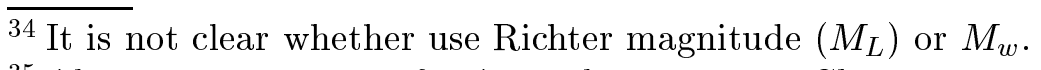

${ }^{35}$ Also derive equations for Australia and N. E. China 
Table A.1: continued

\begin{tabular}{|c|c|c|c|c|c|c|c|c|c|c|c|c|c|c|}
\hline Reference & Area & $\mathrm{H}$ & $\mathrm{V}$ & $\mathrm{E}$ & $M_{\min }$ & $M_{\max }$ & $M$ scale & $d_{\min }$ & $d_{\max }$ & $d$ scale & $\mathrm{S}$ & $\mathrm{C}$ & $\mathrm{R}$ & $\mathrm{M}$ \\
\hline $\begin{array}{l}\text { Ambraseys et al. } \\
(1996) \text { \& Simpson } \\
(1996)\end{array}$ & $\begin{array}{l}\text { Europe \& Mid. } \\
\text { East }\end{array}$ & 422 & - & 157 & 4.0 & 7.9 & $\begin{array}{l}M_{s} \\
\text { (unspec- } \\
\text { ified) }\end{array}$ & 0 & 260 & $\begin{array}{l}d_{f} \quad \text { for } \\
M_{s} \quad> \\
6.0, \quad d_{e} \\
\begin{array}{l}\text { other- } \\
\text { wise }\end{array}\end{array}$ & 3 & $\mathrm{~L}$ & $2 \mathrm{~W}^{3}$ & ${ }^{36} \mathrm{~A}$ \\
\hline $\begin{array}{l}\text { Ambraseys and } \\
\text { Simpson (1996) \& } \\
\text { Simpson }(1996)\end{array}$ & $\begin{array}{l}\text { Europe \& Mid. } \\
\text { East }\end{array}$ & - & 417 & 157 & 4.0 & 7.9 & $\begin{array}{l}M_{s} \\
\text { (unspec- } \\
\text { ified) }\end{array}$ & 0 & 260 & $\begin{array}{l}d_{f} \quad \text { for } \\
M \quad> \\
6.0, \quad d_{e} \\
\text { other- } \\
\text { wise }\end{array}$ & 3 & - & $2 \mathrm{~W}^{3}$ & ${ }^{37} \mathrm{~A}$ \\
\hline $\begin{array}{l}\text { Bommer et al. } \\
(1996)\end{array}$ & $\begin{array}{l}\text { El Salvador \& } \\
\text { Nicaragua }\end{array}$ & 36 & - & 20 & 3.7 & 7.0 & $M_{s}$ & 62 & 260 & $d_{h}$ & 1 & $\mathrm{~L}$ & $\mathrm{U}$ & A \\
\hline $\begin{array}{l}\text { Crouse and } \\
\text { McGuire (1996) }\end{array}$ & $\begin{array}{l}\text { Cen. \& S. Cal- } \\
\text { ifornia }\end{array}$ & 238 & - & 16 & 6.0 & 7.7 & $M_{s}$ & 0.1 & 211 & $d_{r}$ & 4 & G & $1 \mathrm{~W}$ & $\begin{array}{l}\mathrm{R}, \mathrm{S} \\
(\mathrm{R}, \mathrm{S})\end{array}$ \\
\hline $\begin{array}{l}\text { Free } \quad(1996) \& \\
\text { Free et al. }(1998)\end{array}$ & $\begin{array}{l}\text { Stable conti- } \\
\text { nental regions }\end{array}$ & 558 & 478 & $\begin{array}{l}\mathrm{H}: \\
222 \\
\mathrm{~V}: \\
189\end{array}$ & 1.5 & 6.8 & $M_{w}$ & 0 & 820 & $\begin{array}{l}d_{f} \quad \text { for } \\
\text { some, } d_{e} \\
\text { for most }\end{array}$ & 2 & $\mathrm{~L}$ & 1 & $\mathrm{~A}$ \\
\hline
\end{tabular}

continued on next page

$\overline{36}$ Ambraseys et al. (1996) state it is two-stage of Joyner and Boore (1981) but in fact it is two-stage method of Joyner and Boore (1988).

${ }^{37}$ Ambraseys et al. (1996) state it is two-stage of Joyner and Boore (1981) but in fact it is two-stage method of Joyner and Boore (1988). 
Table A.1: continued

\begin{tabular}{|c|c|c|c|c|c|c|c|c|c|c|c|c|c|c|}
\hline Reference & Area & $\mathrm{H}$ & $\mathrm{V}$ & $\mathrm{E}$ & $M_{\min }$ & $M_{\max }$ & $M$ scale & $d_{\min }$ & $d_{\max }$ & $d$ scale & $\mathrm{S}$ & $\mathrm{C}$ & $\mathrm{R}$ & M \\
\hline Ohno et al. (1996) & California & 248 & - & 17 & 5.0 & 7.5 & $\begin{array}{l}M_{w} \\
\left(M_{L}\right)\end{array}$ & 7.2 & 99.6 & $\begin{array}{l}d_{q} \quad \text { for } \\
M \quad> \\
5.3, \quad d_{h} \\
\text { other- } \\
\text { wise }\end{array}$ & 2 & $\mathrm{~B}$ & $2 \mathrm{M}$ & $\mathrm{A}$ \\
\hline $\begin{array}{l}\text { Sarma and } \\
\text { bulov }(1996)\end{array}$ & Worldwide & 350 & - & 114 & 3.9 & 7.7 & $M_{s}$ & 1 & 213 & $d_{f} \& d_{e}$ & 1 & $\begin{array}{l}\mathrm{B}, \\
\mathrm{L}\end{array}$ & $\mathrm{U}$ & A \\
\hline Singh et al. (1996) & Himalayas & 86 & - & 5 & 5.7 & 7.2 & $m_{b}$ & 33.15 & 340.97 & $7 d_{h}$ & 1 & $\mathrm{U}$ & 1 & $\mathrm{~A}$ \\
\hline $\begin{array}{l}\text { Spudich et al. } \\
\text { (1996) \& Spudich } \\
\text { et al. (1997) }\end{array}$ & $\begin{array}{l}\text { Worldwide } \\
\text { extensional } \\
\text { regimes }\end{array}$ & 128 & - & 30 & 5.10 & 6.90 & $M_{w}$ & 0 & 102.1 & $d_{f}$ & 2 & $\begin{array}{l}\mathrm{G}, \\
\mathrm{O}\end{array}$ & $2 \mathrm{M}$ & NS \\
\hline $\begin{array}{l}\text { Campbell (1997) } \\
\text { \& Campbell and } \\
\text { Bozorgnia (1994) }\end{array}$ & Worldwide & 645 & 225 & $\begin{array}{l}\mathrm{H}: 47 \\
\mathrm{~V}: 26\end{array}$ & 4.7 & $\begin{array}{l}\mathrm{H}: 8.0 \\
\mathrm{~V}: 8.1\end{array}$ & $M_{w}$ & 3 & 60 & $d_{s}$ & 3 & $\mathrm{G}$ & 1 & $\mathrm{~A}(\mathrm{~S}, \mathrm{R}, \mathrm{N})$ \\
\hline $\begin{array}{l}\text { Munson and } \\
\text { Thurber (1997) }\end{array}$ & Hawaii & 51 & - & 22 & 4.0 & 7.2 & $\begin{array}{l}M_{s} \quad \text { for } \\
M_{s} \quad \geq \\
6.1, \quad M_{L} \\
\text { other- } \\
\text { wise }\end{array}$ & 0 & 88 & $d_{f}$ & 2 & $\mathrm{~L}$ & $2 \mathrm{M}$ & $\mathrm{A}$ \\
\hline
\end{tabular}


Table A.1: continued

\begin{tabular}{|c|c|c|c|c|c|c|c|c|c|c|c|c|c|c|}
\hline Reference & Area & $\mathrm{H}$ & $\mathrm{V}$ & $\mathrm{E}$ & $M_{\min }$ & $M_{\max }$ & $M$ scale & $d_{\min }$ & $d_{\max }$ & $d$ scale & $\mathrm{S}$ & $\mathrm{C}$ & $\mathrm{R}$ & M \\
\hline $\begin{array}{l}\text { Youngs et al. } \\
(1997)\end{array}$ & $\begin{array}{l}\text { Worldwide } \\
\text { subduction } \\
\text { zones }\end{array}$ & 476 & - & 164 & 5.0 & 8.2 & $\begin{array}{l}M_{w} \\
\left(M_{s}, m_{b}\right)\end{array}$ & 8.5 & 550.9 & $\begin{array}{l}d_{r}, d_{h} \text { for } \\
\text { some }\end{array}$ & 2 & $\mathrm{G}$ & $1 \mathrm{M}$ & $\mathrm{NT}$ \\
\hline Zhao et al. (1997) & $\begin{array}{l}\text { NZ with } 66 \\
\text { foreign }\end{array}$ & $461^{38}+66$ & & $49+17$ & 5.08 & $7.23(7.41$ & $M_{w}$ & $\begin{array}{l}11 \\
(0.1)\end{array}$ & $\begin{array}{l}573 \\
(10)\end{array}$ & $\begin{array}{l}d_{r} \quad \text { for } \\
\text { some, } d_{c} \\
\text { for most }\end{array}$ & 2 & $\mathrm{U}$ & 1 & $A(R)$ \\
\hline $\begin{array}{l}\text { Bouhadad et al. } \\
(1998)\end{array}$ & Algeria & $\mathrm{U}$ & - & 2 & 5.6 & 6.1 & $M_{s}$ & 20 & 70 & $d_{h}$ & 1 & $\begin{array}{l}\mathrm{L}, \\
\mathrm{M}\end{array}$ & 1 & $\mathrm{~A}$ \\
\hline Manic (1998) & N.W. Balkans & $276^{39}$ & - & 56 & 4 & 7 & $M_{s}$ & $\mathrm{U}$ & $\mathrm{U}$ & $d_{h}$ & 2 & $\mathrm{~B}$ & 1 & $\mathrm{~A}$ \\
\hline $\begin{array}{l}\text { Rinaldis et al. } \\
(1998)\end{array}$ & Italy \& Greece & $137^{*}$ & - & $24^{*}$ & 4.5 & 7 & $\begin{array}{ll}M_{s} & \text { or } \\
M_{w} & \end{array}$ & 7 & 138 & $d_{e}$ & 2 & $\mathrm{U}$ & $\mathrm{O}$ & $\begin{array}{l}\mathrm{A} \\
(\mathrm{N}, \mathrm{ST})\end{array}$ \\
\hline $\begin{array}{l}\text { Sadigh and Egan } \\
\text { (1998) }\end{array}$ & $\begin{array}{l}\text { California with } \\
4 \text { foreign }\end{array}$ & $960+4$ & - & $119+2$ & 3.8 & 7.4 & $M_{w}$ & 0.1 & $305^{40}$ & $\begin{array}{l}{ }^{0} d_{r} \quad \text { for } \\
\text { some, } d_{h} \\
\text { for small } \\
\text { ones }\end{array}$ & 2 & $\mathrm{G}$ & $\mathrm{U}$ & $\mathrm{A}(\mathrm{R}, \mathrm{SN})$ \\
\hline
\end{tabular}

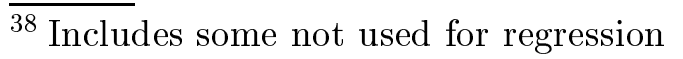

39 Total number of components do not need to be multiplied by two.

${ }^{40}$ Equations stated to be for distances up to $100 \mathrm{~km}$ 
Table A.1: continued

\begin{tabular}{|c|c|c|c|c|c|c|c|c|c|c|c|c|c|c|}
\hline Reference & Area & $\mathrm{H}$ & $\mathrm{V}$ & $\mathrm{E}$ & $M_{\min }$ & $M_{\max }$ & $M$ scale & $d_{\min }$ & $d_{\max }$ & $d$ scale & $\mathrm{S}$ & $\mathrm{C}$ & $\mathrm{R}$ & $\mathrm{M}$ \\
\hline $\begin{array}{l}\text { Sarma and Sr- } \\
\text { bulov (1998) }\end{array}$ & Worldwide & $690^{41}$ & - & 113 & 3.9 & 7.7 & $M_{s}(\mathrm{U})$ & 0 & 197 & $d_{f}, d_{e}$ & 2 & B & 1 & $\mathrm{~A}$ \\
\hline Sharma (1998) & $\begin{array}{l}\text { Indian } \\
\text { malayas }\end{array}$ & 66 & - & 5 & 5.5 & 6.6 & $\mathrm{U}$ & 8 & 248 & $d_{h}$ & 1 & $\mathrm{~L}$ & $1 \mathrm{~W}$ & $\mathrm{~A}$ \\
\hline Smit (1998) & $\begin{array}{l}\text { Switzerland }+ \\
\text { some from S. } \\
\text { Germany }\end{array}$ & $\ll 1546$ & $<1546$ & $\begin{array}{l}\mathrm{H}: \\
<120 \\
\mathrm{~V}: \\
120\end{array}$ & 2.0 & 5.1 & $M_{L}$ & 1 & 290 & $d_{h}$ & 1 & $\mathrm{U}$ & 2 & $\mathrm{~A}$ \\
\hline Chapman (1999) & W. N. America & 304 & - & 23 & 5.0 & 7.7 & $M_{w}$ & 0.1 & 189.4 & $d_{f}$ & 3 & $\mathrm{G}$ & $2 \mathrm{M}$ & $\mathrm{A}$ \\
\hline $\begin{array}{l}\text { Cousins et al. } \\
(1999)\end{array}$ & $\begin{array}{l}\text { NZ with } 66 \\
\text { foreign }\end{array}$ & $610+66$ & - & $25+17$ & 5.17 & $7.09(7.41$ & $M_{w}$ & 0.1 & 400 & $\begin{array}{l}d_{r} \quad \text { for } \\
\text { some, } d_{c} \\
\text { for most }\end{array}$ & 3 & $\mathrm{U}$ & $\mathrm{U}$ & $\mathrm{A}(\mathrm{R})$ \\
\hline $\begin{array}{l}\text { Spudich et al. } \\
(1999)\end{array}$ & $\begin{array}{l}\text { Worldwide } \\
\text { extensional } \\
\text { regimes }\end{array}$ & 142 & - & 39 & 5.1 & 7.2 & $M_{w}$ & 0 & 99.4 & $d_{f}$ & 2 & $\begin{array}{l}\mathrm{G}, \\
\mathrm{O}\end{array}$ & $1 \mathrm{M}$ & NS \\
\hline $\begin{array}{l}\text { Wang et } \\
(1999)\end{array}$ & $\begin{array}{l}\text { Tangshan, N. } \\
\text { China }\end{array}$ & 44 & - & 6 & 3.7 & 4.9 & $\begin{array}{l}M_{s} \\
\left(M_{L}\right)\end{array}$ & 2.1 & 41.3 & $d_{e}$ & 1 & $\mathrm{~L}$ & 1 & $\mathrm{~A}$ \\
\hline
\end{tabular}

continued on next page

$\overline{41}$ Total number of components do not need to be multiplied by two. 
Table A.1: continued

\begin{tabular}{|c|c|c|c|c|c|c|c|c|c|c|c|c|c|c|}
\hline Reference & Area & $\mathrm{H}$ & $\mathrm{V}$ & $\mathrm{E}$ & $M_{\min }$ & $M_{\max }$ & $M$ scale & $d_{\min }$ & $d_{\max }$ & $d$ scale & $\mathrm{S}$ & $\mathrm{C}$ & $\mathrm{R}$ & M \\
\hline $\begin{array}{l}\text { Ambraseys and } \\
\text { Douglas (2000) }\end{array}$ & Worldwide & 186 & 183 & 44 & 5.83 & 7.8 & $M_{s}$ & 0 & 15 & $d_{f}$ & 3 & $\mathrm{~L}$ & 1 & $\mathrm{~A}$ \\
\hline $\begin{array}{l}\text { Bozorgnia et al. } \\
(2000)\end{array}$ & Worldwide & 2823 & 2823 & 48 & 4.7 & 7.7 & $M_{w}$ & $\mathrm{U}$ & $\begin{array}{l}\leq \\
60\end{array}$ & $d_{s}$ & 4 & $\mathrm{G}$ & $\mathrm{U}$ & $\begin{array}{l}\mathrm{A} \\
(\mathrm{R}, \mathrm{S}, \mathrm{T})\end{array}$ \\
\hline $\begin{array}{l}\text { Campbell and Bo- } \\
\text { zorgnia }(2000)\end{array}$ & Worldwide & $960^{42}$ & $941^{43}$ & $49^{44}$ & 4.7 & 7.7 & $M_{w}$ & $1^{*}$ & $60^{*}$ & $d_{s}$ & 4 & G & 1 & $\begin{array}{l}\mathrm{A} \\
(\mathrm{S}, \mathrm{R}, \mathrm{T})\end{array}$ \\
\hline Jain et al. (2000) & $\begin{array}{l}\text { Central Hi- } \\
\text { malayas }\end{array}$ & $\begin{array}{l}32 \\
(117)\end{array}$ & - & 3 & 5.5 & 7.0 & $\mathrm{U}$ & $\begin{array}{l}2 \\
(4)\end{array}$ & $\begin{array}{l}152 \\
(322)\end{array}$ & $d_{e}$ & 1 & $\mathrm{U}$ & 1 & $\mathrm{~T}$ \\
\hline $\begin{array}{l}\text { Kobayashi et al. } \\
(2000)\end{array}$ & Japan & $\mathrm{U}$ & - & $\mathrm{U}$ & 5.0 & 7.8 & $M_{w}$ & $0.9^{*}$ & $400^{*}$ & $\mathrm{U}$ & 4 & B & $1 \mathrm{M}$ & $\mathrm{A}$ \\
\hline $\begin{array}{l}\text { Monguilner et al. } \\
(2000 \mathrm{a})\end{array}$ & W. Argentina & $54^{45}$ & - & $10^{45}$ & $4.3^{45}$ & 7.4 & $\begin{array}{l}M_{s} \quad \text { if } \\
M_{L} \quad \& \\
M_{s}>6 \\
M_{L} \text { oth- } \\
\text { erwise }\end{array}$ & $11^{45}$ & $350^{45}$ & $d_{h}$ & 2 & $\mathrm{U}$ & $1 \mathrm{~W}$ & $\mathrm{~A}$ \\
\hline
\end{tabular}

$\overline{42}$ Equation for corrected PGA uses 443 records.

${ }^{43}$ Equation for corrected PGA uses 439 records.

${ }^{44}$ Equation for corrected PGA uses data from 36 earthquakes.

${ }^{45}$ Assuming they use same data as Monguilner et al. (2000b). 
Table A.1: continued

\begin{tabular}{|c|c|c|c|c|c|c|c|c|c|c|c|c|c|c|}
\hline Reference & Area & $\mathrm{H}$ & $\mathrm{V}$ & $\mathrm{E}$ & $M_{\min }$ & $M_{\max }$ & $M$ scale & $d_{\min }$ & $d_{\max }$ & $d$ scale & $\mathrm{S}$ & $\mathrm{C}$ & $\mathrm{R}$ & M \\
\hline Sharma (2000) & $\begin{array}{l}\text { Indian } \\
\text { malayas }\end{array}$ & - & 66 & 5 & 5.5 & 6.6 & $\mathrm{U}$ & 8 & 248 & $d_{h}$ & 1 & - & $1 \mathrm{~W}$ & $\mathrm{~A}$ \\
\hline $\begin{array}{l}\mathrm{Si} \text { and } \mathrm{Mi}- \\
\text { dorikawa }(2000)\end{array}$ & Japan & 856 & - & 21 & 5.8 & 8.3 & $M_{w}$ & $0^{*}$ & $280^{*}$ & $\begin{array}{l}\text { Both } d_{q} \\
\& d_{r}\end{array}$ & 2 & $\mathrm{~L}$ & $\mathrm{O}$ & $\mathrm{A}$ \\
\hline Smit et al. (2000) & Caucasus & 84 & - & 26 & 4.0 & 7.1 & $M_{s}$ & 4 & 230 & $d_{e}{ }^{46}$ & 1 & $\mathrm{~L}$ & 2 & A \\
\hline $\begin{array}{l}\text { Takahashi et al. } \\
(2000)\end{array}$ & $\begin{array}{l}\text { Japan }+166 \\
\text { foreign }\end{array}$ & 1332 & - & $\mathrm{U}+7^{*}$ & $\begin{array}{l}5^{*} \\
\left(5.8^{*}\right)\end{array}$ & $\begin{array}{l}8.3^{*} \\
\left(8^{*}\right)\end{array}$ & $M_{w}$ & $\begin{array}{l}1^{*} \\
\left(0.1^{*}\right)\end{array}$ & $\left\{\begin{array}{l}300^{*} \\
\left(100^{*}\right.\end{array}\right.$ & $\begin{array}{l}d_{r}, d_{h} \text { for } \\
\text { () some }\end{array}$ & 4 & G & $\mathrm{O}$ & A \\
\hline $\begin{array}{l}\text { Wang and Tao } \\
(2000)\end{array}$ & W. N. America & 182 & - & 23 & 5.0 & 7.7 & $\begin{array}{l}M_{w} \\
\left(M_{L}\right)\end{array}$ & 0.5 & 370 & $d_{f}$ & 2 & $\mathrm{~L}$ & $\mathrm{O}$ & $\mathrm{A}$ \\
\hline $\begin{array}{l}\text { Chang et al. } \\
(2001)\end{array}$ & Taiwan & $\begin{array}{l}4720^{47} \\
2528^{48}\end{array}$ & - & $\begin{array}{l}45^{47} \\
19^{48}\end{array}$ & $\begin{array}{l}4.1^{47} \\
4.6^{48}\end{array}$ & $\begin{array}{l}7.0^{47} \\
6.3^{48}\end{array}$ & $\begin{array}{lr}M_{w} & \\
\left(M_{L}\right. & \text { for } \\
M_{L} & < \\
6.5) & \end{array}$ & $\begin{array}{l}0^{47} \\
40.2^{4 \varepsilon}\end{array}$ & $\begin{array}{r}264.4 \\
8272.4\end{array}$ & $\begin{array}{l}4 \tilde{d}_{e}{ }^{47} \\
4_{h} \ddot{d}_{h}^{48}\end{array}$ & 1 & $\mathrm{G}$ & 2 & A \\
\hline $\begin{array}{l}\text { Lussou } \\
(2001)\end{array}$ et al. & Japan & 3011 & 3011 & 102 & 3.7 & 6.3 & $M_{\mathrm{JMA}}$ & $4^{*}$ & $600^{*}$ & $d_{h}$ & 4 & $\mathrm{~B}$ & 2 & $\mathrm{~A}$ \\
\hline
\end{tabular}

continued on next page

$\overline{{ }^{46} \text { Smit }}$ et al. (2000) give $d_{h}$ but this is typographical error (Smit, 2000).

${ }^{47}$ Shallow crustal records.

${ }^{48}$ Subduction records. 
Table A.1: continued

\begin{tabular}{|c|c|c|c|c|c|c|c|c|c|c|c|c|c|c|}
\hline Reference & Area & $\mathrm{H}$ & $\mathrm{V}$ & $\mathrm{E}$ & $M_{\min }$ & $M_{\max }$ & $M$ scale & $d_{\min }$ & $d_{\max }$ & $d$ scale & $\mathrm{S}$ & $\mathrm{C}$ & $\mathrm{R}$ & $\mathrm{M}$ \\
\hline $\begin{array}{l}\text { Campbell and Bo- } \\
\text { zorgnia (2002) }\end{array}$ & Worldwide & $443^{49}$ & $439^{50}$ & $36^{51}$ & 4.7 & 7.7 & $M_{w}$ & $2^{*}$ & $60^{*}$ & $d_{s}$ & 4 & $\mathrm{G}$ & 1 & $\begin{array}{l}\mathrm{A} \quad(\mathrm{S} \quad \& \\
\mathrm{N}, \mathrm{R}, \mathrm{T})\end{array}$ \\
\hline $\begin{array}{l}\text { Tromans and } \\
\text { Bommer (2002) }\end{array}$ & Europe & 249 & - & 51 & 5.5 & 7.9 & $M_{s}$ & 1 & 359 & $d_{f}$ & 3 & $\mathrm{~L}$ & 2 & $\mathrm{~A}$ \\
\hline
\end{tabular}

$\overline{49}$ There are 960 components for uncorrected PGA.

50 There are 941 components for uncorrected PGA.

${ }^{51}$ For horizontal corrected records. There are 49 for horizontal uncorrected PGA. There are 36 for vertical corrected records and 46 for vertical uncorrected PGA. 


\section{B General characteristics of published equations for estimating spectral ordinates}

Table B.1 gives the general characteristics of published equations for estimating spectral ordinates. The columns are the same as in Table A.1 with three extra columns:

Ts Number of periods for which attenuation equations are derived

$T_{\min }$ Minimum period for which attenuation equation is derived

$T_{\max }$ Maximum period for which attenuation equation is derived 
Table B.1: Characteristics of published spectral relations

\begin{tabular}{|c|c|c|c|c|c|c|c|c|c|c|c|c|c|c|c|c|}
\hline Reference & Area & $\mathrm{H}$ & $\mathrm{V}$ & $\mathrm{E}$ & $M_{\min }$ & $M_{\max }$ & $M$ scale & $d_{\min }$ & $d_{\max } d$ scale & $\mathrm{S}$ & $T \mathrm{~s}$ & $T_{\min }$ & $T_{\max }$ & $\mathrm{C}$ & $\mathrm{R}$ & M \\
\hline $\begin{array}{l}\text { Johnson } \\
\text { (1973) }\end{array}$ & W. USA & 41 & - & 23 & 5.3 & 7.7 & $m_{b}$ & 6.3 & $149.8 d_{e}$ & 1 & 14 & 0.055 & 2.469 & $\mathrm{M}$ & 1 & A \\
\hline $\begin{array}{l}\text { Kobayashi } \\
\text { and Na- } \\
\text { gahashi } \\
(1977)\end{array}$ & Japan & $\mathrm{U}$ & - & $\mathrm{U}$ & $5.4^{*}$ & $7.9^{*}$ & $\mathrm{U}$ & $60 *$ & $210^{*} d_{h}$ & $\mathrm{I}$ & $\mathrm{U}$ & 0.1 & 5 & $\mathrm{R}^{52}$ & $\mathrm{O}$ & A \\
\hline $\begin{array}{l}\text { McGuire } \\
(1977)\end{array}$ & W. USA & 34 & - & 22 & 5.3 & 7.6 & $M_{L}$ & 14 & $125 d_{h}$ & 1 & 16 & 0.1 & 8 & B & $\mathrm{U}$ & A \\
\hline $\begin{array}{l}\text { Trifunac } \\
(1977)\end{array}$ & $\begin{array}{l}\text { W. N. } \\
\text { America }\end{array}$ & 186 & 186 & $\mathrm{U}$ & $\mathrm{U}$ & $\mathrm{U}$ & $\mathrm{U}$ & $\mathrm{U}$ & $\mathrm{U} \quad d_{e}$ & 3 & $\mathrm{U}$ & $0.04^{*}$ & $15^{*}$ & $\mathrm{U}$ & $\mathrm{O}$ & A \\
\hline $\begin{array}{l}\text { Faccioli } \\
(1978)\end{array}$ & $\begin{array}{l}\text { W. USA, } \\
\text { Japan, } \\
\text { Papua } \\
\text { New } \\
\text { Guinea, } \\
\text { Mex- } \\
\text { ico \& } \\
\text { Greece }\end{array}$ & $26^{53}$ & - & 11 & 5.3 & 7.8 & $\mathrm{U}$ & 15 & $342 \quad d_{h}$ & 1 & 15 & 0.1 & 4 & $\mathrm{~B}$ & $\mathrm{U}$ & A \\
\hline
\end{tabular}

continued on next page

52 They state it is two dimensional response spectrum which assume to be resolved component.

53 Total earthquake components (does not need to be multiplied by two) 
Table B.1: continued

\begin{tabular}{|c|c|c|c|c|c|c|c|c|c|c|c|c|c|c|c|c|}
\hline Reference & Area & $\mathrm{H}$ & $\mathrm{V}$ & $\mathrm{E}$ & $M_{\min }$ & $M_{\max }$ & $M$ scale & $d_{\min }$ & $d_{\max } d$ scale & $\mathrm{S}$ & $T \mathrm{~s}$ & $T_{\min }$ & $T_{\max }$ & $\mathrm{C}$ & $\mathrm{R}$ & M \\
\hline $\begin{array}{l}\text { McGuire } \\
\text { (1978) }\end{array}$ & W. USA & 70 & - & $17+^{*}$ & $4.5^{*}$ & 7.7 & $\mathrm{U}^{54}$ & $11^{*}$ & $210^{*} d_{h}$ & 2 & 1 & 1 & 1 & $\mathrm{~B}$ & $\mathrm{U}$ & $\mathrm{A}$ \\
\hline $\begin{array}{l}\text { Trifunac } \\
\text { (1978) }\end{array}$ & $\begin{array}{l}\text { W. N. } \\
\text { America }\end{array}$ & 187 & 187 & 57 & 3.0 & 7.7 & $\mathrm{U}$ & $\mathrm{U}$ & $\mathrm{U} \quad d_{e}$ & 3 & $\mathrm{U}$ & $0.04 *$ & $15^{*}$ & $\mathrm{U}$ & $\mathrm{O}$ & $\mathrm{A}$ \\
\hline $\begin{array}{l}\text { Trifunac } \\
\text { and Ander- } \\
\text { son (1978) }\end{array}$ & $\begin{array}{l}\text { W. N. } \\
\text { America }\end{array}$ & $\mathrm{U}$ & $\mathrm{U}$ & $\mathrm{U}$ & $\mathrm{U}$ & $\mathrm{U}$ & $\mathrm{U}$ & $\mathrm{U}$ & $\mathrm{U} \quad d_{e}$ & 3 & $\mathrm{U}$ & $\mathrm{U}$ & $\mathrm{U}$ & $\mathrm{U}$ & $\mathrm{U}$ & $\mathrm{A}$ \\
\hline $\begin{array}{l}\text { Cornell } \\
\text { et al. (1979) }\end{array}$ & W. USA & 70 & - & $\mathrm{U}$ & $\mathrm{U}$ & $\mathrm{U}$ & $M_{L}$ & $\mathrm{U}$ & $\mathrm{U} \quad d_{h}$ & 1 & 7 & 0.17 & 5 & $\mathrm{C}$ & $\mathrm{U}$ & $\mathrm{A}$ \\
\hline $\begin{array}{l}\text { Trifunac } \\
\text { and Lee } \\
(1979)\end{array}$ & $\begin{array}{l}\text { W. N. } \\
\text { America }\end{array}$ & $\mathrm{U}$ & $\mathrm{U}$ & $\mathrm{U}$ & $\mathrm{U}$ & $\mathrm{U}$ & $\mathrm{U}$ & $\mathrm{U}$ & $\mathrm{U} \quad d_{e}$ & 3 & 91 & 0.04 & 15 & $\mathrm{U}$ & $\mathrm{U}$ & $\mathrm{A}$ \\
\hline $\begin{array}{l}\text { Ohsaki et al. } \\
\text { (1980a) }\end{array}$ & Japan & 95 & - & $29+$ & $3.9^{*}$ & $7.2^{*}$ & $\mathrm{U}$ & $3^{*}$ & $500^{*} d_{h}$ & 2 & 86 & 0.02 & 5 & $\mathrm{U}$ & 1 & $\mathrm{~A}$ \\
\hline $\begin{array}{l}\text { Ohsaki et al. } \\
\text { (1980b) }\end{array}$ & Japan & 75 & - & $\mathrm{U}$ & 4 & 7.4 & $\mathrm{U}$ & 6 & $500 \quad d_{h}$ & 1 & $\mathrm{U}$ & 0.02 & 5 & $\mathrm{U}$ & 1 & $\mathrm{~A}$ \\
\hline $\begin{array}{l}\text { Trifunac } \\
\text { (1980) }\end{array}$ & W. USA & $\mathrm{U}$ & - & $\mathrm{U}$ & $\mathrm{U}$ & $\mathrm{U}$ & $\mathrm{U}$ & $\mathrm{U}$ & $\mathrm{U} \quad d_{e}$ & $\mathrm{C}$ & 91 & 0.04 & 7.5 & $\mathrm{U}$ & $\mathrm{U}$ & $\mathrm{A}$ \\
\hline
\end{tabular}

continued on next page

$\overline{{ }^{54} \text { Idriss }}$ (1978) finds magnitudes to be mixture of $M_{L}, m_{b}$ and $M_{s}$. 
Table B.1: continued

\begin{tabular}{|c|c|c|c|c|c|c|c|c|c|c|c|c|c|c|c|c|}
\hline Reference & Area & $\mathrm{H}$ & $\mathrm{V}$ & $\mathrm{E}$ & $M_{\min }$ & $M_{\max }$ & $M$ scale & $d_{\min }$ & $d_{\max } d$ scale & $\mathrm{S}$ & $T \mathrm{~s}$ & $T_{\min }$ & $T_{\max }$ & $\mathrm{C}$ & $\mathrm{R}$ & M \\
\hline $\begin{array}{l}\text { Devillers } \\
\text { and Mo- } \\
\text { ham- } \\
\text { madioun } \\
(1981)\end{array}$ & W. USA & 186 & - & $\mathrm{U}$ & $3.3^{*}$ & $7.7^{*}$ & $\mathrm{U}$ & $\begin{array}{l}\geq \\
10\end{array}$ & $250^{*} d_{h}$ & 1 & 46 & 0.04 & 10 & $\mathrm{U}$ & 1 & $\mathrm{~A}$ \\
\hline $\begin{array}{l}\text { Kobayashi } \\
\text { and Mi- } \\
\text { dorikawa } \\
(1982)\end{array}$ & Japan & 45 & - & $\mathrm{U}$ & 5.1 & 7.5 & $\mathrm{U}$ & 50 & $280 \quad d_{h}$ & 1 & $\mathrm{U}$ & 0.1 & 5 & $\mathrm{U}$ & $\mathrm{O}$ & $\mathrm{A}$ \\
\hline \begin{tabular}{lr}
\multicolumn{2}{l}{ Joyner } \\
and & Fu- \\
mal & $(1984)$ \\
$\&$ & Joyner \\
and & Boore \\
\multicolumn{2}{c}{$(1988)$}
\end{tabular} & $\begin{array}{l}\text { W. N. } \\
\text { America }\end{array}$ & $\overline{\mathrm{U}}$ & - & $\mathrm{U}$ & 5.0 & 7.7 & $M_{w}\left(M_{L}\right)$ & $\overline{\mathrm{U}}$ & $\mathrm{U} \quad d_{f}$ & $\mathrm{C}$ & 12 & 0.1 & 4 & $\mathrm{~L}$ & $\mathrm{U}$ & $\mathrm{A}$ \\
\hline $\begin{array}{l}\text { Kawashima } \\
\text { et al. (1984) }\end{array}$ & Japan & 197 & - & 90 & 5.0 & $\mathrm{U}$ & $M_{\mathrm{JMA}}$ & $\mathrm{U}$ & $\mathrm{U} \quad d_{e}$ & 3 & 10 & 0.1 & 3 & $\mathrm{R}$ & 1 & $\mathrm{~A}$ \\
\hline $\begin{array}{l}\text { Kawashima } \\
\text { et al. (1985) }\end{array}$ & Japan & - & 119 & $90^{*}$ & $5.0^{*}$ & $7.5^{*}$ & $M_{\mathrm{JMA}}$ & $5^{*}$ & $500^{*} d_{e}$ & 3 & 10 & 0.1 & 3 & - & 1 & $\mathrm{~A}$ \\
\hline
\end{tabular}


Table B.1: continued

\begin{tabular}{|c|c|c|c|c|c|c|c|c|c|c|c|c|c|c|c|c|c|}
\hline Reference & Area & $\mathrm{H}$ & $\mathrm{V}$ & $\mathrm{E}$ & $M_{\min }$ & $M_{\max }$ & $M$ scale & $d_{\min }$ & $d_{\max }$ & $d$ scale & $\mathrm{S}$ & $T \mathrm{~s}$ & $T_{\min }$ & $T_{\max }$ & $\mathrm{C}$ & $\mathrm{R}$ & $\mathrm{M}$ \\
\hline $\begin{array}{l}\text { Trifunac } \\
\text { and Lee } \\
(1985)\end{array}$ & $\begin{array}{l}\text { W. N. } \\
\text { America }\end{array}$ & 438 & 438 & 104 & $\mathrm{U}$ & $\mathrm{U}$ & $\mathrm{U}$ & $\mathrm{U}$ & $\mathrm{U}$ & $d_{h}$ & $\begin{array}{l}3, \\
\mathrm{C}\end{array}$ & 91 & 0.04 & 15 & $\mathrm{U}$ & $\mathrm{U}$ & $\mathrm{A}$ \\
\hline $\begin{array}{l}\text { Kamiyama } \\
\text { and Yanagi- } \\
\text { sawa (1986) }\end{array}$ & Japan & 228 & - & 69 & 4.5 & 7.9 & $M_{\mathrm{JMA}}$ & 3 & 323 & $d_{e}$ & I & 45 & 0.1 & 10 & $\mathrm{U}$ & 1 & $\mathrm{~A}$ \\
\hline $\begin{array}{l}\text { C.B. Crouse } \\
(1987)^{55}\end{array}$ & $\begin{array}{l}\text { S. Cali- } \\
\text { fornia }\end{array}$ & $\mathrm{U}$ & - & $\mathrm{U}$ & $\mathrm{U}$ & $\mathrm{U}$ & $M_{s}$ & $\mathrm{U}$ & $\mathrm{U}$ & $d_{r}$ & 1 & 10 & 0.05 & 6 & B & $\mathrm{U}$ & $\mathrm{A}$ \\
\hline $\begin{array}{l}\text { K. Sadigh } \\
(1987)^{56}\end{array}$ & $\begin{array}{l}\text { W. USA } \\
+ \text { others }\end{array}$ & $\mathrm{U}$ & - & $\mathrm{U}$ & $\mathrm{U}$ & $\mathrm{U}$ & $M_{w}$ & $\mathrm{U}$ & $\mathrm{U}$ & $d_{r}$ & 2 & 7 & 0.1 & 4 & B & $\mathrm{U}$ & $\mathrm{A}(\mathrm{S}, \mathrm{R})$ \\
\hline $\begin{array}{l}\text { Annaka and } \\
\text { Nozawa } \\
(1988)\end{array}$ & Japan & $\mathrm{U}$ & - & 45 & $\mathrm{U}$ & $\mathrm{U}$ & $\mathrm{U}$ & $\mathrm{U}$ & $\mathrm{U}$ & $\mathrm{U}$ & 1 & $\mathrm{U}$ & $0.04^{*}$ & $4^{*}$ & $\mathrm{U}$ & 1 & $\mathrm{~A}$ \\
\hline $\begin{array}{l}\text { Crouse et al. } \\
\text { (1988) }\end{array}$ & $\begin{array}{l}\text { N. Hon- } \\
\text { shu }\end{array}$ & 64 & - & $\mathrm{U}$ & 5.1 & 8.2 & $\begin{array}{l}M_{w}, M_{s} \\
\& M_{\mathrm{JMA}} \\
\text { for }<7.5\end{array}$ & 42 & 407 & $\begin{array}{l}d_{E}, \\
d_{h} \quad \text { for } \\
M<7.5\end{array}$ & 1 & 10 & 0.1 & 4 & B & 1 & $\mathrm{~A}$ \\
\hline
\end{tabular}

continued on next page

$\overline{55}$ Reported in Joyner and Boore (1988).

${ }^{56}$ Reported in Joyner and Boore (1988). 
Table B.1: continued

\begin{tabular}{|c|c|c|c|c|c|c|c|c|c|c|c|c|c|c|c|c|}
\hline Reference & Area & $\mathrm{H}$ & $\mathrm{V}$ & $\mathrm{E}$ & $M_{\min }$ & $M_{\max }$ & $M$ scale & $d_{\min }$ & $d_{\max } d$ scale & $\mathrm{S}$ & $T \mathrm{~s}$ & $T_{\min }$ & $T_{\max }$ & $\mathrm{C}$ & $\mathrm{R}$ & M \\
\hline $\begin{array}{l}\text { Yokota et al. } \\
(1988)\end{array}$ & Tokyo & 154 & 24 & $\begin{array}{l}75 \\
(\mathrm{U})\end{array}$ & 4.0 & 6.1 & $M_{\mathrm{JMA}}$ & $\begin{array}{l}59 \\
(60)\end{array}$ & $\begin{array}{l}206 d_{h} \\
(100)\end{array}$ & 1 & $\mathrm{U}$ & $\begin{array}{l}0.1 \\
(0.05)\end{array}$ & $\begin{array}{l}10 \\
(5)\end{array}$ & $\mathrm{U}$ & $\mathrm{U}$ & $\mathrm{A}$ \\
\hline $\begin{array}{l}\text { Youngs } \\
\text { et al. (1988) }\end{array}$ & $\begin{array}{l}\text { Worldwide } \\
\text { subduc- } \\
\text { tion } \\
\text { zones }\end{array}$ & $\begin{array}{l}20+ \\
197+ \\
389\end{array}$ & - & $\begin{array}{l}16^{*} \\
(60)\end{array}$ & $\begin{array}{l}5.6^{*} \\
(5)\end{array}$ & $\begin{array}{l}8.1^{*} \\
(8.1 \\
8.2)^{57}\end{array}$ & $\begin{array}{l}M_{w}\left(M_{s},\right. \\
\left.m_{b}\right)\end{array}$ & $\begin{array}{l}\mathrm{U} \\
\left(15^{*},\right. \\
\left.20^{*}\right)\end{array}$ & $\begin{array}{l}\mathrm{U} \quad d_{r}, d_{h} \text { for } \\
\left(450^{*} M_{w} \lesssim\right. \\
\left.450^{*}\right) 7.5\end{array}$ & 1 & 15 & 0.07 & 4 & $\mathrm{G}$ & $1 \mathrm{~W}$ & $\mathrm{~A}(\mathrm{~B}, \mathrm{~F})$ \\
\hline $\begin{array}{l}\text { Kamiyama } \\
(1989)\end{array}$ & Japan & 228 & - & $\mathrm{U}$ & 4.1 & 7.9 & $M_{\mathrm{JMA}}$ & 3 & $350 \quad d_{e}$ & I & $\mathrm{U}$ & $0.05^{*}$ & $10^{*}$ & $\mathrm{U}$ & 1 & $\mathrm{~A}$ \\
\hline $\begin{array}{l}\text { Trifunac } \\
\text { and Lee } \\
(1989)\end{array}$ & $\begin{array}{l}\text { Mostly } \\
\text { Califor- } \\
\text { nia }\end{array}$ & 438 & 438 & 104 & $\mathrm{U}$ & $\mathrm{U}$ & $\mathrm{U}$ & $\mathrm{U}$ & $\mathrm{U} \quad d_{e}$ & $\mathrm{C}$ & 12 & 0.04 & 14 & B & $\mathrm{U}$ & $\mathrm{A}$ \\
\hline $\begin{array}{l}\text { Atkinson } \\
(1990)\end{array}$ & $\begin{array}{l}\text { E. } \quad \text { N. } \\
\text { America } \\
+\quad 10 \\
\text { others }\end{array}$ & $92+10^{5}$ & & $8+3$ & $\begin{array}{l}3.60 \\
(5.16)\end{array}$ & $\begin{array}{l}6.00 \\
(6.84)\end{array}$ & $M_{w}$ & $\begin{array}{l}8 \\
(8)\end{array}$ & $\begin{array}{l}1215 d_{h} \\
(23)\end{array}$ & 1 & 4 & 0.1 & 1 & B & 2 & $\mathrm{~A}$ \\
\hline
\end{tabular}

continued on next page

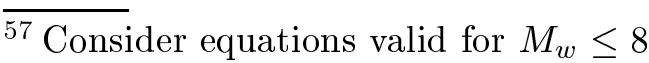

${ }^{58}$ Total earthquake components (does not need to be multiplied by two). $79+10$ records for $0.1 \mathrm{~s}$ equation. 
Table B.1: continued

\begin{tabular}{|c|c|c|c|c|c|c|c|c|c|c|c|c|c|c|c|c|}
\hline Reference & Area & $\mathrm{H}$ & $\mathrm{V}$ & $\mathrm{E}$ & $M_{\min }$ & $M_{\max }$ & $M$ scale & $d_{\min }$ & $d_{\max } d$ scale & $\mathrm{S}$ & $T \mathrm{~s}$ & $T_{\min }$ & $T_{\max }$ & $\mathrm{C}$ & $\mathrm{R}$ & $\mathrm{M}$ \\
\hline $\begin{array}{l}\text { Campbell } \\
(1990)\end{array}$ & Unknown & $\mathrm{U}$ & - & $\mathrm{U}$ & $\mathrm{U}$ & $\mathrm{U}$ & $\begin{array}{l}M_{L} \text { for } \\
M<6, \\
M_{s} \text { for } \\
M \geq 6\end{array}$ & $\mathrm{U}$ & $\mathrm{U} \quad d_{s}$ & 1 & 15 & 0.04 & 4 & $\mathrm{U}$ & $\mathrm{U}$ & $\mathrm{A}$ \\
\hline $\begin{array}{l}\text { Dahle et al. } \\
(1990 b) \quad \& \\
\text { Dahle et al. } \\
(1990 a)\end{array}$ & $\begin{array}{l}\text { Worldwide } \\
\text { in- } \\
\text { traplate } \\
\text { regions }\end{array}$ & & - & 56 & 2.9 & 7.8 & $\begin{array}{l}M_{s}\left(M_{L},\right. \\
m_{b}, \\
M_{C L}\end{array}$ & 6 & $1300 d_{h}$ & 1 & 89 & 0.025 & 4 & $\mathrm{~L}$ & 2 & $\mathrm{~A}$ \\
\hline $\begin{array}{l}\text { Tamura } \\
\text { et al. (1990) }\end{array}$ & Japan & 97 & - & 7 & 7.1 & 7.9 & $M_{\mathrm{JMA}}$ & $\mathrm{U}$ & $\mathrm{U} \quad d_{e}$ & 3 & 13 & 2 & 20 & $\mathrm{~L}$ & $\begin{array}{l}1 \\
\mathrm{O}\end{array}$ & $\mathrm{A}$ \\
\hline $\begin{array}{l}\text { Tsai et al. } \\
(1990)\end{array}$ & Worldwide & $e<88$ & - & $<51$ & $4.9^{*}$ & 7.4 & $M_{w}$ & $3^{*}$ & $150^{*} d_{r}$ & 1 & 14 & 0.07 & 1 & $\mathrm{U}$ & $\mathrm{M}$ & $\mathrm{T}(\mathrm{S}, \mathrm{O})$ \\
\hline $\begin{array}{l}\text { Crouse } \\
(1991)\end{array}$ & $\begin{array}{l}\text { Worldwide } \\
\text { subduc- } \\
\text { tion } \\
\text { zones }\end{array}$ & e 235 & - & $\mathrm{U}$ & 5.1 & 8.2 & $\begin{array}{l}M_{w}\left(M_{s},\right. \\
\left.M_{\mathrm{JMA}}\right)\end{array}$ & $>8$ & $\begin{array}{l}>469 d_{E}, \\
d_{h} \quad \text { for } \\
M<7.5\end{array}$ & 1 & 10 & 0.1 & 4 & $\mathrm{~B}$ & 1 & $\mathrm{~A}$ \\
\hline
\end{tabular}


Table B.1: continued

\begin{tabular}{|c|c|c|c|c|c|c|c|c|c|c|c|c|c|c|c|c|}
\hline Reference & Area & $\mathrm{H}$ & $\mathrm{V}$ & $\mathrm{E}$ & $M_{\min }$ & $M_{\max }$ & $M$ scale & $d_{\min }$ & $d_{\max } d$ scale & $\mathrm{S}$ & $T \mathrm{~s}$ & $T_{\min }$ & $T_{\max }$ & $\mathrm{C}$ & $\mathrm{R}$ & M \\
\hline $\begin{array}{l}\text { Dahle et al. } \\
(1991)\end{array}$ & $\begin{array}{l}\text { Intraplate } \\
\text { (partic- } \\
\text { ularly } \\
\text { Norway) }\end{array}$ & $395+31$ & - & $136+11$ & $2.4^{*}(4.1)$ & $5.2^{*}(6.9)$ & $\begin{array}{l}M_{s} \\
\left(M_{L}, M_{C L}\right)\end{array}$ & $\begin{array}{l}20^{*} \\
(9.7)\end{array}$ & $\begin{array}{l}1200 * d_{h} \\
(1300)\end{array}$ & 1 & $4^{59}$ & 0.1 & 1 & $\mathrm{~L}$ & $\mathrm{O}$ & $\mathrm{A}$ \\
\hline $\begin{array}{l}\text { I.M. Idriss } \\
(1991)^{60}\end{array}$ & Unknown & 572 & - & $30^{*}$ & 4.6 & 7.4 & $\begin{array}{l}M_{L} \quad \text { for } \\
M<6 \\
M_{s} \quad \text { for } \\
M \geq 6\end{array}$ & 1 & $\begin{array}{c}100 \quad d_{r}, d_{h} \text { for } \\
M<6\end{array}$ & 1 & 23 & 0.03 & 5 & $\mathrm{U}$ & $\mathrm{U}$ & $\mathrm{A}$ \\
\hline $\begin{array}{l}\text { Mohammadioı } \\
(1991)\end{array}$ & uftaly & 144 & - & 46 & 3.0 & 6.5 & $\mathrm{U}$ & 6 & $\begin{aligned} 186 & d_{h}, 1 \text { eq. } \\
& \text { with } d_{r}\end{aligned}$ & 1 & 81 & 0.013 & 1.95 & $\mathrm{~B}$ & $\mathrm{U}$ & $\mathrm{A}$ \\
\hline $\begin{array}{l}\text { Niazi and } \\
\text { Bozorgnia } \\
(1992)\end{array}$ & $\begin{array}{l}\text { SMART-1 } \\
\text { array, } \\
\text { Taiwan }\end{array}$ & 236 & 234 & 12 & 3.6 & 7.8 & $\begin{array}{l}M_{L} \\
\left(M_{D}\right) \\
\text { for } \\
M_{L} \quad< \\
6.6, \text { else } \\
M_{s} \\
\end{array}$ & $3.1^{61}$ & ${ }^{1} 119.7 \mathrm{~g}_{h}$ & 1 & 23 & 0.03 & 10 & $\mathrm{M}$ & $2 \mathrm{~W}$ & $\mathrm{~A}$ \\
\hline
\end{tabular}

continued on next page

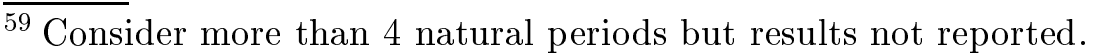

${ }^{60}$ Reported in Idriss (1993).

${ }^{61}$ Distance to centre of array 
Table B.1: continued

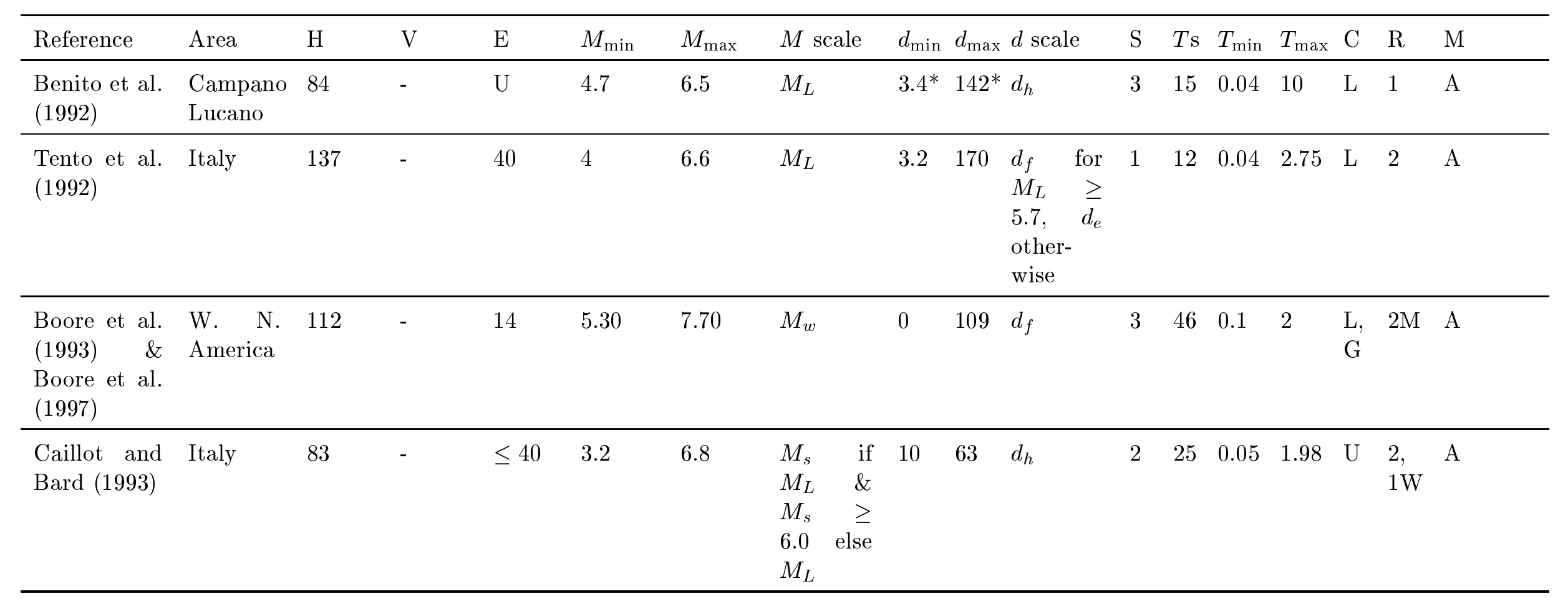

continued on next page 
Table B.1: continued

\begin{tabular}{|c|c|c|c|c|c|c|c|c|c|c|c|c|c|c|c|c|c|}
\hline Reference & Area & $\mathrm{H}$ & $\mathrm{V}$ & $\mathrm{E}$ & $M_{\min }$ & $M_{\max }$ & $M$ scale & $d_{\min }$ & $d_{\max }$ & $d$ scale & $\mathrm{S}$ & $T \mathrm{~s}$ & $T_{\min }$ & $T_{\max }$ & $\mathrm{C}$ & $\mathrm{R}$ & M \\
\hline $\begin{array}{l}\text { Campbell } \\
(1993)\end{array}$ & Worldwide & & - & $\mathrm{U}$ & $\mathrm{U}^{62}$ & $\mathrm{U}$ & $\begin{array}{l}M_{L} \text { for } \\
M<6.0 \\
\text { and } M_{s} \\
\text { other- } \\
\text { wise }\end{array}$ & $\mathrm{U}$ & $\mathrm{U}^{63}$ & $d_{s}$ & 2 & 15 & 0.04 & 4 & M & $\mathrm{O}$ & $\mathrm{A}(\mathrm{T}, \mathrm{S})$ \\
\hline Lee (1993) & $\begin{array}{l}\text { Mostly } \\
\text { Califor- } \\
\text { nia }\end{array}$ & 494 & 494 & 106 & $\mathrm{U}$ & $\mathrm{U}$ & $\begin{array}{lr}M_{L} \quad \text { for } \\
M \quad \lesssim \\
6.5, \text { oth- } \\
\text { ers for } \\
M>6.5\end{array}$ & $\mathrm{U}$ & $\mathrm{U}$ & $d_{e}$ & 3 & 91 & 0.04 & 15 & B & $\mathrm{U}$ & $\mathrm{A}$ \\
\hline $\begin{array}{l}\text { Sadigh et al. } \\
(1993) \quad \& \\
\text { Sadigh et al. } \\
(1997)\end{array}$ & $\begin{array}{l}\text { California } \\
\text { with } 4 \\
\text { foreign }\end{array}$ & $960+4$ & $\mathrm{U}$ & $119+2$ & $\begin{array}{l}3.8 \\
(6.8)\end{array}$ & $\begin{array}{l}7.4 \\
(7.4)\end{array}$ & $M_{w}$ & $\begin{array}{l}0.1 \\
(3)\end{array}$ & $\begin{array}{l}305 \\
(172) \\
\end{array}$ & $\begin{array}{l}d_{r} \quad \text { for } \\
\text { ) } 54 \text { me, } d_{h} \\
\text { for small } \\
\text { ones }\end{array}$ & 2 & 21 & $0.05^{6}$ & $57.5^{66}$ & $\mathrm{G}$ & $\mathrm{U}$ & $\mathrm{A}(\mathrm{R}, \mathrm{S})$ \\
\hline
\end{tabular}

${ }^{62}$ Considers equation valid for $M \geq 4.7$.

${ }^{63}$ Considers equation valid for $d \leq 300 \mathrm{~km}$.

${ }^{64}$ Equations stated to be for distances up to $100 \mathrm{~km}$

${ }^{65}$ Minimum period for vertical equations is $0.04 \mathrm{~s}$.

${ }^{66}$ Maximum period for vertical equations is $3 \mathrm{~s}$. 
Table B.1: continued

\begin{tabular}{|c|c|c|c|c|c|c|c|c|c|c|c|c|c|c|c|c|}
\hline Reference & Area & $\mathrm{H}$ & $\mathrm{V}$ & $\mathrm{E}$ & $M_{\min }$ & $M_{\max }$ & $M$ scale & $d_{\min }$ & $d_{\max } d$ scale & $\mathrm{S}$ & $T \mathrm{~s}$ & $T_{\min }$ & $T_{\max }$ & $\mathrm{C}$ & $\mathrm{R}$ & M \\
\hline $\begin{array}{l}\text { Sun and } \\
\text { Peng (1993) }\end{array}$ & $\begin{array}{l}\text { W. USA } \\
\text { with } 1 \\
\text { foreign }\end{array}$ & $150+1$ & - & $42+1$ & 4.1 & 7.7 & $\begin{array}{l}M_{L} \quad \text { for } \\
M<6 \\
\text { else } M_{s}\end{array}$ & $2^{*}$ & $150^{*} d_{e}$ & $\mathrm{C}$ & $\mathrm{U}$ & 0.04 & 10 & $\mathrm{R}$ & 1 & $\mathrm{~A}$ \\
\hline $\begin{array}{l}\text { Boore et al. } \\
(1994 a) \quad \& \\
\text { Boore et al. } \\
(1997)\end{array}$ & $\begin{array}{l}\text { W. N. } \\
\text { America }\end{array}$ & $\begin{array}{l}112 \\
(70)\end{array}$ & - & $14(9)$ & 5.30 & $\begin{array}{l}7.70 \\
(7.40)\end{array}$ & $M_{w}$ & 0 & $109 d_{f}$ & $\mathrm{C}$ & 46 & 0.1 & 2 & $\begin{array}{l}\mathrm{L}, \\
\mathrm{G}\end{array}$ & $\begin{array}{l}1 \mathrm{M} \\
2 \mathrm{M}\end{array}$ & $\begin{array}{l}\mathrm{A} \\
(\mathrm{R}, \mathrm{S})^{67}\end{array}$ \\
\hline $\begin{array}{l}\text { Climent } \\
\text { et al. (1994) }\end{array}$ & $\begin{array}{l}\text { Central } \\
\text { Amer- } \\
\text { ica \& } \\
\text { Mexico }\end{array}$ & 280 & $\mathrm{U}$ & 72 & $\mathrm{U}$ & $\mathrm{U}$ & $\mathrm{U}$ & $\mathrm{U}$ & $\mathrm{U} \quad \mathrm{U}$ & $\mathrm{U}$ & $\mathrm{U}$ & $0.05^{*}$ & $\geq 2$ & $\mathrm{U}$ & $\mathrm{U}$ & $\mathrm{A}$ \\
\hline $\begin{array}{l}\text { Fukushima } \\
\text { et al. } \\
\text { (1994) \& } \\
\text { Fukushima } \\
\text { et al. (1995) }\end{array}$ & $\begin{array}{l}3 \quad \text { ver- } \\
\text { tical } \\
\text { arrays in } \\
\text { Japan }\end{array}$ & 285 & 284 & 42 & 5.0 & 7.7 & $M_{\mathrm{JMA}}$ & $60^{*}$ & $400^{*} d_{h}$ & $\mathrm{I}$ & $\mathrm{U}$ & 0.05 & 2 & B & 1,2 & $\mathrm{~A}$ \\
\hline $\begin{array}{l}\text { Lawson and } \\
\text { Krawinkler } \\
\text { (1994) }\end{array}$ & W. USA & $250+$ & - & 11 & 5.8 & 7.4 & $M_{w}$ & $\mathrm{U}$ & $100 d_{f}$ & 3 & 38 & 0.1 & 4 & $\mathrm{U}$ & $1 \mathrm{M}$ & $\mathrm{A}$ \\
\hline
\end{tabular}

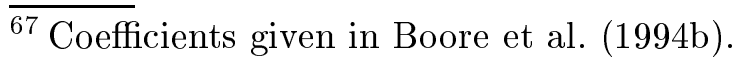


Table B.1: continued

\begin{tabular}{|c|c|c|c|c|c|c|c|c|c|c|c|c|c|c|c|c|c|}
\hline Reference & Area & $\mathrm{H}$ & $\mathrm{V}$ & $\mathrm{E}$ & $M_{\min }$ & $M_{\max }$ & $M$ scale & $d_{\min }$ & $d_{\max }$ & $d$ scale & $\mathrm{S}$ & $T \mathrm{~s}$ & $T_{\min }$ & $T_{\max }$ & $\mathrm{C}$ & $\mathrm{R}$ & M \\
\hline $\begin{array}{l}\text { Lee and } \\
\text { Manić } \\
(1994) \quad \& \\
\text { Lee (1995) }\end{array}$ & $\begin{array}{l}\text { Former } \\
\text { Yu- } \\
\text { goslavia }\end{array}$ & 313 & 313 & 183 & 3.75 & 7.0 & $\mathrm{U}$ & 4 & 250 & $d_{e}$ & 6 & 12 & 0.04 & 2 & $\mathrm{U}$ & $2 \mathrm{R}$ & $\mathrm{A}$ \\
\hline \multicolumn{2}{|c|}{$\begin{array}{l}\text { MohammadiouCalifornia } \\
\text { (1994a) }\end{array}$} & $108^{68}$ & 56 & 23 & 5.3 & 7.7 & $M_{L}$ & 3 & 136 & $\begin{array}{l}\text { Often } \\
d_{r}, d_{h} \text { in } \\
\text { far field }\end{array}$ & 1 & 96 & 0.013 & 5 & B & 1 & $\mathrm{~A}$ \\
\hline \multicolumn{2}{|c|}{$\begin{array}{l}\text { Mohammadiouw. USA } \\
\text { (1994b) }\end{array}$} & $530^{69}$ & $\approx 265$ & $\mathrm{U}$ & $\bar{U}$ & $\bar{U}$ & $M_{L}$ & 1 & 250 & $\begin{array}{l}d_{r}, \quad d_{E} \\
\text { if more } \\
\text { appro- } \\
\text { priate, } \\
d_{h} \text { in far } \\
\text { field }\end{array}$ & 1 & 96 & 0.013 & 5 & $\mathrm{~B}$ & 1 & $\mathrm{~A}$ \\
\hline $\begin{array}{l}\text { Musson } \\
\text { et al. (1994) }\end{array}$ & $\begin{array}{l}\text { UK } \\
+\quad 28^{*} \\
\text { foreign }\end{array}$ & \multicolumn{2}{|c|}{$88^{*}+28^{*} \underline{7} 0$} & $15+16$ & $3(3.7)$ & $\begin{array}{l}4.1 \\
(6.4)\end{array}$ & $M_{L}$ & $\begin{array}{l}70^{*} \\
(>1 .\end{array}$ & $>477$ & & 1 & 4 & 0.1 & 1 & \multicolumn{2}{|c|}{$\mathrm{U}^{71} \mathrm{O}$} & $\mathrm{A}$ \\
\hline
\end{tabular}

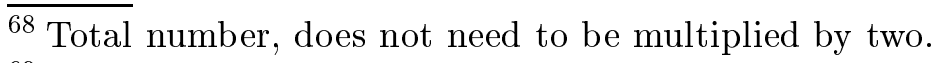

69 Total number, does not need to be multiplied by two.

70 There are 116 records in total.

${ }^{71}$ Free (1996) believes it is largest horizontal component. 
Table B.1: continued

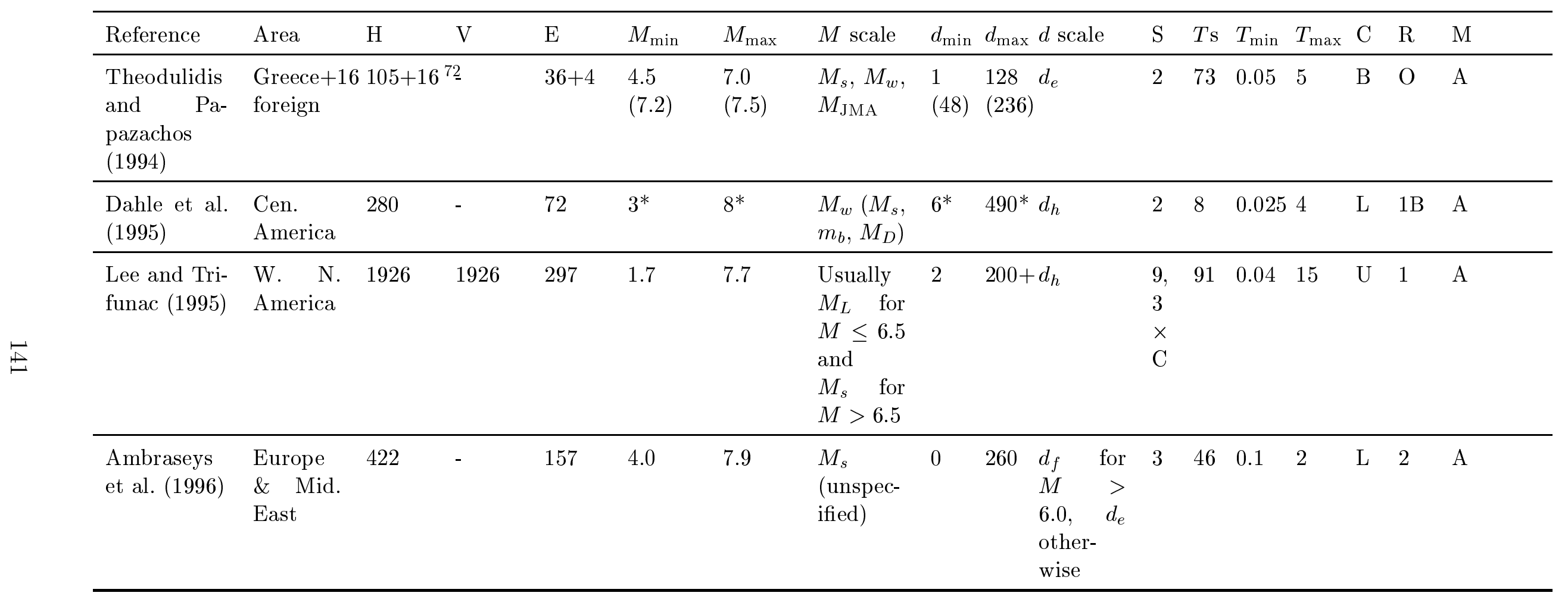

continued on next page

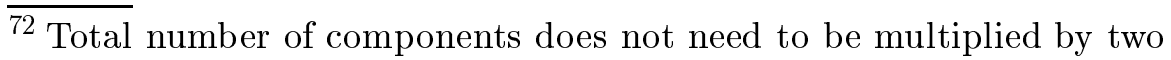


Table B.1: continued

\begin{tabular}{|c|c|c|c|c|c|c|c|c|c|c|c|c|c|c|c|c|c|}
\hline Reference & Area & $\mathrm{H}$ & $\mathrm{V}$ & $\mathrm{E}$ & $M_{\min }$ & $M_{\max }$ & $M$ scale & $d_{\min }$ & $d_{\text {max }}$ & $d$ scale & $\mathrm{S}$ & $T \mathrm{~s}$ & $T_{\min }$ & $T_{\max }$ & $\mathrm{C}$ & $\mathrm{R}$ & $\mathrm{M}$ \\
\hline $\begin{array}{l}\text { Ambraseys } \\
\text { and Simp- } \\
\text { son (1996) }\end{array}$ & $\begin{array}{l}\text { Europe } \\
\& \quad \text { Mid. } \\
\text { East }\end{array}$ & - & 417 & 157 & 4.0 & 7.9 & $\begin{array}{l}M_{s} \\
\text { (unspec- } \\
\text { ified) }\end{array}$ & 0 & 260 & $\begin{array}{l}d_{f} \quad \text { for } \\
M \quad> \\
6.0, \quad d_{e} \\
\text { other- } \\
\text { wise }\end{array}$ & 3 & 46 & 0.1 & 2 & $\mathrm{~L}$ & 2 & A \\
\hline $\begin{array}{l}\text { Bommer } \\
\text { et al. (1996) }\end{array}$ & $\begin{array}{l}\text { El Sal- } \\
\text { vador \& } \\
\text { Nicaragua }\end{array}$ & 36 & - & 20 & 3.7 & 7.0 & $M_{s}$ & 62 & 260 & $d_{h}$ & 1 & 10 & 0.1 & 2 & $\mathrm{~L}$ & $\mathrm{U}$ & A \\
\hline $\begin{array}{l}\text { Crouse and } \\
\text { McGuire } \\
(1996)\end{array}$ & $\begin{array}{l}\text { Cen. \& } \\
\text { S. Cali- } \\
\text { fornia }\end{array}$ & 238 & - & 16 & 6.0 & 7.7 & $M_{s}$ & 0.1 & 211 & $d_{r}$ & 4 & 14 & 0.04 & 14 & $\mathrm{G}$ & $1 \mathrm{~W}$ & $\begin{array}{l}\mathrm{R}, \mathrm{S} \\
(\mathrm{R}, \mathrm{S})\end{array}$ \\
\hline $\begin{array}{l}\text { Free }(1996) \\
\& \text { Free et al. } \\
(1998)\end{array}$ & $\begin{array}{l}\text { Stable } \\
\text { conti- } \\
\text { nental } \\
\text { regions }\end{array}$ & $\begin{array}{l}399- \\
410\end{array}$ & $\begin{array}{l}347- \\
477\end{array}$ & $\begin{array}{l}\text { H: } \\
137- \\
138, \\
\text { V: } \\
126^{-} \\
132\end{array}$ & 1.5 & 6.8 & $M_{w}$ & 0 & 820 & $\begin{array}{l}d_{f} \quad \text { for } \\
\text { some, } d_{e} \\
\text { for most }\end{array}$ & 2 & 52 & 0.04 & 2 & $\mathrm{~L}$ & 1 & $\mathrm{~A}$ \\
\hline
\end{tabular}


Table B.1: continued

\begin{tabular}{|c|c|c|c|c|c|c|c|c|c|c|c|c|c|c|c|c|}
\hline Reference & Area & $\mathrm{H}$ & $\mathrm{V}$ & $\mathrm{E}$ & $M_{\min }$ & $M_{\max }$ & $M$ scale & $d_{\min }$ & $d_{\max } d$ scale & $\mathrm{S}$ & $T \mathrm{~s}$ & $T_{\min }$ & $T_{\max }$ & $\mathrm{C}$ & $\mathrm{R}$ & $\mathrm{M}$ \\
\hline $\begin{array}{l}\text { Molas and } \\
\text { Yamazaki } \\
(1996)\end{array}$ & Japan & 2166 & - & 387 & 4.1 & 7.8 & $M_{\mathrm{JMA}}$ & $8^{*}$ & $\begin{array}{c}1000^{*} d_{r} \text { for } 2 \\
\text { earth- } \\
\text { quakes, } \\
d_{h} \text { oth- } \\
\text { erwise }\end{array}$ & $\mathrm{I}$ & 12 & 0.1 & 4 & $\mathrm{~L}$ & $\mathrm{O}$ & $\mathrm{A}$ \\
\hline $\begin{array}{l}\text { Ohno et al. } \\
(1996)\end{array}$ & California & 248 & - & 17 & 5.0 & 7.5 & $\begin{array}{l}M_{w} \\
\left(M_{L}\right)\end{array}$ & 7.2 & $\begin{array}{rlr}99.6 & d_{q} \quad \text { for } \\
& M \quad> \\
& 5.3, \quad d_{h} \\
& \text { other- } \\
& \text { wise }\end{array}$ & 2 & $\mathrm{U}$ & 0.02 & 2 & $\mathrm{~B}$ & $2 \mathrm{M}$ & $\mathrm{A}$ \\
\hline $\begin{array}{l}\text { Sabetta and } \\
\text { Pugliese } \\
(1996)\end{array}$ & Italy & 95 & 95 & 17 & 4.6 & 6.8 & $\begin{array}{lr}M_{s} & \text { if } \\
M_{L} & \& \\
M_{s} & \geq \\
5.5 & \text { else } \\
M_{L} & \end{array}$ & $\begin{array}{l}1.5 \\
1.5\end{array}$ & $\begin{array}{l}179, \text { Both } d_{f} \\
180^{73} \& d_{e}\end{array}$ & 3 & 14 & 0.04 & 4 & $\mathrm{~L}$ & 1 & $\mathrm{~A}$ \\
\hline $\begin{array}{l}\text { Spudich } \\
\text { et al. (1996) }\end{array}$ & $\begin{array}{l}\text { Worldwide } \\
\text { exten- } \\
\text { sional } \\
\text { regimes }\end{array}$ & $\begin{array}{l}99- \\
118\end{array}$ & - & $27-29$ & 5.10 & 6.90 & $M_{w}$ & 0 & $102.1 d_{f}$ & 2 & 46 & 0.1 & 2 & $\begin{array}{l}\mathrm{G}, \\
\mathrm{C}\end{array}$ & $2 \mathrm{M}$ & NS \\
\hline
\end{tabular}

continued on next page

$\overline{{ }^{73} \text { State }}$ equations should not be used for distances $>100 \mathrm{~km}$ 
Table B.1: continued

\begin{tabular}{|c|c|c|c|c|c|c|c|c|c|c|c|c|c|c|c|c|}
\hline Reference & Area & $\mathrm{H}$ & $\mathrm{V}$ & $\mathrm{E}$ & $M_{\min }$ & $M_{\max }$ & $M$ scale & $d_{\min }$ & $d_{\max } d$ scale & $\mathrm{S}$ & $T \mathrm{~s}$ & $T_{\min }$ & $T_{\max }$ & $\mathrm{C}$ & $\mathrm{R}$ & $\mathrm{M}$ \\
\hline $\begin{array}{l}\text { Abrahamson } \\
\text { and Silva } \\
(1997)\end{array}$ & $\begin{array}{l}\text { California } \\
\text { with } \\
\text { some } \\
\text { others }\end{array}$ & $\begin{array}{l}\leq \\
655^{*}\end{array}$ & $\begin{array}{l}\leq \\
650^{*}\end{array}$ & $\leq 58$ & 4.4 & 7.4 & $\mathrm{U}$ & 0.1 & $220^{*} d_{r}$ & 2 & 28 & 0.01 & 5 & G & $1 \mathrm{M}$ & $\begin{array}{l}\mathrm{A} \\
(\mathrm{S}, \mathrm{O}, \mathrm{T})\end{array}$ \\
\hline $\begin{array}{l}\text { Atkinson } \\
\text { (1997) }\end{array}$ & $\begin{array}{l}\text { Cascadia } \\
\text { with } \\
\text { some } \\
\text { foreign }\end{array}$ & $\mathrm{U}$ & - & $11+9$ & 4.1 & $6.7(8.2)$ & $M_{w}$ & $20^{*}$ & $\begin{aligned} 580^{*} & d_{c} \quad \text { for } \\
& \text { some, } d_{h} \\
& \text { for small } \\
& \text { ones }\end{aligned}$ & 2 & 12 & 0.1 & 2 & B & 2 & $\mathrm{~A}$ \\
\hline $\begin{array}{l}\text { Campbell } \\
(1997)\end{array}$ & Worldwide & $\begin{array}{l}266 \\
74\end{array}$ & 173 & $\begin{array}{l}\mathrm{H}: 30 \\
\mathrm{~V}: 22\end{array}$ & 4.7 & 8.1 & $\begin{array}{l}M_{s} \text { for } \\
M_{s} \geq 6, \\
M_{L} \text { for } \\
M_{s}<6\end{array}$ & 3 & $50 \quad d_{s}$ & 3 & 13 & 0.05 & 4 & G & IW & $\begin{array}{l}\mathrm{A} \\
(\mathrm{S}, \mathrm{R}, \mathrm{N})\end{array}$ \\
\hline $\begin{array}{l}\text { Youngs } \\
\text { et al. (1997) }\end{array}$ & $\begin{array}{l}\text { Worldwide } \\
\text { subduc- } \\
\text { tion } \\
\text { zones }\end{array}$ & $\leq 476$ & - & $\leq 164$ & 5.0 & 8.2 & $\begin{array}{l}M_{w} \\
\left(M_{s}, m_{b}\right)\end{array}$ & 8.5 & $\begin{array}{c}550.9 d_{r}, d_{h} \text { for } \\
\text { some }\end{array}$ & 2 & 11 & 0.075 & 3 & $\mathrm{G}$ & $1 \mathrm{M}$ & $\begin{array}{l}\mathrm{NT} \\
(\mathrm{N}, \mathrm{T})\end{array}$ \\
\hline
\end{tabular}

continued on next page

$\overline{74}$ Typographic error in Table 3 of Campbell (1997) does not match number of recordings in Table 4 
Table B.1: continued

\begin{tabular}{|c|c|c|c|c|c|c|c|c|c|c|c|c|c|c|c|c|c|}
\hline Reference & Area & $\mathrm{H}$ & $\mathrm{V}$ & $\mathrm{E}$ & $M_{\min }$ & $M_{\max }$ & $M$ scale & $d_{\min }$ & $d_{\max }$ & $d$ scale & $\mathrm{S}$ & $T \mathrm{~s}$ & $T_{\min }$ & $T_{\max }$ & $\mathrm{C}$ & $\mathrm{R}$ & $\mathrm{M}$ \\
\hline $\begin{array}{l}\text { Bommer } \\
\text { et al. (1998) }\end{array}$ & $\begin{array}{l}\text { Europe } \\
\& \quad \text { Mid. } \\
\text { East }\end{array}$ & $\begin{array}{l}121- \\
183\end{array}$ & - & $34-43$ & 5.5 & 7.9 & $M_{s}$ & 3 & 260 & $\begin{array}{l}d_{f} \quad \text { for } \\
\text { most, } d_{e} \\
\text { other- } \\
\text { wise }\end{array}$ & 3 & 66 & 0.04 & 3 & $\mathrm{~L}$ & 2 & $\mathrm{~A}$ \\
\hline $\begin{array}{l}\text { Perea and } \\
\text { Sordo } \\
(1998)\end{array}$ & $\begin{array}{l}\text { Urban } \\
\text { area of } \\
\text { Puebla, } \\
\text { Mexico }\end{array}$ & $10^{75}$ & - & 8 & 5.8 & 8.1 & $\begin{array}{l}m_{b} \quad \text { for } \\
M<6, \\
M_{s} \text { oth- } \\
\text { erwise }\end{array}$ & 274 & 663 & $d_{e}$ & 1 & 195 & 0.01 & 3.5 & $\mathrm{~L}$ & 1 & $\mathrm{~A}$ \\
\hline $\begin{array}{l}\text { Shabestari } \\
\text { and Ya- } \\
\text { mazaki } \\
(1998)\end{array}$ & Japan & 3990 & - & 1020 & $\mathrm{U}$ & 8.1 & $M_{\mathrm{JMA}}$ & $\mathrm{U}$ & $\mathrm{U}$ & $d_{r}$ & $\mathrm{U}$ & 35 & 0.04 & 10 & $\mathrm{~L}$ & $\mathrm{O}$ & A \\
\hline $\begin{array}{l}\text { Chapman } \\
\text { (1999) }\end{array}$ & $\begin{array}{l}\text { W. N. } \\
\text { America }\end{array}$ & 304 & - & 23 & 5.0 & 7.7 & $M_{w}$ & 0.1 & 189.4 & & 3 & 24 & 0.1 & 2 & $\mathrm{G}$ & $2 \mathrm{M}$ & $\mathrm{A}$ \\
\hline $\begin{array}{l}\text { Spudich } \\
\text { et al. (1999) }\end{array}$ & $\begin{array}{l}\text { Worldwide } \\
\text { exten- } \\
\text { sional } \\
\text { regimes }\end{array}$ & $\begin{array}{l}105- \\
132\end{array}$ & - & $\leq 38$ & 5.1 & 7.2 & $M_{w}$ & 0 & 99.4 & & 2 & 46 & 0.1 & 2 & $\mathrm{G}$ & $1 \mathrm{M}$ & NS \\
\hline
\end{tabular}

continued on next page

$\overline{75}$ Typographical error in Figure $3 \mathrm{~b})$ of Perea and Sordo (1998) because it does not match their Table 1. 
Table B.1: continued

\begin{tabular}{|c|c|c|c|c|c|c|c|c|c|c|c|c|c|c|c|c|c|}
\hline Reference & Area & $\mathrm{H}$ & $\mathrm{V}$ & $\mathrm{E}$ & $M_{\min }$ & $M_{\max }$ & $M$ scale & $d_{\min }$ & $d_{\max }$ & $d$ scale & $\mathrm{S}$ & $T \mathrm{~s}$ & $T_{\min }$ & $T_{\max }$ & $\mathrm{C}$ & $\mathrm{R}$ & $\mathrm{M}$ \\
\hline $\begin{array}{l}\text { Ambraseys } \\
\text { and Douglas } \\
(2000)\end{array}$ & Worldwide & 186 & 183 & 44 & 5.83 & 7.8 & $M_{s}$ & 0 & 15 & $d_{f}$ & 3 & 46 & 0.1 & 2 & $\mathrm{~L}$ & 1 & A \\
\hline $\begin{array}{l}\text { Bozorgnia } \\
\text { et al. }(2000)\end{array}$ & Worldwide & 1308 & 1308 & 33 & $\mathrm{U}$ & $\mathrm{U}$ & $M_{w}$ & $\mathrm{U}$ & $\begin{array}{l}\leq \\
60\end{array}$ & $d_{s}$ & 4 & $\mathrm{U}$ & 0.05 & 4 & G & $\mathrm{U}$ & $\begin{array}{l}\mathrm{A} \\
(\mathrm{R}, \mathrm{S}, \mathrm{T})\end{array}$ \\
\hline $\begin{array}{l}\text { Campbell } \\
\text { and Bo- } \\
\text { zorgnia } \\
(2000)\end{array}$ & Worldwide & $\begin{array}{l}275- \\
435\end{array}$ & $\begin{array}{l}274- \\
434\end{array}$ & $\leq 36$ & $\geq 4.7$ & $\leq 7.7$ & $M_{w}$ & $\geq$ & $\begin{array}{l}\leq \\
60^{*}\end{array}$ & $d_{s}$ & 4 & 14 & 0.05 & 4 & $\mathrm{G}$ & 1 & $\begin{array}{l}\mathrm{A} \\
(\mathrm{S}, \mathrm{R}, \mathrm{T})\end{array}$ \\
\hline $\begin{array}{l}\text { Chou and } \\
\text { Uang (2000) }\end{array}$ & California & 273 & - & 15 & 5.6 & 7.4 & $M_{w}$ & $0^{*}$ & 120 & $d_{f}$ & 3 & 25 & 0.1 & 3 & G & $2 \mathrm{M}$ & $\mathrm{A}$ \\
\hline $\begin{array}{l}\text { Kawano } \\
\text { et al. (2000) }\end{array}$ & Japan & 107 & 107 & 44 & 5.5 & 7.0 & $M_{\mathrm{JMA}}$ & 27 & 202 & $d_{q}$ & $\begin{array}{l}\mathrm{I}, \\
\mathrm{C}\end{array}$ & $\mathrm{U}$ & 0.02 & 5 & $\mathrm{U}$ & $\mathrm{O}$ & $\mathrm{A}$ \\
\hline $\begin{array}{l}\text { Kobayashi } \\
\text { et al. }(2000)\end{array}$ & Japan & $\mathrm{U}$ & - & $\mathrm{U}$ & 5.0 & 7.8 & $M_{w}$ & $0.9^{*}$ & $400^{*}$ & $\mathrm{U}$ & 4 & 17 & 0.1 & 5 & B & $1 \mathrm{M}$ & $\mathrm{A}$ \\
\hline $\begin{array}{l}\text { McVerry } \\
\text { et al. }(2000)\end{array}$ & $\begin{array}{l}\text { NZ } \\
\text { with } 66 \\
\text { foreign }\end{array}$ & $\begin{array}{l}\leq 224 \\
(461+66)\end{array}$ & & \multicolumn{2}{|c|}{$(51+17)(5.08)$} & \multicolumn{2}{|c|}{$\left(7.23(7.41) M I_{w}\right.$} & (0.1) & (573) & $\begin{array}{l}\left(d_{r} \text { for }\right. \\
\text { some, } \\
d_{c} \text { for } \\
\text { most })\end{array}$ & 4 & $\mathrm{U}$ & $0.01^{*}$ & $4^{*}$ & $\mathrm{U}$ & $\mathrm{O}$ & $\begin{array}{l}\mathrm{A}(\mathrm{N}, \mathrm{R}, \\
\mathrm{RO})\end{array}$ \\
\hline
\end{tabular}


Table B.1: continued

\begin{tabular}{|c|c|c|c|c|c|c|c|c|c|c|c|c|c|c|c|c|}
\hline Reference & Area & $\mathrm{H}$ & $\mathrm{V}$ & $\mathrm{E}$ & $M_{\min }$ & $M_{\max }$ & $M$ scale & $d_{\min }$ & $d_{\max } d$ scale & $\mathrm{S}$ & $T \mathrm{~s}$ & $T_{\min }$ & $T_{\max }$ & $\mathrm{C}$ & $\mathrm{R}$ & $\mathrm{M}$ \\
\hline $\begin{array}{l}\text { Monguilner } \\
\text { et al. } \\
(2000 \mathrm{~b})\end{array}$ & $\begin{array}{l}\text { W. Ar- } \\
\text { gentina }\end{array}$ & 54 & 54 & 10 & 4.3 & 7.4 & $\begin{array}{l}M_{s} \quad \text { if } \\
M_{L} \quad \& \\
M_{s}>6 \\
M_{L} \text { oth- } \\
\text { erwise }\end{array}$ & 11 & $350 \quad d_{h}$ & 2 & 200 & 0.1 & 6 & $\mathrm{U}$ & $1 \mathrm{~W}$ & A \\
\hline $\begin{array}{l}\text { Shabestari } \\
\text { and Ya- } \\
\text { mazaki } \\
(2000)\end{array}$ & Japan & 6017 & - & 94 & 5.0 & 6.6 & $M_{\mathrm{JMA}}$ & $7^{*}$ & $950^{*} d_{r}$ & $\mathrm{I}$ & 35 & 0.04 & 10 & $\mathrm{~L}$ & $\mathrm{O}$ & $\mathrm{A}$ \\
\hline $\begin{array}{l}\text { Smit et al. } \\
(2000)\end{array}$ & Caucasus & 84 & - & 26 & 4.0 & 7.1 & $M_{s}$ & 4 & $230 \quad d_{h}$ & 1 & 22 & 0.05 & 1 & $\mathrm{~L}$ & 2 & A \\
\hline $\begin{array}{l}\text { Takahashi } \\
\text { et al. (2000) }\end{array}$ & $\begin{array}{l}\text { Japan }+166 \\
\text { foreign }\end{array}$ & $6 \leq 1332$ & - & $\mathrm{U}+7^{*}$ & $\begin{array}{l}5^{*} \\
\left(5.8^{*}\right) \\
\end{array}$ & $\begin{array}{l}8.3^{*} \\
\left(8^{*}\right) \\
\end{array}$ & $M_{w}$ & $\begin{array}{l}1^{*} \\
\left(0.1^{*}\right) \\
\end{array}$ & $\begin{array}{l}300^{*} d_{r}, d_{h} \text { for } \\
)\left(100^{*} \text { some }\right.\end{array}$ & 4 & 20 & 0.05 & 5 & $\mathrm{G}$ & $\mathrm{O}$ & A \\
\hline $\begin{array}{l}\text { Lussou et al. } \\
\text { (2001) }\end{array}$ & Japan & 3011 & 3011 & 102 & 3.7 & 6.3 & $M_{\mathrm{JMA}}$ & $4^{*}$ & $600^{*} d_{h}$ & 4 & 63 & 0.02 & 10 & $\mathrm{~B}$ & 2 & A \\
\hline
\end{tabular}


Table B.1: continued

\begin{tabular}{|c|c|c|c|c|c|c|c|c|c|c|c|c|c|c|c|}
\hline Reference & Area & $\mathrm{V}$ & $\mathrm{E}$ & $M_{\min }$ & $M_{\max }$ & $M$ scale & $d_{\min }$ & $d_{\max } d$ scale & S & $T \mathrm{~s}$ & $T_{\min }$ & $T_{\max }$ & $\mathrm{C}$ & $\mathrm{R}$ & M \\
\hline
\end{tabular}

$\overline{76 \text { There }}$ are 960 components for uncorrected PGA.

77 There are 941 components for uncorrected PGA.

${ }^{78}$ For horizontal corrected records. There are 49 for horizontal uncorrected PGA. There are 36 for vertical corrected records and 46 for vertical uncorrected PGA. 
Table 2

Examples of selection criteria based on source depth in past ground motion estimation relations.

\begin{tabular}{lll}
\hline Criterion & Reference & Reasons \\
\hline Maximum depth & $\begin{array}{l}20 \mathrm{~km} \text { (Boore et al., 1993) } \\
\text { and } 30 \mathrm{~km} \text { (Ambraseys et al., } \\
1996)\end{array}$ & $\begin{array}{l}\text { To restrict to shallow crustal } \\
\text { earthquakes }\end{array}$ \\
\cline { 2 - 3 } & $\begin{array}{l}\text { Fukm (Iwasaki et al., 1980; } \\
\text { (Japan) }\end{array}$ & $\begin{array}{l}\text { Definition of } M_{\text {JMA }} \text { is differ- } \\
\text { ent for deeper shocks }\end{array}$ \\
\cline { 2 - 3 } & $<91 \mathrm{~km}$ (Sharma, 1998) & $\begin{array}{l}\text { Two deeper earthquakes } \\
\text { caused large errors in regres- } \\
\text { sion coefficients }\end{array}$ \\
\hline $\begin{array}{l}\text { Reliable } \\
\text { mates of focal } \\
\text { depth }\end{array}$ & $\begin{array}{l}\text { Ambraseys and Bommer } \\
(1991)\end{array}$ & $\begin{array}{l}\text { There is high attenuation in } \\
\text { the mantle }\end{array}$ \\
\hline $\begin{array}{l}\text { Exclude deep slab } \\
\text { earthquakes }\end{array}$ & McVerry et al. (2000) & $\begin{array}{l}\text { There are differences in travel } \\
\text { path and stress condition } \\
\text { compared with shallow crustal } \\
\text { earthquakes }\end{array}$ \\
\hline $\begin{array}{l}\text { Exclude deep sub- } \\
\text { duction shocks }\end{array}$ & Campbell (1981) & \\
\hline
\end{tabular}


Table 3

Examples of minimum magnitude selection criteria in past ground motion estimation relations.

\begin{tabular}{ll}
\hline Reason & Minimum magnitude \\
\hline $\begin{array}{l}\text { Restrict data to earthquakes with engineering } \\
\text { significance }\end{array}$ & $\begin{array}{l}M_{s}=4 \text { (Ambraseys } \\
\text { et al., 1996) and } M=5 \\
\text { (Campbell, } \quad 1981 ;\end{array}$ \\
& $\begin{array}{l}\text { Iwasaki et al., 1980) } \\
\text { Restrict data to earthquakes with smaller errors }\end{array}$ \\
$\begin{array}{l}M=5 \quad \text { (Fukushima } \\
\text { in the independent parameters }\end{array}$ & $\begin{array}{l}M_{s}=5.5 \quad \text { (Bommer } \\
\text { et al., 1998) }\end{array}$ \\
Interested in long-period motions & $\begin{array}{l}M_{s}=5.5 \quad \text { (Bommer } \\
\text { Restrict to data with high signal-to-noise ratio }\end{array}$ \\
\hline
\end{tabular}


Table 4

Examples of minimum PGA selection criteria in past ground motion estimation relations.

\begin{tabular}{lll}
\hline Minimum PGA $\left(\mathrm{ms}^{-2}\right)$ & Reference & Reasons \\
\hline 0.01 & $\begin{array}{l}\text { Molas and Yamazaki } \\
(1995)\end{array}$ & $\begin{array}{l}\text { Weaker records are not reli- } \\
\text { able because of resolution of } \\
\text { instruments }\end{array}$ \\
0.10 & $\begin{array}{l}\text { Iwasaki et al. (1980) } \\
\text { Chiaruttini and Siro } \\
(1981)\end{array}$ & $\begin{array}{l}\text { To avoid possible bias } \\
\text { Campbell (1981) }\end{array}$ \\
0.15 & To avoid bias in trigger \\
0.50 & threshold \\
Near triggering level & Ambraseys (1995) & $\begin{array}{l}\text { To avoid too much contribu- } \\
\text { tion from far field } \\
\text { Processing errors can be large }\end{array}$ \\
\hline
\end{tabular}


Table 5

Types of strong-motion stations included in past ground motion estimation relations.

Include records from Reference Comments

Faccioli (1978)

Free-field and basements of build- McGuire (1978)

ings

Free-field and small structures $\quad$ Campbell (1981)

Effects of site geology, building size, instrument location and mechanism are found to be extensively interrelated

Buildings Crouse (1991)

Notes that PGA could be underestimated

Buildings with four stories or less

McVerry et al. (2000)

$\vec{c} \quad$ Buildings with more than three Zhao et al. (1997) storeys

Buildings with up to eight stories

Theodulidis and Papazachos (1992)

Four and six storey buildings

Crouse and McGuire (1996)

Included because of lack of data in site and distance range where these records are and because structure is thought not to have affected ground motion too much.

Abutments of dams

Ambraseys (1995); Campbell (1997)

Campbell (1997) includes records from dam abutments because they comprise a significant number of rock records and because stiff foundations are not thought to be significantly affected by dam.

Dams and special structures

McCue et al. (1988)

Included because of lack of available data 
Table 6

Types of strong-motion stations excluded in past ground motion estimation relations.

\begin{tabular}{|c|c|c|c|}
\hline Exclude records from & \multicolumn{2}{|l|}{ Reference } & Comments \\
\hline Basements & \multicolumn{3}{|c|}{ Kawashima et al. (1986) } \\
\hline Buildings with three or more storeys & $\begin{array}{l}\text { Joyner and } \\
(1981)\end{array}$ & Boore & \\
\hline $\begin{array}{l}\text { Buildings with more than two } \\
\text { storeys }\end{array}$ & \multicolumn{2}{|l|}{ Campbell (1997) } & $\begin{array}{l}\text { For sites on soil or soft } \\
\text { rock }\end{array}$ \\
\hline $\begin{array}{l}\text { Buildings with more than five } \\
\text { storeys }\end{array}$ & \multicolumn{2}{|l|}{ Campbell (1997) } & For sites on hard rock \\
\hline First floor & \multicolumn{3}{|c|}{ Kawashima et al. (1986) } \\
\hline Abutments of dams & $\begin{array}{l}\text { Joyner and } \\
(1981)\end{array}$ & Boore & \\
\hline Tokyo-Yokohama & $\begin{array}{l}\text { Yamabe and } \\
(1988)\end{array}$ & Kanai & $\begin{array}{l}\text { They conclude they } \\
\text { are affected by nearby } \\
\text { buildings }\end{array}$ \\
\hline
\end{tabular}


Table 7

Examples of record-dependent low $\left(f_{l}\right)$ and high $\left(f_{h}\right)$ cut-off frequencies used for filtering in past ground motion estimation relations.

\begin{tabular}{|c|c|c|c|}
\hline$f_{l}(\mathrm{~Hz})$ & $f_{h}(\mathrm{~Hz})$ & Selection method & Reference \\
\hline & & $\begin{array}{l}\text { Chosen to account for length and mean sampling rate of records and response char- } \\
\text { acteristics of accelerographs used }\end{array}$ & Faccioli (1978) \\
\hline $0.2-0.4$ & $25-35$ & Visual inspection in order to maximise signal-to-noise ratio within the passband & Sabetta and Pugliese (1987) \\
\hline \multirow[t]{2}{*}{$0.13-1.18$} & & & Tento et al. (1992) \\
\hline & $25-30$ & Site dependent & Fukushima et al. (1995) \\
\hline \multirow[t]{2}{*}{$0.2-0.7$} & $20-35$ & Compare the Fourier spectrum of signal to that of fixed trace & Sabetta and Pugliese (1996) \\
\hline & & $\begin{array}{l}\text { Visual inspection of the Fourier amplitude spectrum and doubly integrated displace- } \\
\text { ment. }\end{array}$ & Spudich et al. (1996) \\
\hline \multirow[t]{2}{*}{$0.15-0.5$} & 25 & Compare the Fourier amplitude spectrum of signal to that of noise spectrum & Cousins et al. (1999) \\
\hline & & $\begin{array}{l}\text { Use Fourier amplitude spectrum to choose the high cut-off frequency and integrated } \\
\text { displacements to choose low-frequency cut-off. }\end{array}$ & Abrahamson and Silva (1997) \\
\hline \multirow{2}{*}{\multicolumn{2}{|c|}{0.1 upwards }} & $\begin{array}{l}\text { Use a time-consuming method where the low cut-off frequency is selected by visual } \\
\text { inspection of velocity and displacement time-histories, selecting the cut-off which } \\
\text { they feel eliminates the noise }\end{array}$ & Bommer et al. (1998) \\
\hline & & $\begin{array}{l}\text { Visual inspection of the displacements (found using the Fast Fourier Transform } \\
\text { method) in prefixed and appended } 5 \mathrm{~s} \text { sections }\end{array}$ & Kobayashi et al. (2000) \\
\hline $\begin{array}{l}0.15, \quad 0.20 \\
\text { and } 0.33\end{array}$ & & Use noise level in each record & Si and Midorikawa (2000) \\
\hline
\end{tabular}


Figure captions

(1) Model usually used to model structural response caused by earthquakes where $m$ is the mass of the system, $k$ is the stiffness of the system, $c$ is the viscous damping of the system and $U_{t t}$ is the ground acceleration. The undamped natural period of the system is $T_{0}=2 \pi \sqrt{\mathrm{m} / \mathrm{k}}$ and the ratio of critical damping is $\xi_{0}=c / 2 \sqrt{\mathrm{km}}$.

(2) Comparison of scaling of horizontal peak ground acceleration at rock sites with $M_{w}$ in four recent equations to estimate strong ground motions from shallow crustal strike-slip earthquakes for two distances: a) $d_{f}, d_{r}=$ $10 \mathrm{~km}$ and $d_{s}=10.4 \mathrm{~km}$ and b) $d_{f}, d_{r}=50 \mathrm{~km}$ and $d_{s}=50.1 \mathrm{~km}$, where $d_{f}$ is shortest distance to surface projection of rupture, $d_{r}$ is shortest distance to rupture and $d_{s}$ is shortest distance to seismogenic rupture. These distances correspond to distances from a vertical fault with depth to seismogenic layer of $3 \mathrm{~km}$. The curves are plotted for those magnitudes which fall within the magnitude range of the data used to derive the equation. Conversion from $M_{w}$ to $M_{s}$ for equation of Ambraseys et al. (1996) done using Equation 1 of Ekström and Dziewonski (1988).

(3) Comparison of estimated ratio of horizontal peak ground acceleration and response spectral amplitudes for ground motions due to reverse faulting earthquakes and strike-slip faulting earthquakes for four recent equations to estimate strong ground motions from shallow crustal earthquakes. For the equation of Abrahamson and Silva (1997) a magnitude of $M_{w}=6.5$ was used; all other ratios are independent of magnitude.

(4) Comparison of estimated horizontal peak ground acceleration for ground motions due to subduction zone earthquakes for four equations to estimate strong ground motions for an earthquake of magnitude $M_{w}=7.0$ 
and hypocentral distance of $100 \mathrm{~km}$. Equation of Crouse (1991) is plotted for stiff soil site, equation of Molas and Yamazaki (1995) is plotted for site coefficient $c_{i}=0$ (average site), equation of Cousins et al. (1999) is plotted for soil site and a slab earthquake and equation of Takahashi et al. (2000) is plotted for medium soil site. Assumed that all definitions of depth used in the equations are equivalent to focal depth for this magnitude and distance.

(5) Comparison of estimated ratio of horizontal peak ground acceleration and response spectral amplitudes for ground motions on: a) soft soil sites and hard rock sites and on: b) stiff soil sites and hard rock sites, for four recent equations to estimate strong ground motions. Soft soil sites were assumed to have an average shear-wave velocity in the top $30 \mathrm{~m}$ of $310 \mathrm{~ms}^{-1}$ and hence be within category $\mathrm{S}\left(180<V_{s, 30} \leq 360 \mathrm{~ms}^{-1}\right)$ of Ambraseys et al. (1996) and category $\mathrm{C}\left(200<V_{s, 30} \leq 400 \mathrm{~ms}^{-1}\right)$ of Lussou et al. (2001); for the equations of Boore et al. (1997) the actual shear-wave velocity was used and for the equations of Campbell and Bozorgnia (2002) $S_{V F S}=$ $0.25, S_{S R}=0$ and $S_{H R}=0$ as suggested by Table 5 of Campbell and Bozorgnia (2002). Stiff soil sites were assumed to have an average shearwave velocity in the top $30 \mathrm{~m}$ of $420 \mathrm{~ms}^{-1}$ and hence be within category A $\left(360<V_{s, 30} \leq 750 \mathrm{~ms}^{-1}\right)$ of Ambraseys et al. (1996) and category B $\left(400<V_{s, 30} \leq 800 \mathrm{~ms}^{-1}\right)$ of Lussou et al. (2001); for the equations of Boore et al. (1997) the actual shear-wave velocity was used and for the equations of Campbell and Bozorgnia (2002) $S_{V F S}=0, S_{S R}=1$ and $S_{H R}=0$ as suggested by Table 5 of Campbell and Bozorgnia (2002). Hard rock sites were assumed to have an average shear-wave velocity in the top $30 \mathrm{~m}$ of $800 \mathrm{~ms}^{-1}$ and hence be within category $\mathrm{R}\left(V_{s, 30}>750 \mathrm{~ms}^{-1}\right)$ of Ambraseys et al. (1996) and category $\mathrm{A}\left(V_{s, 30}>800 \mathrm{~ms}^{-1}\right)$ of Lussou 
et al. (2001); for the equations of Boore et al. (1997) the actual shearwave velocity was used and for the equations of Campbell and Bozorgnia (2002) $S_{V F S}=0, S_{S R}=0$ and $S_{H R}=1$ as suggested by Table 5 of Campbell and Bozorgnia (2002). A seismogenic distance of $10.4 \mathrm{~km}$ and a magnitude of $M_{w}=6.5$ was used to compute the ratios for the equations of Campbell and Bozorgnia (2002); all the other ratios are independent of distance and magnitude.

(6) Comparison of the contours of Equivalent Hypocentral Distance for uniform moment release (dashed curves) and linearly increasing moment release (dotted curves) for horizontal line source (solid line). Length of fault $50 \mathrm{~km}$ and $M_{0}=1.6 \times 10^{19} \mathrm{Nm}$.

(7) Results of different inversions of fault slip performed for the Imperial Valley earthquake (15/10/1979), a) Olson and Apsel (1982), b) Hartzell and Helmberger (1982), c), d), e) Hartzell and Heaton (1983) and f) Archuleta (1984). From Gariel et al. (1990).

(8) Comparison of the contours of equal distance using four different distance measures for a fault of length $50 \mathrm{~km}$, width $20 \mathrm{~km}$, dip $30^{\circ}$ [corresponding to an earthquake of $M_{w} \approx 7.0$ (Wells and Coppersmith, 1994)] which reached the surface, with the hypocentre at the bottom of the north eastern corner of the rupture. Dotted box is the surface projection of the rupture plane. Top left is for epicentral distance, top right is for surface projection distance, bottom left is for rupture distance and bottom right is for elliptical distance.

(9) Comparison of scaling of horizontal peak ground acceleration at rock sites with $M_{w}$ in four early equations to estimate strong ground motions from shallow crustal strike-slip earthquakes for two distances: a) $d_{f}, d_{r}=$ $10 \mathrm{~km}$ and $d_{s}=10.4 \mathrm{~km}$ and b) $d_{f}, d_{r}=50 \mathrm{~km}$ and $d_{s}=50.1 \mathrm{~km}$, where 
$d_{f}$ is shortest distance to surface projection of rupture, $d_{r}$ is shortest distance to rupture and $d_{s}$ is shortest distance to seismogenic rupture. These distances correspond to distances from a vertical fault with depth to seismogenic layer of $3 \mathrm{~km}$. The curves are plotted for those magnitudes which fall within the magnitude range of the data used to derive the equation. Assumed magnitude scales (mainly $M_{L}$ ) used by the authors of these studies equal $M_{w}$ for magnitude range of interest.

(10) Uncertainty in published equations for the estimation of horizontal peak ground acceleration against date when the equation was first published. Uncertainty is expressed as a factor of one standard deviation; therefore since almost all equations are derived using the logarithm of acceleration the uncertainty is either $\exp (\sigma)$ or $10^{\sigma}$ depending on whether natural or common logarithms are used, where $\sigma$ is the report standard deviation. The shape of the marker indicates the method of combining the two horizontal components, where o means larger horizontal component is used, $\square$ means mean horizontal component (geometric or arithmetic) is used, $\diamond$ means both horizontal components are used, $\triangle$ means resolved component is used, $\triangleleft$ means randomly chosen component is used and $\nabla$ means unknown method for combining components is used. The greyshade of the markers indicates the geographical (or tectonic) origin of the data used to derive the equation. 


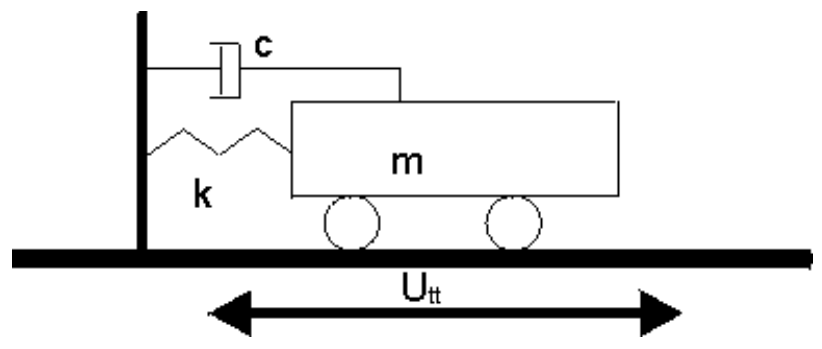

Fig. 1. 


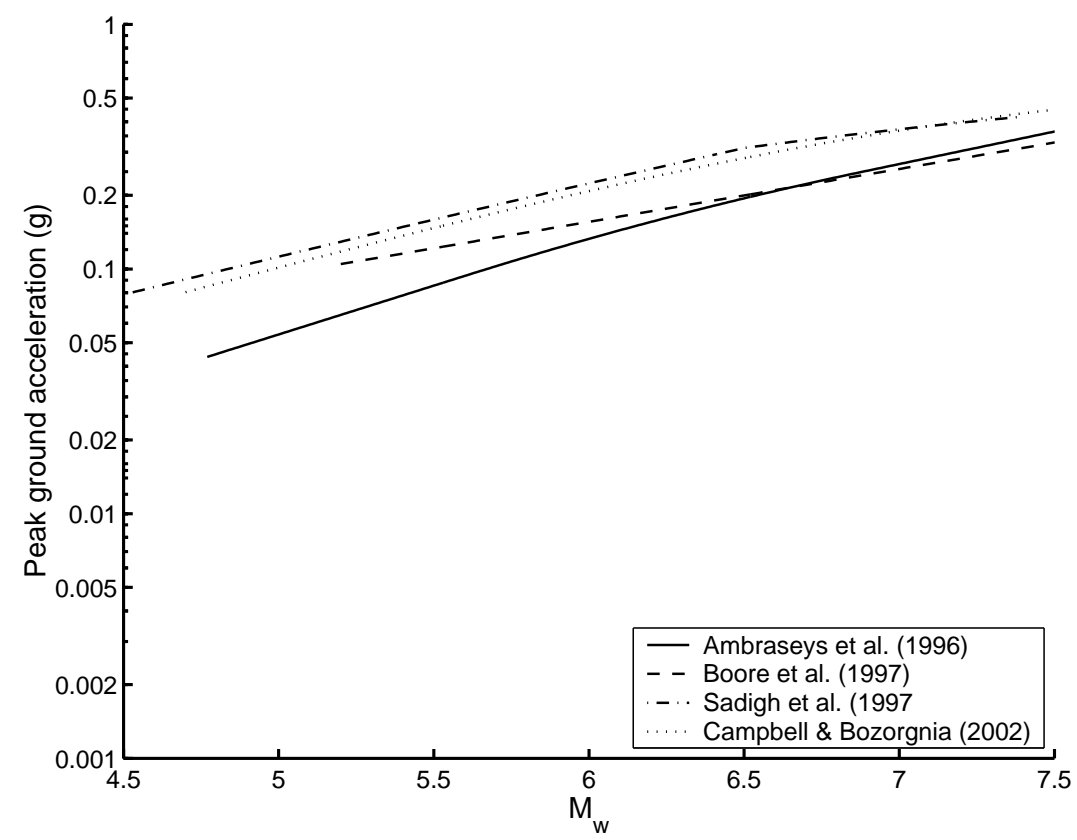

(a) $d_{f}, d_{r}=10 \mathrm{~km}$ and $d_{s}=10.4 \mathrm{~km}$

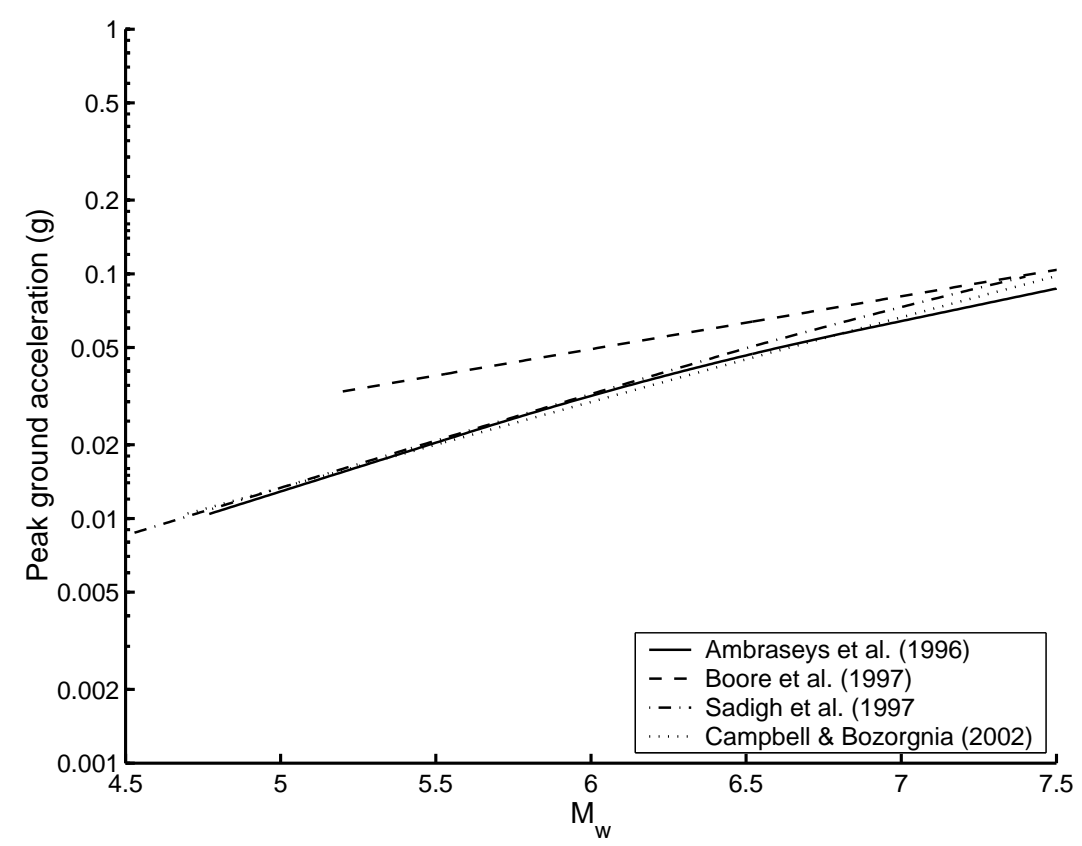

(b) $d_{f}, d_{r}=50 \mathrm{~km}$ and $d_{s}=50.1 \mathrm{~km}$

Fig. 2. 


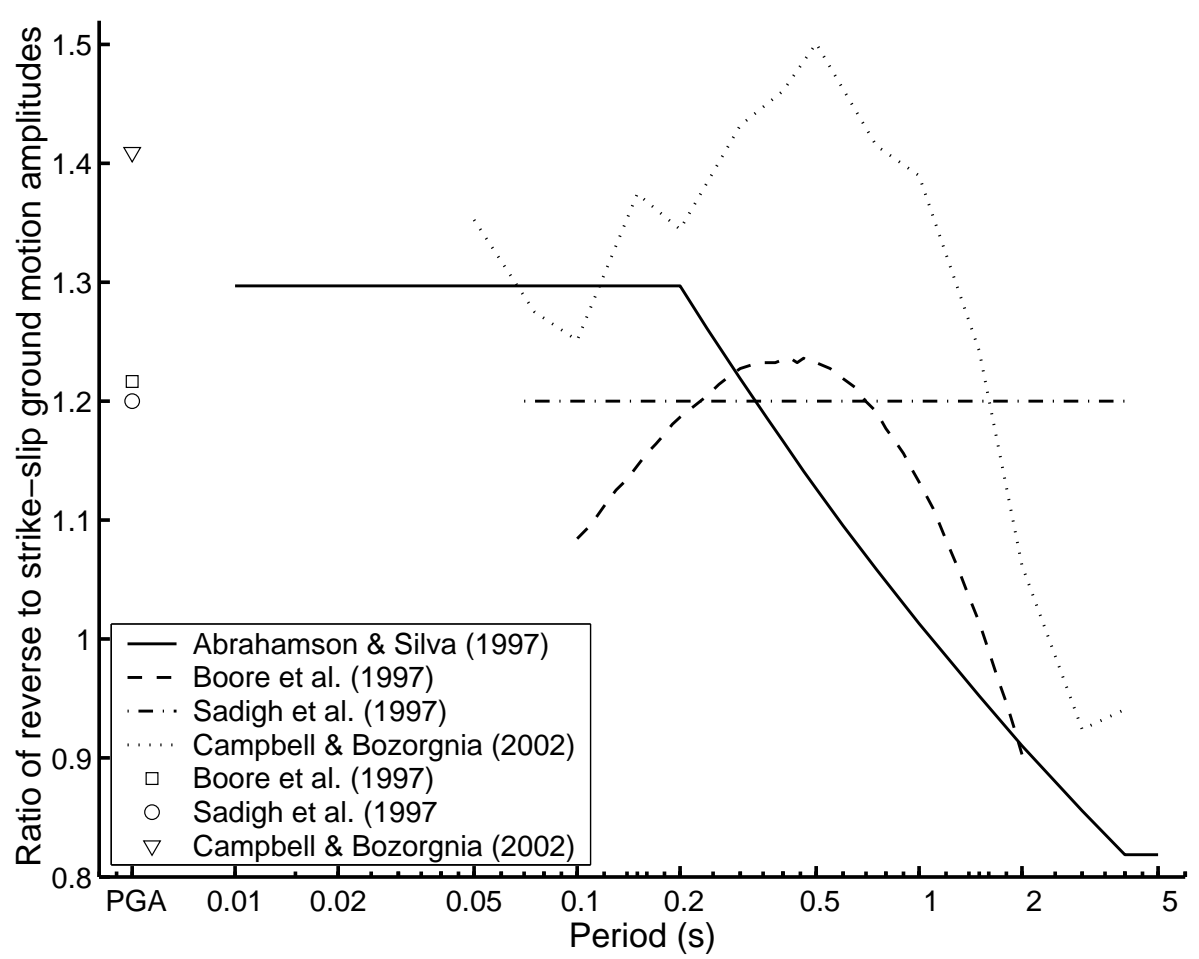

Fig. 3.

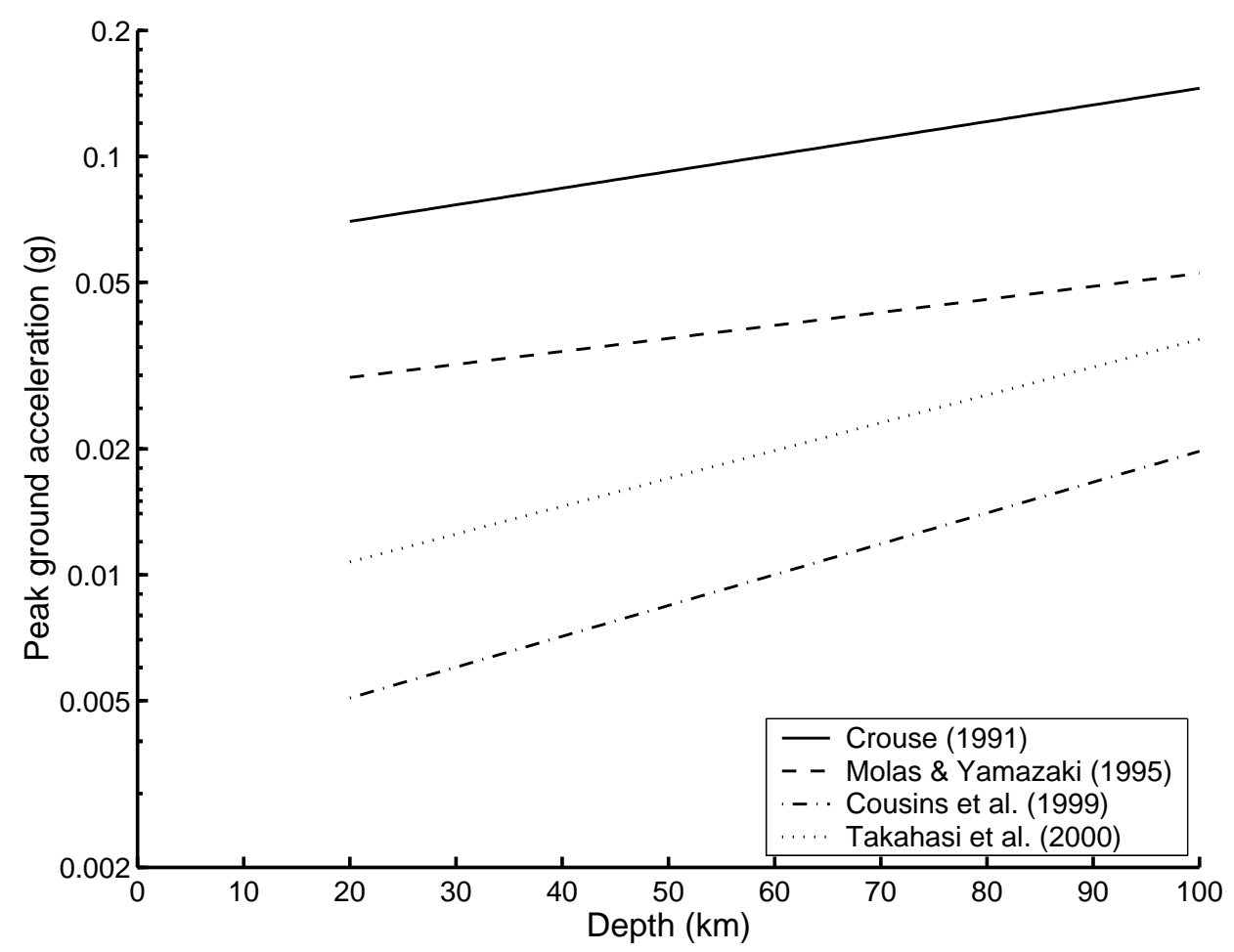

Fig. 4. 


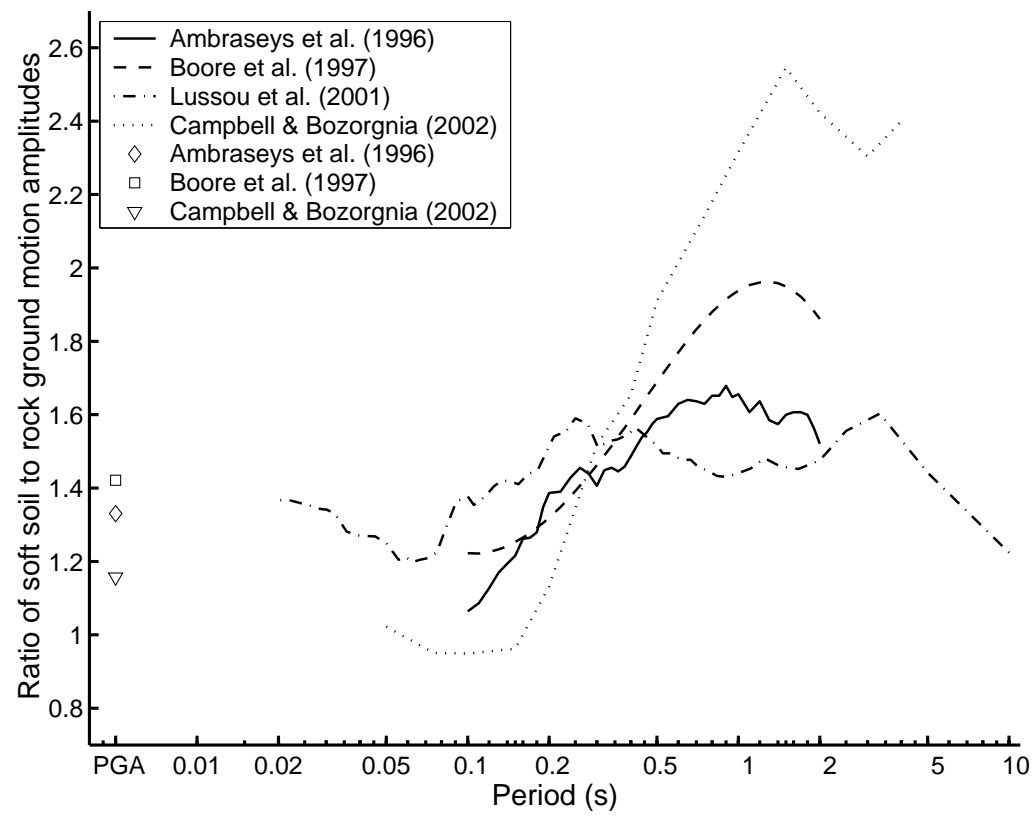

(a) Soft soil.

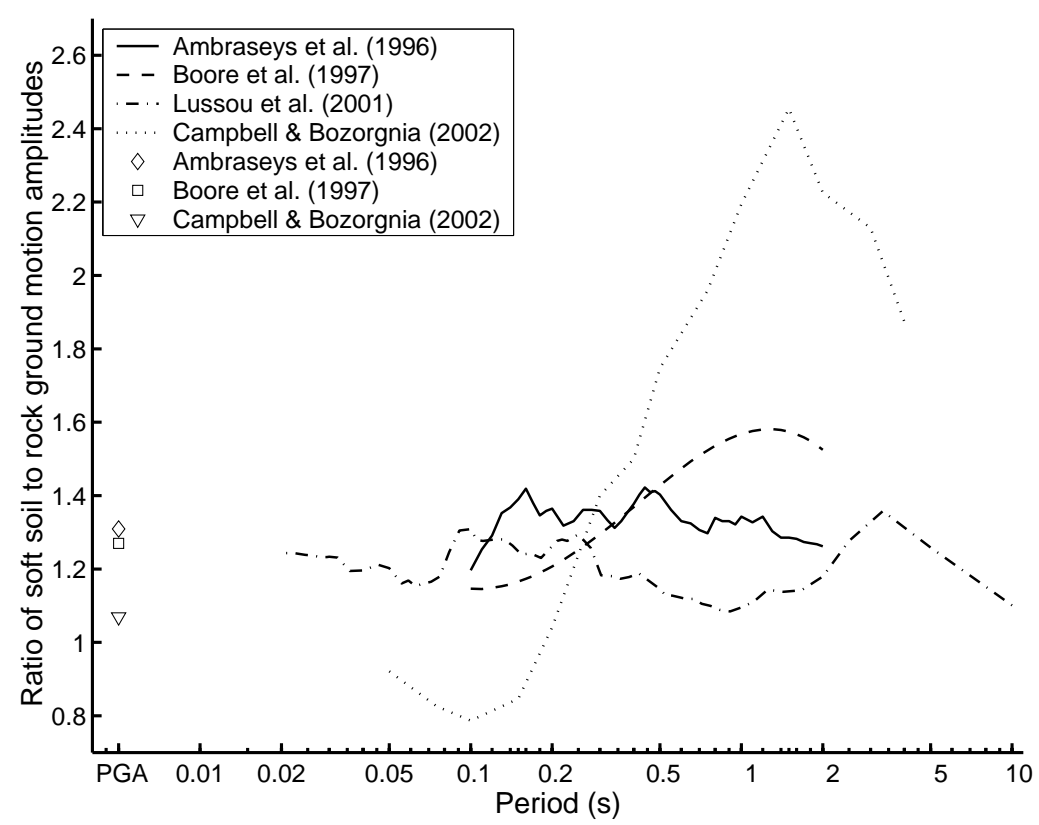

(b) Stiff soil.

Fig. 5. 


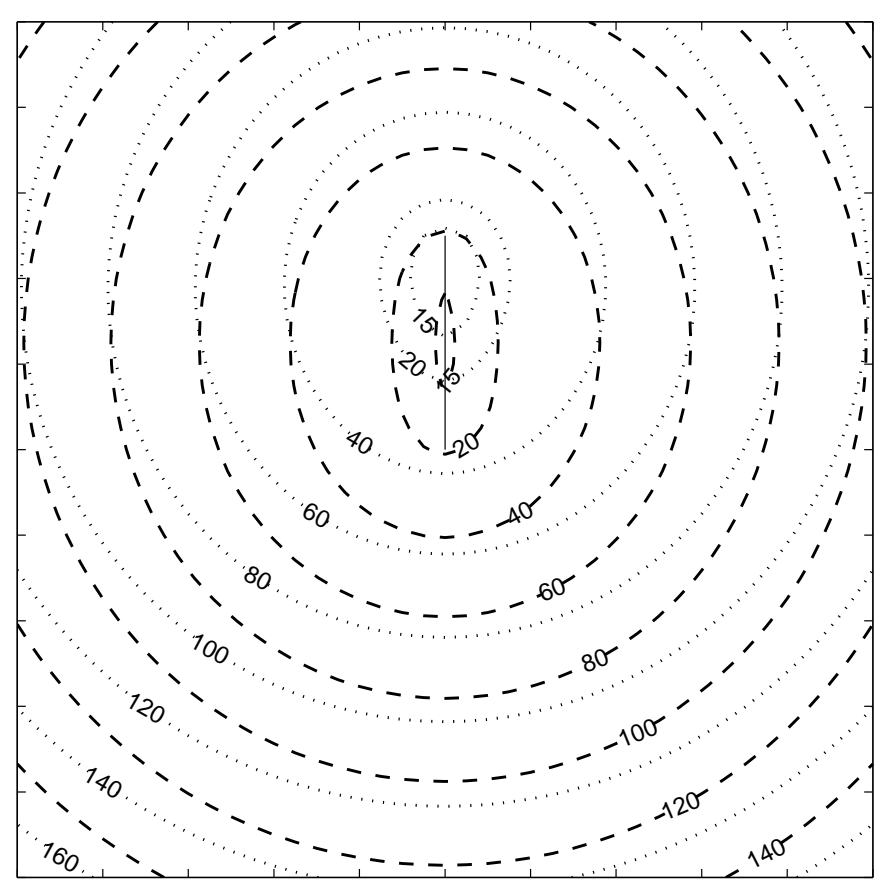

Fig. 6. 


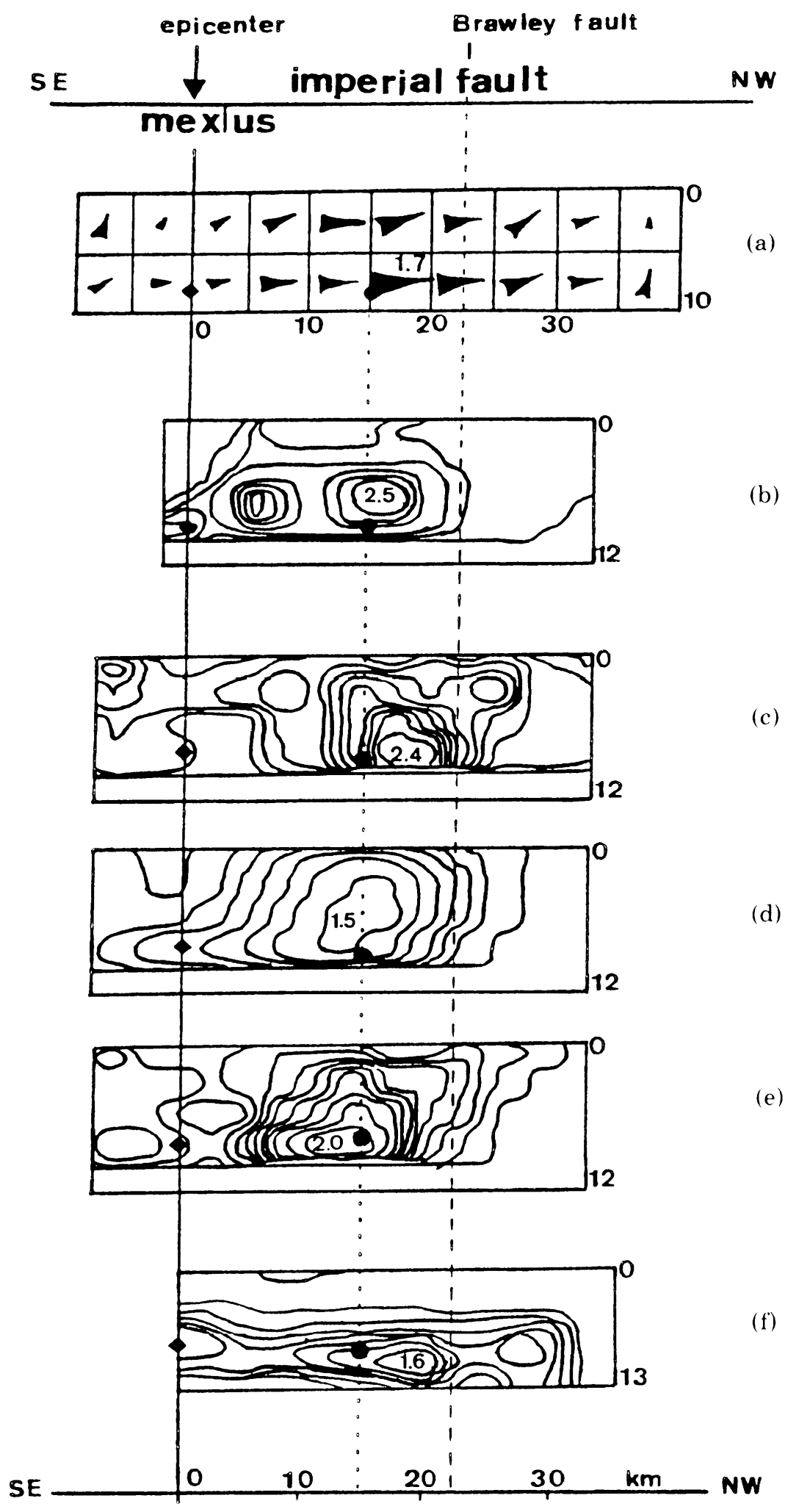

Fig. 7. 

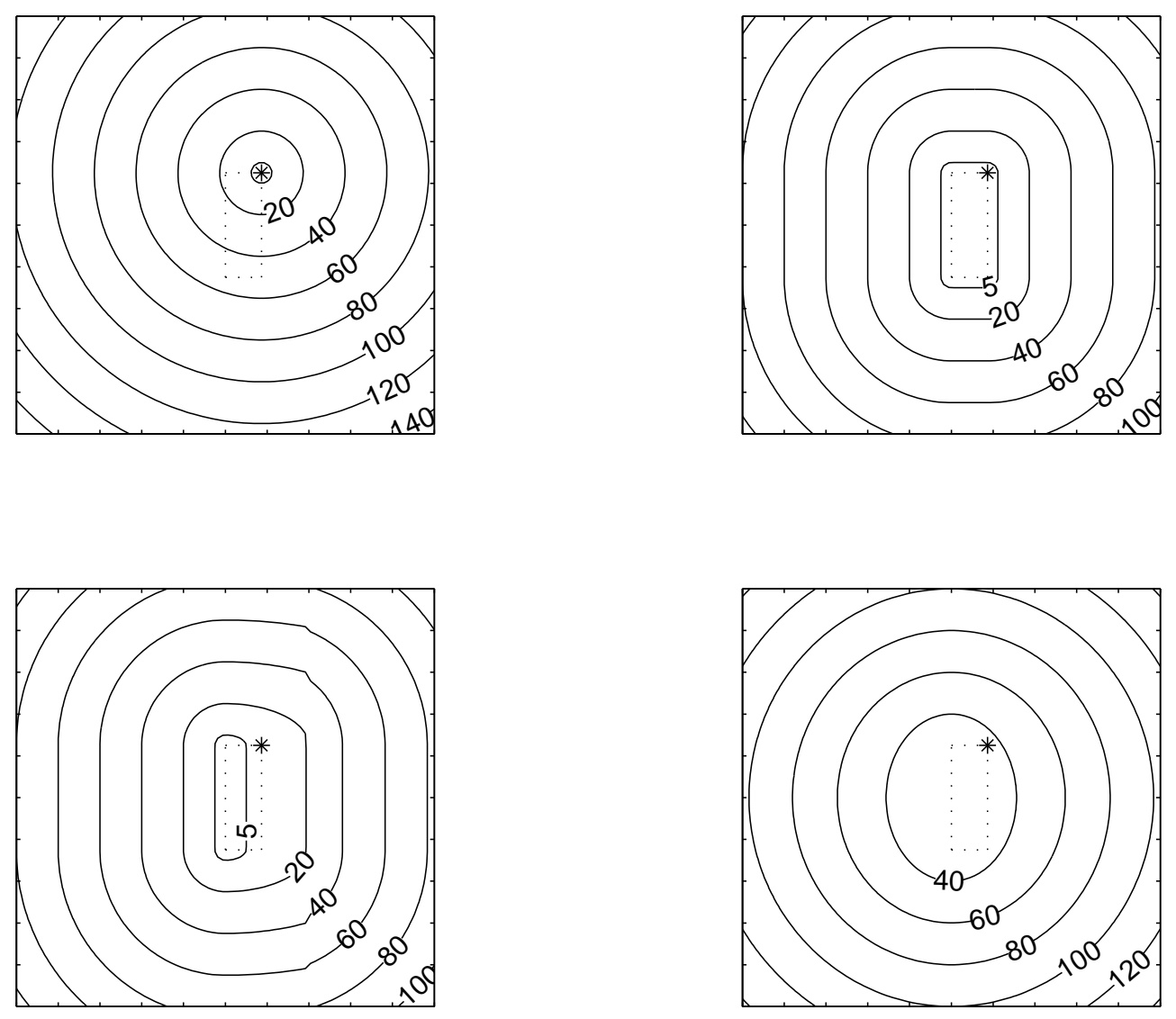

Fig. 8 . 


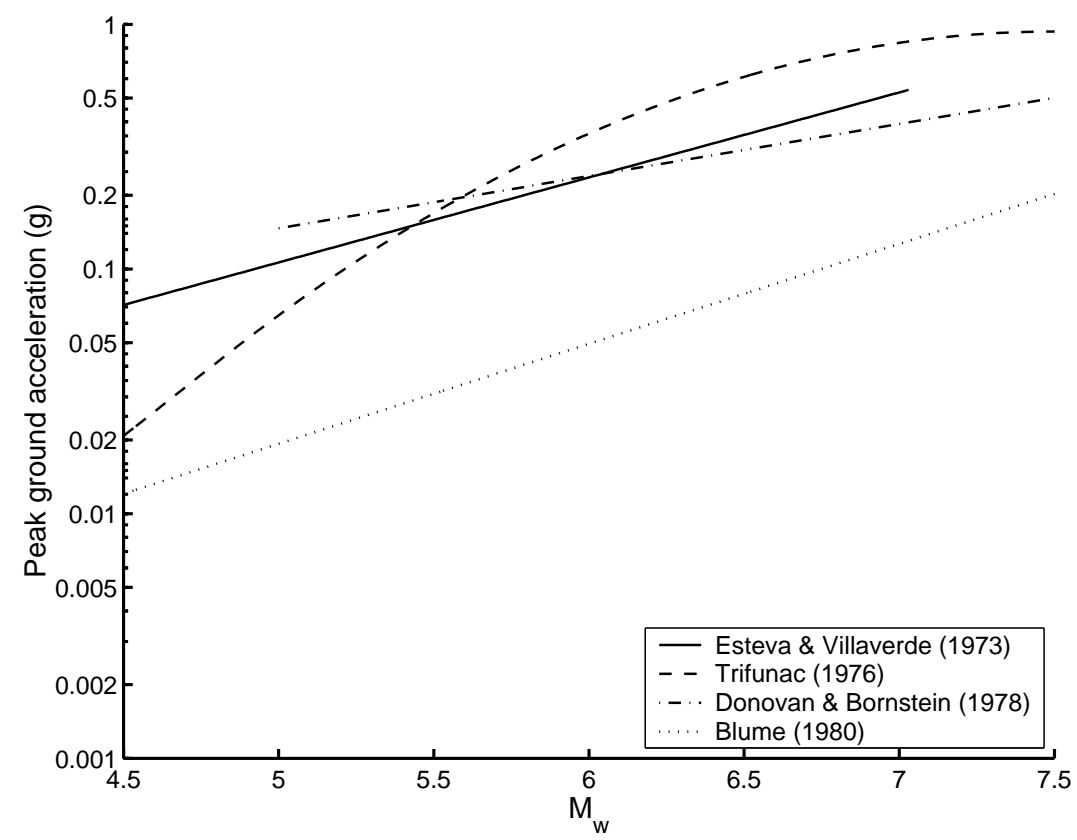

(a) $d_{f}, d_{r}=10 \mathrm{~km}$ and $d_{s}=10.4 \mathrm{~km}$

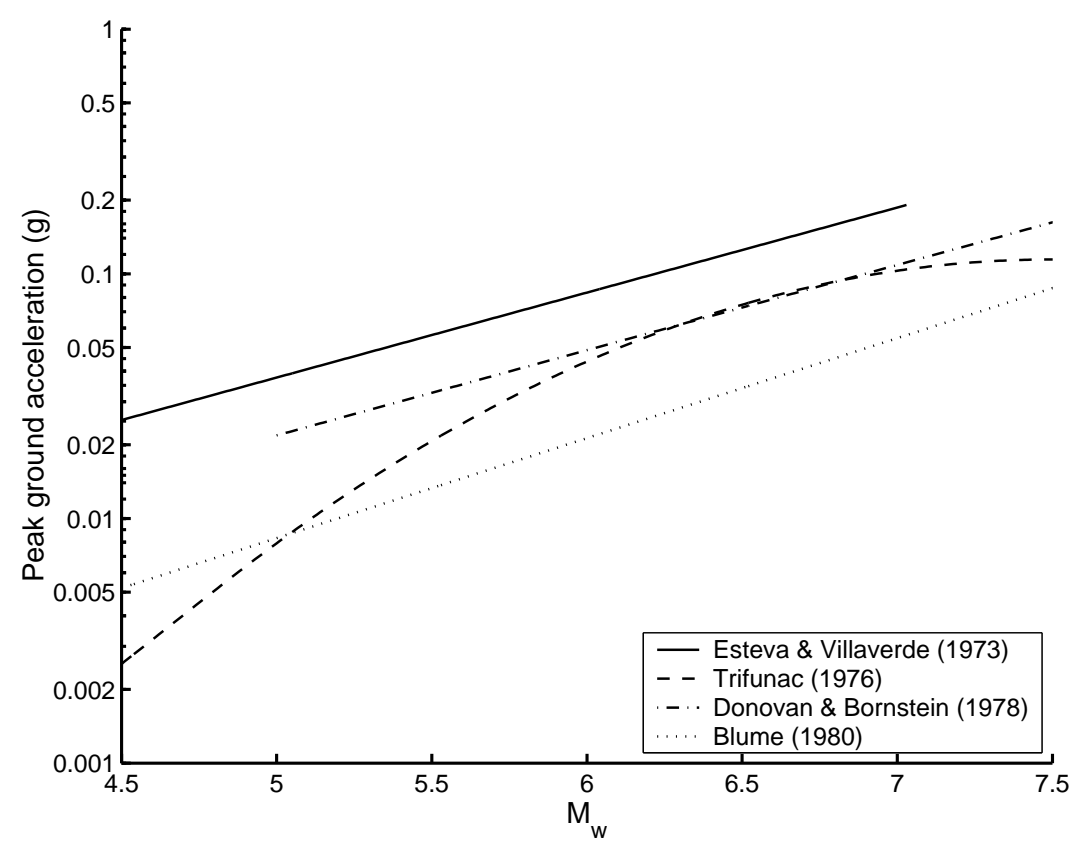

(b) $d_{f}, d_{r}=50 \mathrm{~km}$ and $d_{s}=50.1 \mathrm{~km}$

Fig. 9. 
$\square$ Europe \& Middle East $\square$ Western North America $\square$ Japan $\square$ Subduction zones \& others $\square$ Worldwide

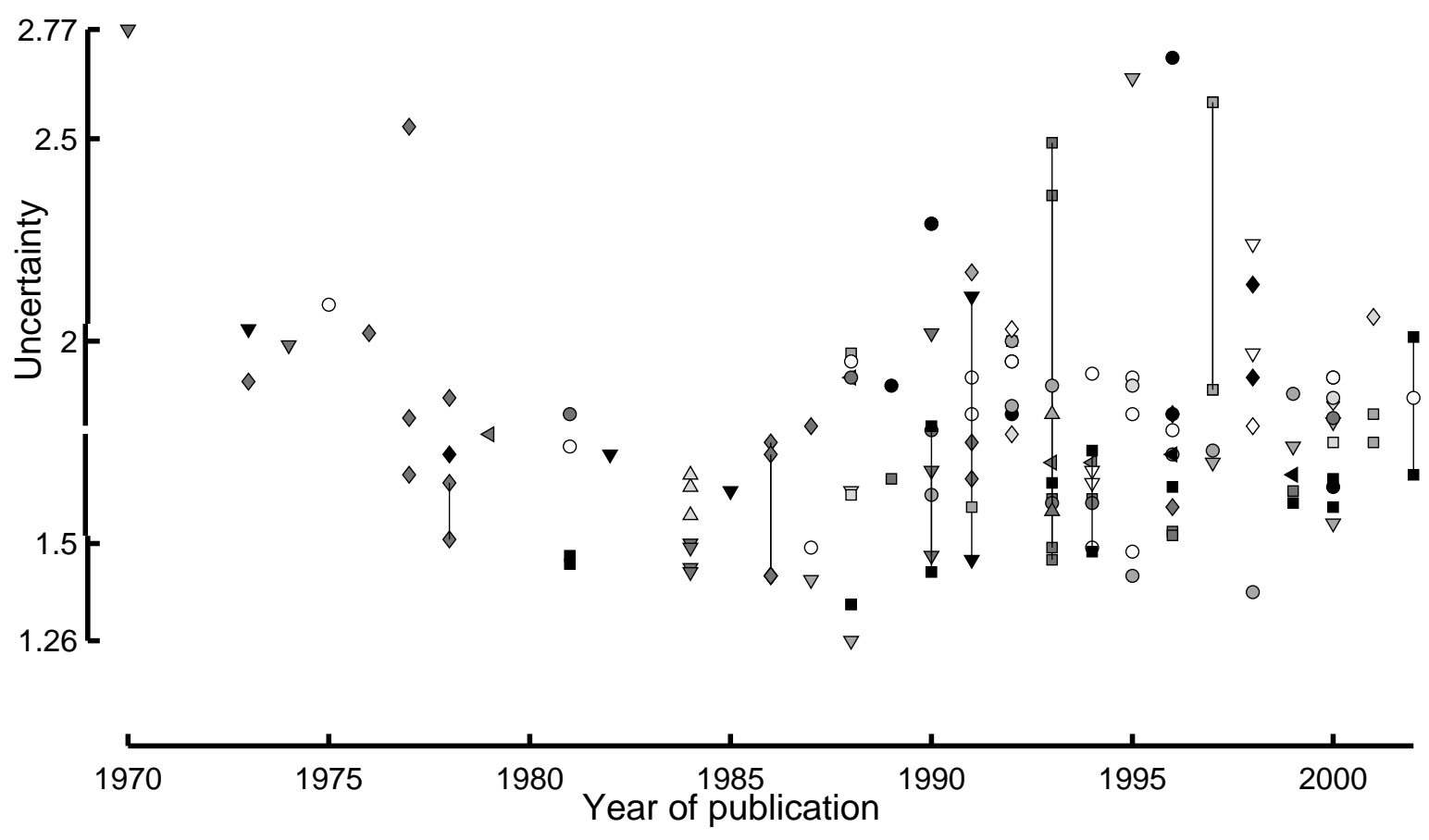

Fig. 10. 